Universidade de São Paulo

Faculdade de Medicina de Ribeirão Preto

Departamento de Medicina Social

Programa de Pós-Graduação em Saúde na Comunidade

ANDRÉ LUIZ TEIXEIRA VINCI

Análise e avaliação do controle de qualidade de dados hospitalares na região de Ribeirão Preto 



\section{Análise e avaliação do controle de qualidade de dados hospitalares na região de Ribeirão Preto}

Dissertação de mestrado apresentada ao Programa de Pós-Graduação em Saúde na Comunidade, da Faculdade de Medicina de Ribeirão Preto da Universidade de São Paulo, como parte dos requisitos para a obtenção do título de Mestre em Ciências - Programa de Saúde na Comunidade.

Orientador:

Prof. Dr. Domingos Alves 
Autorizo a reprodução e divulgação total ou parcial deste trabalho, por qualquer meio convencional ou eletrônico, para fins de estudo e pesquisa, desde que citada a fonte.

Vinci, André Luiz Teixeira

Análise e avaliação do controle de qualidade de dados hospitalares na região de Ribeirão Preto. Ribeirão Preto, 2015.

90 p. : il. ; $30 \mathrm{~cm}$

Dissertação de Mestrado, apresentada à Faculdade de Medicina de Ribeirão Preto/USP. Área de concentração: Saúde na Comunidade.

Orientador: Alves, Domingos.

1. Sistemas de Informação em Saúde. 2. Qualidade de Dados. 3. Ficha de Alta Hospitalar. 4. Saúde Coletiva. 
Nome: André Luiz Teixeira Vinci

Título: Análise e avaliação do controle de qualidade de dados hospitalares na região de Ribeirão Preto

Dissertação de mestrado apresentada ao Programa de Pós-Graduação em Saúde na Comunidade, da Faculdade de Medicina de Ribeirão Preto da Universidade de São Paulo, como parte dos requisitos para a obtenção do título de Mestre em Ciências - Programa de Saúde na Comunidade.

Orientador:

Prof. Dr. Domingos Alves

Aprovado em: de de

Banca Examinadora

Prof. Dr. Domingos Alves (FMRP/USP)

Assinatura:

Prof. Dr. Paulo Mazzoncini de Azevedo Marques (FMRP/USP)

Assinatura:

Prof. Dr. José Alberto da Silva Freitas (FMUP/UP)

Assinatura: 

Aos meus pais, Luís e Solange, pelo apoio incondicional durante toda essa jornada.

Muito Obrigado! 


\section{Agradecimentos}

À minha família pelo entendimento e carinho durante toda essa jornada.

Às minhas amigas Beatriz, Daniane, Isabelle e Lariza. Obrigado pelo carinho, pelos conselhos, pelos puxões de orelha e principalmente por me mostrarem que sempre estarão dispostas a doar um tempo da vida de vocês para alegrar a minha.

Ao meu orientador, Prof. Dr. Domingos Alves, por toda a ajuda na elaboração deste trabalho e também por me colocar no caminho correto, mesmo após vários desvios durante o percurso.

À equipe do Centro de Processamento de Dados Hospitalares (CPDH), em especial a Rosane, Dulce e Goreti, pois sem o seu trabalho e ajuda esse trabalho não seria possível.

Agradeço ao Conselho Nacional de Desenvolvimento Científico e Tecnológico (CNPQ) pela concessão da bolsa durante um período da realização deste mestrado.

Por fim, agradeço a todos aqueles que de diferentes formas me apoiaram e incentivaram durante toda a minha vida. Sem vocês eu com certeza não conseguiria chegar aonde cheguei. 


\section{Resumo}

$\mathrm{VINCl}$, A. L. T. Análise e avaliação do controle da qualidade de dados hospitalares na região de Ribeirão Preto. 2015. 90p. Dissertação (Mestrado). Faculdade de Medicina de Ribeirão Preto, Universidade de São Paulo, Ribeirão Preto, 2015.

Introdução: A Qualidade de Dados é de extrema importância atualmente pela crescente utilização de sistemas de informação, em especial na área da Saúde. O Observatório Regional de Atenção Hospitalar (ORAH) é tido como referência na coleta, processamento e manutenção da qualidade de informações hospitalares devida a extensa base de dados de informações oriundas das Folhas de Alta Hospitalar de hospitais públicos, mistos e privados da região de Ribeirão Preto. Uma verificação sistemática é feita para melhorar a qualidade desses dados impedindo a existência de incompletudes e inconsistências ao final do seu processamento. Objetivo: Estabelecer o panorama da qualidade dos dados das altas hospitalares ocorridas em 2012 para cada hospital parceiro do ORAH na região de Ribeirão Preto. Analisar e identificar o ganho ou perda de qualidade durante as etapas de coleta e processamento dos mesmos. Métodos: Análise do fluxo das informações dentro dos hospitais conveniados ao ORAH em conjunto com a análise da qualidade dos dados armazenados pelo ORAH após seu processamento, a partir da criação de indicadores de completude e consistência. Avaliação da qualidade dos dados em cada etapa do protocolo interno de verificação adotado pelo ORAH, a partir da criação de indicadores de qualidade específicos. Por fim, avaliação da concordância entre as informações de uma amostra das Folha de Alta registradas no ORAH e o Prontuário Médico do Paciente por meio da mensuração da sensibilidade, especificidade e acurácia da amostra. Resultados: Um panorama com foco na produção dos dados dos pacientes e nível de informatização foi elaborado para os hospitais complementarmente a análise de qualidade dos dados do ORAH. Tal análise constatou coeficientes médios de $99,6 \%$ de completude e $99,5 \%$ de consistência e um percentual de preenchimento acima de $99,2 \%$ para todos os campos da Folha de Alta. Por meio do indicador de qualidade elaborado a partir das comparações das dimensões de completude e consistência entre etapas do processamento dos dados pelo ORAH, foi possível averiguar a manutenção na qualidade das informações pela execução dos protocolos de validação e consistência adotados. Entretanto, com a apreciação entre as etapas da dimensão de volatilidade dos valores contidos nos campos, foi possível confirmar e quantificar a ocorrência de mudanças dos campos. A exatidão dos dados presentes na Folha de Alta com os do Prontuário do Paciente também pode ser comprovada pelas altas sensibilidade (99,0\%; IC95\% 98,8\% - 99,2\%), especificidade $(97,9 \%$; IC95\% 97,5\% - 98,2\%) e acurácia (96,3\%; IC95\% 96,0\% - 96,6\%) encontradas na amostra. Conclusão: Como consequência de todas essas análises, foi possível comprovar a excelência da qualidade das informações disponibilizadas pelo ORAH, estabelecer uma metodologia abrangente para a análise dessa qualidade e definir possíveis problemas a serem enfrentados para a constante melhoria da qualidade das informações presentes na Folha de Alta Hospitalar e no banco de dados do ORAH por completo.

Palavras Chaves: Sistemas de Informação em Saúde; Qualidade de Dados; Folha de Alta Hospitalar, Saúde Coletiva. 


\begin{abstract}
$\mathrm{VINCI}, \mathrm{A}$. L. T. Analysis and evaluation of the quality control of hospital data in the Ribeirão Preto region. 2015. 90p. Dissertation (Masters). Faculdade de Medicina de Ribeirão Preto, Universidade de São Paulo, Ribeirão Preto, 2015.

Introduction: The Data Quality is of utmost importance nowadays due the increasing use of information systems, especially in healthcare. The Regional Health Care Observatory (ORAH) is considered as reference in gathering, processing and maintaining the quality of hospital data due to the extensive database of information derived from the hospital discharge sheets of public, mixed and private hospitals. A systematic verification of those data is made to improve their data quality preventing the existence of incompleteness and inconsistencies at the end in their processing. Aim: Establish the overall picture of the data quality of hospital discharge sheets occurred in 2012 for each partner hospital in the Ribeirão Preto region. Analyze and identify the quality gain or loss during the gathering and processing stages of the data by the ORAH. Methods: Analysis of the information flow within the hospitals in partnership with the ORAH together with the analysis of the quality of the data stored by ORAH after its processing through the creation of completeness and consistency indicators. Data quality assessment at each stage of the internal protocol checking adopted by the ORAH through the establishment of specific quality indicators. Finally, evaluation of the agreement between the information in a sample of the hospital discharge sheets recorded in the ORAH and the patient medical records by measuring the sensitivity, specificity and accuracy of the sample. Results: Na overall picture focused on the patient data and the informatization level was developed for the hospitals in complement of the analysis of ORAH's data quality. This analysis found $99.6 \%$ completeness and $99.5 \%$ consistency mean rates and a completion percentage above $99.2 \%$ for all the fields of the discharge. Through the data quality indicator created from the comparisons of the completeness and consistency dimensions between the data processing steps of the ORAH was possible to verify the maintenance of the information quality by the implementation of validation and consistency protocols in use by the ORAH staff. However, with the assessment between the steps of the volatility dimension of the values contained in the fields, was possible to confirm and quantify the occurrence of changes in the fields. The agreement between the data in the hospital discharge sheets and the patient health record data can be proven by the high sensitivity $(99.0 \%$; Cl95\% $98.8 \%-99.2 \%)$, specificity (97.9\%; CI95\% 97.5\% - 98.2\%) and accuracy (96.3\%; CI95\% 96.0\% $96.6 \%)$ found in the sample. Conclusion: As a result of all these analyzes, was possible to prove the excellence of the quality of the information provided by the ORAH, establish a comprehensive methodology for the analysis of this quality and identify possible problems to be addressed further improve the quality of information in the hospital discharge sheet and the ORAH database altogether.
\end{abstract}

Keywords: Health Information Systems; Data Quality; Hospital Discharge Sheet; Public Health. 


\section{Lista de Equações}

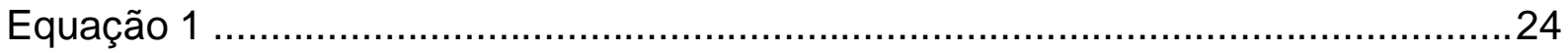

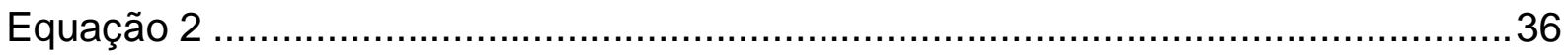

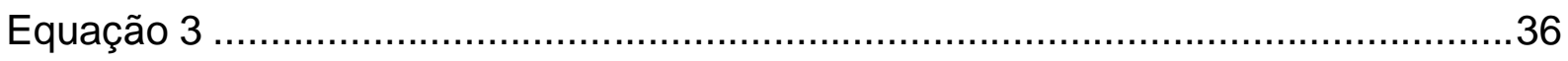

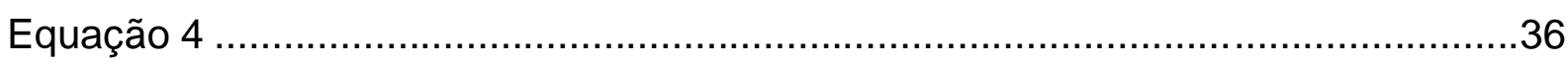

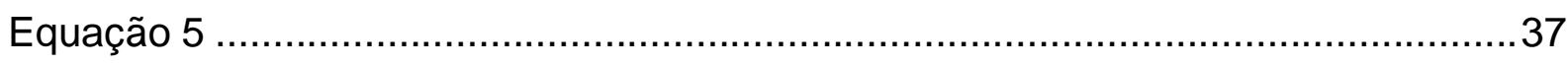

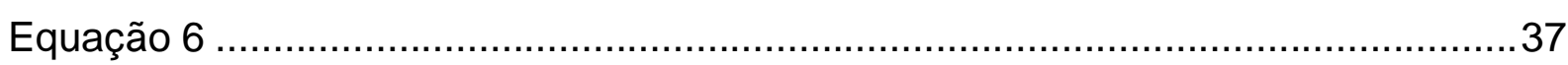

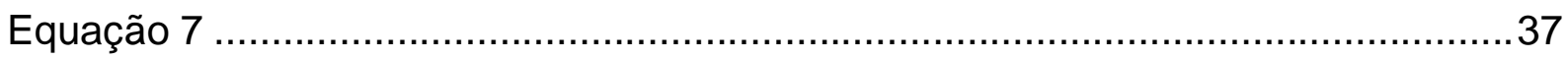

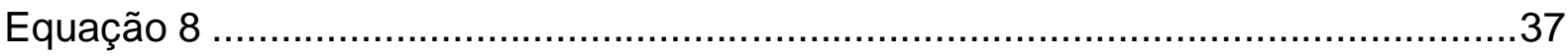

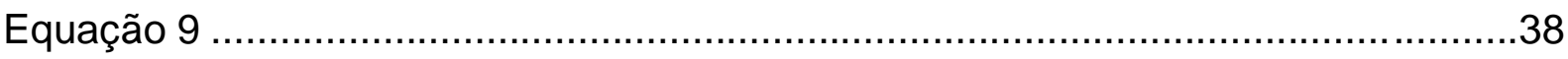

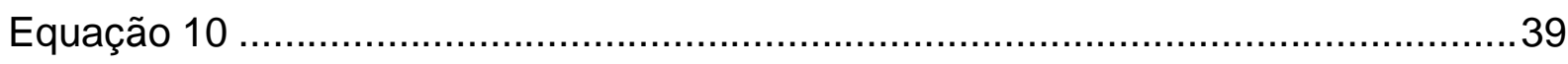

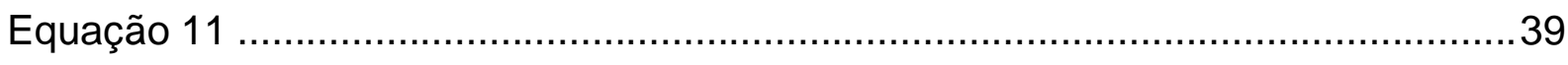

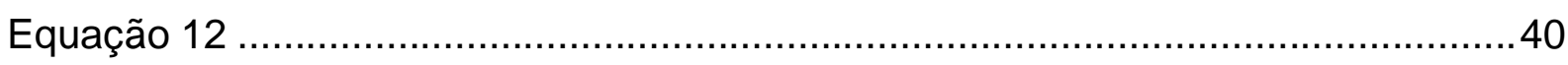

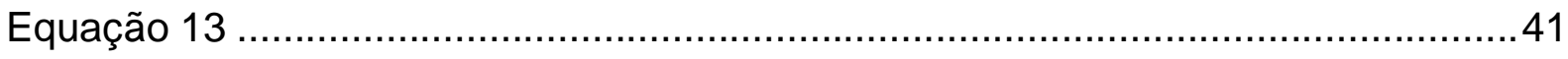

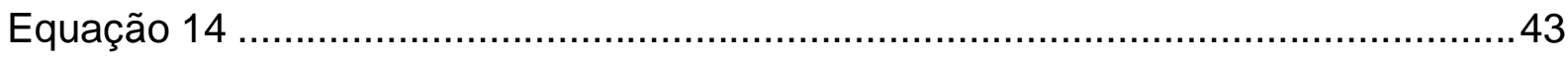

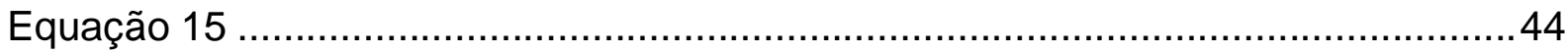

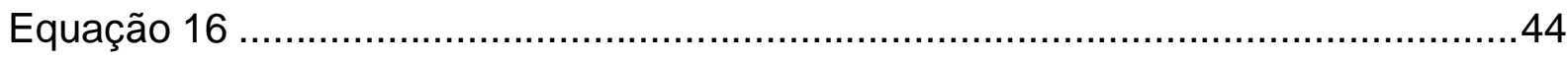

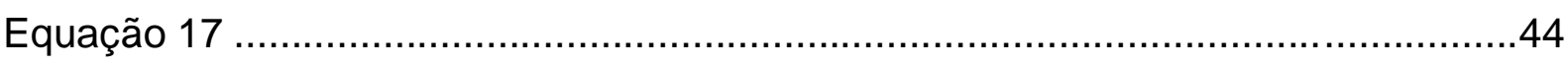




\section{Lista de Figuras}

Figura 1 - Principais Questões Científicas e Domínios de Aplicação da Qualidade de Dados. 22

Figura 2 - Ciclo da Gestão Total da Qualidade dos Dados...................................23

Figura 3 - Fluxograma da Obtenção e Processamento das Folhas de Altas no CPDH. .31

Figura 4 - Folha de Alta Hospitalar usada pelos hospitais conveniados aos CPDH. 81

Figura 5 - Dados do Prontuário Médico. .89

Figura 6 - Termo de Responsabilidade. .90 


\section{Lista de Quadros}

Quadro 1 - Descrição dos Campos e Variáveis da Folha de Alta Hospitalar............82

Quadro 2 - Códigos de Inconsistências....................................................... 87

Quadro 3 - Diagnósticos específicos para cada sexo....................................88 


\section{Lista de Tabelas}

Tabela 1 - Categorias para a Classificação de Medidas de Qualidade .38

Tabela 2 - Categorias para a Classificação do Indicador de Qualidade dos Dados entre os Processos do Observatório Regional de Atenção Hospitalar (IQP).

Tabela 3 - Categorias para a Classificação do Coeficiente de Volatilidade (CV) entre os Processos do Observatório Regional de Atenção Hospitalar.

Tabela 4 - Total de internações da amostra de Prontuários e Folhas de Alta a serem avaliadas por hospital, Novembro de 2011 a Janeiro de 2012.

Tabela 5 - Tabela de Contingência 2x2 do Preenchimentos dos Campos da Folha de Alta e do Prontuário do Paciente.

Tabela 6 - Distribuição dos Hospitais por Município. 46

Tabela 7 - Categoria de Internação atendida pelos Hospitais entrevistados. 47 Tabela 8 - Características dos Hospitais entrevistados, segundo o tipo de especialidade atendida.

Tabela 9 - Periodicidade da contagem ou verificação da ocupação dos leitos nos Hospitais entrevistados.

Tabela 10 - Presença de Computadores nos Setores dos Hospitais entrevistados. 48 Tabela 11 - Nível de Informatização do Prontuário do Paciente nos Hospitais entrevistados.

Tabela 12 - Informatização do preenchimento dos diagnósticos nos Hospitais entrevistados.

Tabela 13 - Sistema de Informação utilizado para armazenamento dos dados do Observatório Regional de Atenção Hospitalar (ORAH) nos Hospitais entrevistados.

Tabela 14 - Fluxo da informação do paciente durante a internação até o preenchimento da Folha de Alta nos Hospitais entrevistados.

Tabela 15 - Local da impressão da Folha de Alta nos Hospitais entrevistados. 50

Tabela 16 - Profissional responsável pelo registro do diagnóstico na Folha de Alta nos Hospitais entrevistados.

Tabela 17 - Setor onde os diagnósticos são preenchidos na Folha de Alta nos Hospitais entrevistados. 
Tabela 18 - Profissional responsável pelo registro dos procedimentos cirúrgicos na Folha de Alta nos Hospitais entrevistados.

Tabela 19 - Profissional responsável pelo registro da condição de saída do paciente na Folha de Alta nos Hospitais entrevistados.

Tabela 20 - Identificação da presença de um profissional codificador de doenças nos Hospitais entrevistados. .52

Tabela 21 - Proporção de Preenchimento (\%) de cada Variável presente na Folha de Alta por Hospital do Município de Ribeirão Preto conveniados ao Observatório Regional de Atenção Hospitalar (ORAH), 2012.

Tabela 22 - Proporção de Preenchimento (\%) de cada Variável presente na Folha de Alta por Hospital de Municípios da Região de Ribeirão Preto conveniados ao Observatório Regional de Atenção Hospitalar (ORAH), 2012. .54

Tabela 23 - Percentual de Ocorrência (\%) Não Nulos para as Regra de Consistência utilizada pelo Observatório Regional de Atenção Hospitalar (ORAH), 2012. 55 Tabela 24 - Percentual de Ocorrência (\%) para cada Regra de Consistência por Hospital do Município de Ribeirão Preto conveniados ao Observatório Regional de Atenção Hospitalar (ORAH), 2012.

Tabela 25 - Percentual de Ocorrência (\%) para cada Regra de Consistência por Hospital de Municípios da Região de Ribeirão Preto conveniados ao Observatório Regional de Atenção Hospitalar (ORAH), 2012.

Tabela 26 - Percentual Médio do Grau de Completude $\left(C_{p}\right)$ por Hospital Conveniado ao Observatório Regional de Atenção Hospitalar (ORAH), 2012.

Tabela 27 - Percentual Médio do Grau de Consistência $\left(C_{t}\right)$ por Hospital conveniado ao Observatório Regional de Atenção Hospitalar (ORAH), 2012.

Tabela 28 - Percentual Médio do Grau de Consistência (Ct) para cada Hospital conveniado ao Observatório Regional de Atenção Hospitalar (ORAH), Jan-Dez/ 2012

Tabela 29 - Coeficiente de Volatilidade (CV) entre a Etapa de Recebimento dos dados Eletrônicos Oriundos dos Hospitais e a Etapa de Digitação e Codificação dos dados do Observatório Regional de Atenção Hospitalar (ORAH)

Tabela 30 - Coeficiente de Volatilidade (CV) entre a Etapa de Digitação e Codificação e a Etapa de Revisão e Conferência dos dados do Observatório Regional de Atenção Hospitalar (ORAH). 
Tabela 31 - Coeficiente de Volatilidade (CV) entre a Etapa de Recebimento dos dados Eletrônicos Oriundos dos Hospitais e a Etapa de Revisão e Conferência dos dados do Observatório Regional de Atenção Hospitalar (ORAH). 64

Tabela 32 - Sensibilidade (S) no preenchimento da Folha de Alta em relação ao Prontuário do Paciente para os dados da amostra. 66

Tabela 33 - Especificidade (E) no preenchimento da Folha de Alta em relação ao Prontuário do Paciente para os dados da amostra. .66

Tabela 34 - Acurácia (A) dos valores contidos nos campos para os dados da amostra.

Tabela 35 - Percentual Médio de Acerto $(\bar{A} \%)$ dos valores por campo da Folha de Alta para a amostra. 68 Tabela 36 - Percentual Médio de Acerto $(\bar{A} \%)$ dos valores por campo da Folha de Alta para cada hospital da amostra. .70 


\section{Sumário}

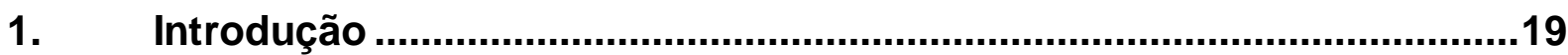

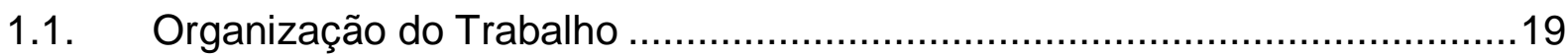

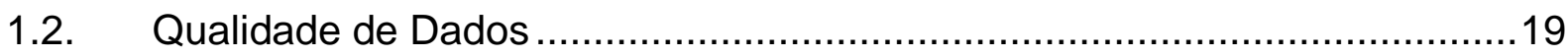

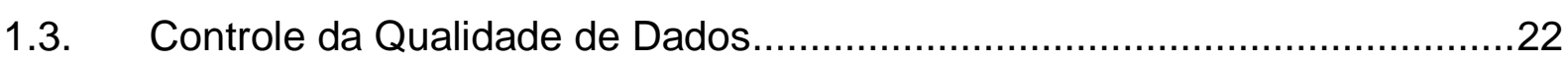

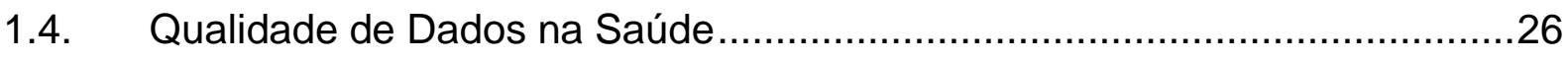

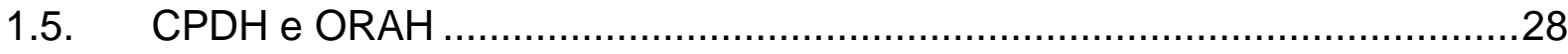

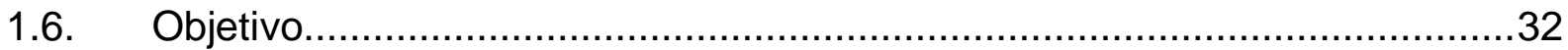

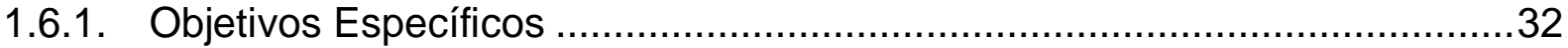

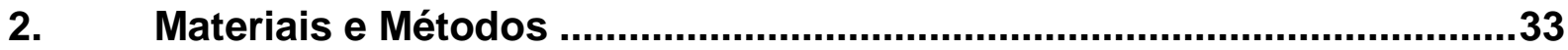

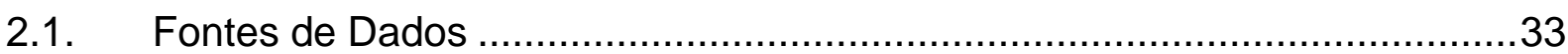

2.2. Descrição e Análise da Produção dos Dados e do Fluxo de Informação nos Hospitais conveniados ao ORAH 34

2.3. Descrição e Análise da Qualidade dos Dados produzidos pelos Hospitais e processados pelo ORAH .35

2.4. Avaliação da Qualidade nas Etapas de Processamento das Folhas de Alta no

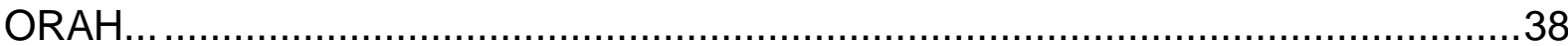

2.5. Avaliação da Correção entre a Folha de Alta e o Prontuário Médico ...........42

2.6. Aspectos Éticos ............................................................................ 44

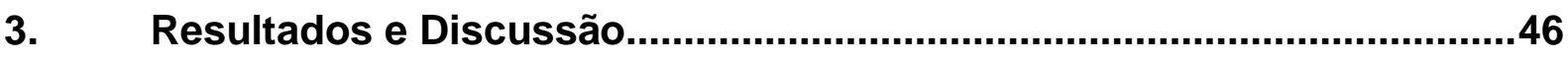

3.1. Descrição e Análise da Produção dos Dados e do Fluxo de Informação nos

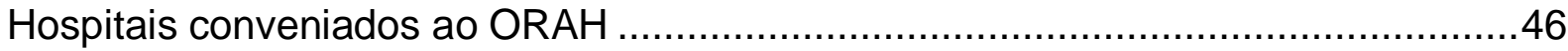

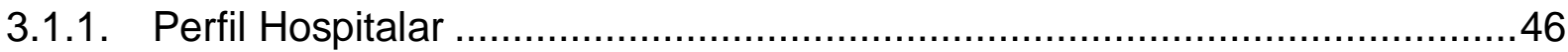

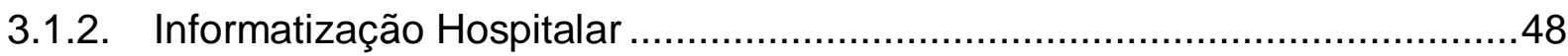

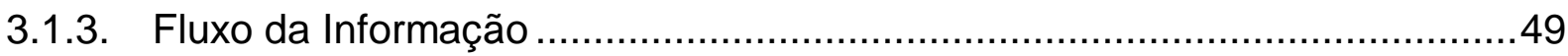

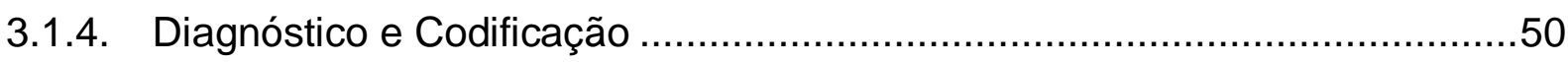

3.2. Descrição e Análise da Qualidade dos Dados produzidos pelos Hospitais e

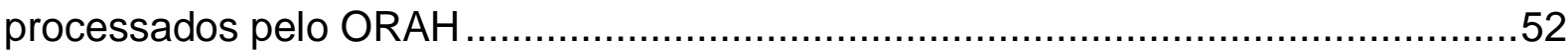

3.2.1. Descrição e Análise da Qualidade dos Dados de cada campo presente na

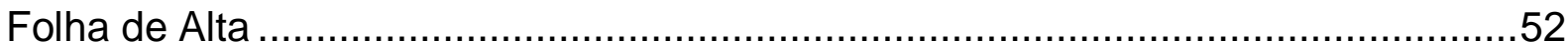

3.2.2. Análise da Completude da Folha de Alta.................................................58 
3.2.3. Análise da Consistência da Folha de Alta .59

3.3. Avaliação da Qualidade nas Etapas de Processamento das Folhas de Alta no ORAH.......

3.3.1. Avaliação da Qualidade nas Etapas de Processamento das Folhas de Alta dos Hospitais que Não Enviaram Arquivo Eletrônico

3.3.2. Avaliação da Qualidade nas Etapas de Processamento das Folhas de Alta dos Hospitais que Enviaram Arquivo Eletrônico. 62

3.4. Avaliação da Correção entre a Folha de Alta e o Prontuário Médico .65

3.5. Outros Resultados .71

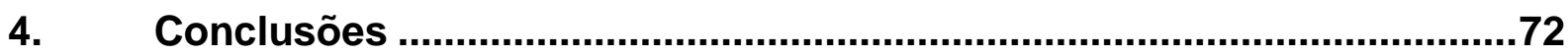

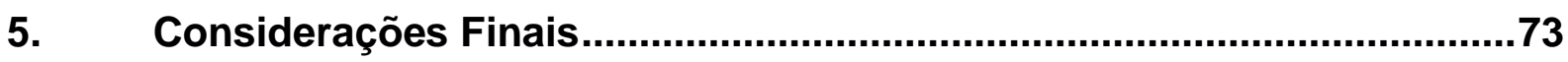

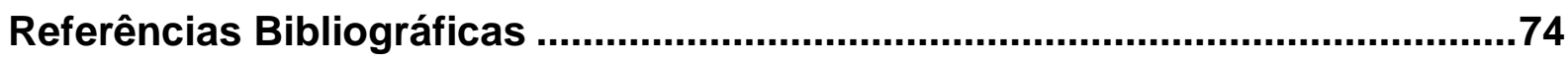

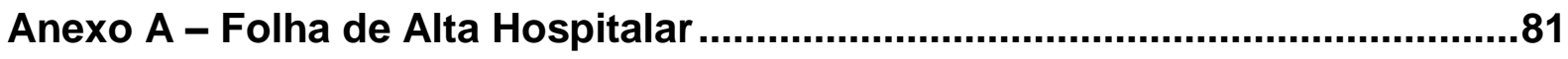

Anexo B - Questionário para Avaliação da Coleta de Dados Hospitalares .......83

Anexo C - Quadros de Códigos de Consistência ................................................87

Anexo D - Instrumento para Avaliação da Qualidade dos Dados Registrados no

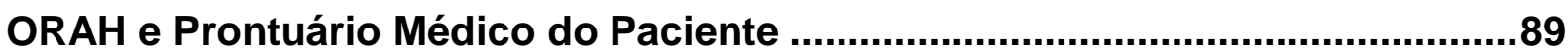

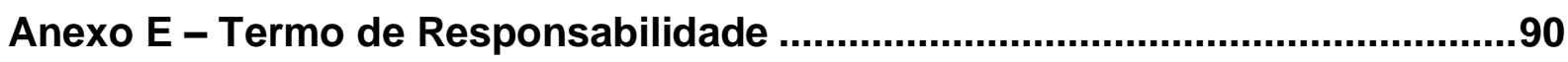




\section{Introdução}

\subsection{Organização do Trabalho}

Esta dissertação está organizada em seções, sendo que a primeira seção relata os fundamentos teóricos relacionados ao conceito de Qualidade de Dados e suas aplicações na área da Saúde, especificamente no caso do Centro de Processamento de Dados Hospitalares (CPDH) e Observatório Regional de Atenção Hospitalar (ORAH) da Faculdade de Medicina de Ribeirão Preto da Universidade de São Paulo (FMRP/USP), além do objetivo do trabalho. A segunda seção descreve os materiais e métodos que foram utilizados no desenvolvimento das atividades propostas e a terceira expõe os resultados encontrados e também uma discussão sobre os mesmos. $\mathrm{Na}$ quarta seção é apresentada a conclusão do estudo realizado e na quinta se encontram as considerações finais do mesmo. Por fim, a sexta seção contém as referências bibliográficas utilizadas, sendo seguida pelos anexos do trabalho.

\subsection{Qualidade de Dados}

A temática da Qualidade de Dados nos dias atuais é de extrema importância pelo uso cada vez crescente de Sistemas de Informação Informatizados e também dada a sua multidisciplinaridade, em especial na área da Saúde (OLIVEIRA, 2008).

Podemos definir dados como representações de objetos do mundo real em um formato que pode ser armazenado, recuperado, transformado por procedimentos de informática e disseminados. Normalmente, se associa qualidade de dados ao conceito de dados estruturados, mas ela também pode ser aplicada a todos os tipos de dado (OLIVEIRA, 2008). Já a qualidade da informação pressupõe a qualidade do dado, do sistema de informação e eventualmente do ambiente computacional (XAVIER; GOMES, 1999 apud ARAÚJO; BATISTA, 2013).

Tipicamente em muitas organizações, os dados são utilizados a partir de sistemas de informação com o objetivo de fornecer suporte aos processos de negócio e à tomada de decisão, além de contribuírem para uma melhor confiança organizacional e satisfação de clientes (ARAÚJO; BATISTA, 2013; BATINI; SCANNAPIECA, 2006; GOMES; FARINHA; TRIGUEIROS, 2007; REDMAN, 2004; 
SADIQ; YEGANEH; INDULSKA, 2011). Atualmente, um dos maiores problemas enfrentados pelas empresas está relacionado à baixa qualidade de seus dados, pois, assim, o seu uso torna-se um obstáculo ao sucesso das mesmas por incidir em uma menor eficiência e eficácia no planejamento de suas ações. O grande volume de dados produzidos pelas empresas também pode ser considerado um fator complicador para a manutenção da qualidade dos dados (SADIQ; YEGANEH; INDULSKA, 2011), resultando na ocorrência de uma quantidade significativa de dados imprecisos na maioria dos sistemas de informação (SALVADOR et al., 2006).

A qualidade, por si só, é análoga à satisfação e é totalmente dependente dos consumidores de produtos, serviços e/ou dados (OLIVEIRA, 2008; SALVADOR et al., 2006). A princípio, a qualidade de um produto está sujeita ao seu processo de concepção e produção e só é totalmente conquistada quando está de acordo com as necessidades exigidas pelos seus consumidores (REDMAN, 2004; WAND; WANG, 1996; WANG; STRONG, 1996). Este conceito de qualidade pode ser estendido à temática de Qualidade de Dados, de modo que a qualidade de um dado é determinada e avaliada pelos usuários do mesmo, os tornando interdependentes (STRONG; LEE; WANG, 1997).

Existe uma grande variedade de definições para Qualidade de Dados, o que faz com que não haja um consenso no conjunto de critérios a ser utilizado para sua conceituação (ARAÚJO; BATISTA, 2013; GERTZ et al., 2004). Entretanto, a maioria dos pesquisadores concorda que seu conceito deve ser construído a partir da adequação do uso dos dados por seus consumidores, assim como é feito com a qualidade de produtos (ARAÚJO; BATISTA, 2013; OLIVEIRA, 2008; REDMAN, 1997; WANG; STRONG, 1996). Consequentemente, a qualidade acaba por se tornar subjetiva e de difícil quantificação.

Definições mais comuns estabelecem que os dados somente são considerados com qualidade quando os mesmos estão adequados à finalidade que seus usuários determinam. Entretanto, tais pensamentos implicam que um mesmo conjunto de dados pode ser considerado adequado em alguns casos e não ser suficiente em outros (SALVADOR et al., 2006; WAND; WANG, 1996; WANG; STRONG, 1996).

Outra definição de Qualidade de Dados refere-se ao grau de aderência entre os dados no mundo real e suas perspectivas apresentadas pelo sistema de informação. De modo que um sistema com perfeita aderência ao mundo real se 
constituiria de dados de qualidade excelente, enquanto a total falta de aderência seria representada pela qualidade ruim de dados (SALVADOR et al., 2006).

Em vários estudos, a Qualidade de Dados é considerada multidimensional e é expressa a partir de dimensões representativas das propriedades dos dados. Vale ressaltar que, entre tais estudos, um mesmo nome é utilizado para conceituar dimensões com significados diferentes e também nomes diferentes apresentam significados semelhantes entre as diversas propostas de dimensões (BATINI; SCANNAPIECA, 2006; KAHN; STRONG; WANG, 2002; OLIVEIRA, 2008; SADIQ; YEGANEH; INDULSKA, 2011; WAND; WANG, 1996; WANG; STRONG, 1996).

Definições mais simplistas e tradicionais conceituam a Qualidade de Dados em relação aos valores armazenados a partir de três dimensões básicas: a completude, a consistência e a correção, sendo que cada uma delas guardam aspectos específicos de qualidade (ARAÚJO; BATISTA, 2013; BATINI; SCANNAPIECA, 2006). A completude é caracterizada pela presença de todos os valores necessários para a representação do dado. A consistência é caracterizada pela inexistência de contradições entre os valores representantes de um dado específico e também entre as regras que caracterizam um dado e os valores armazenados. A correção é caracterizada pela ausência de erros nos valores, ressaltando que essa noção é mutável em relação ao tempo e ao usuário que acessa o dado. Usualmente, estes conceitos são adotados por profissionais da computação por representar uma visão mais objetiva da Qualidade de Dados (OLIVEIRA, 2008).

Entretanto, vários pesquisadores consideram outros critérios na conceituação das dimensões da Qualidade de Dados por não acharem que somente essas três abranjam todas as necessidades dos usuários, mesmo concordando que elas são as de maior importância (OLIVEIRA, 2008; SADIQ; YEGANEH; INDULSKA, 2011; WANG; STRONG, 1996). Investigadores oriundos da área de gestão tendem a acrescentar dimensões como a atualidade, temporalidade, volatilidade, acessibilidade e interpretabilidade na conceituação da qualidade (BATINI; SCANNAPIECA, 2006; GOMES; FARINHA; TRIGUEIROS, 2007; OLIVEIRA, 2008; MADNICK et al., 2009).

A despeito da Qualidade de Dados ser uma área com importância e valor comprovados e objeto de estudo de diversas ciências, como a estatística, gestão e informática, ela ainda é bastante negligenciada (BATINI; SCANNAPIECA, 2006; OLIVEIRA, 2008). Apesar das diversas pesquisas neste campo, ainda há uma lacuna 
quando a definição de padrões que permitam a portabilidade e reutilização das ferramentas e soluções já desenvolvidas (GOMES; FARINHA; TRIGUEIROS, 2007).

Para que se tenha uma resposta adequada aos desafios resultantes do estudo científico da Qualidade de Dados, é necessária a criação de um framework que una os resultados destes diversos estudos e que também seja capaz de colocar a Qualidade dos Dados como centro do desenvolvimento de novos sistemas de informação (SADIQ; YEGANEH; INDULSKA, 2011).

As questões científicas relacionadas a Qualidade de Dados e os diferentes domínios em que ela pode ser aplicada, tais como: e-Governo, Ciências Naturais e Dados Biológicos, dados da Internet, Saúde, entre outros; podem ser vistos na figura abaixo (BATINI; SCANNAPIECA, 2006). Neste trabalho tais problemas serão focados para um caso específico dentro do domínio da Saúde.

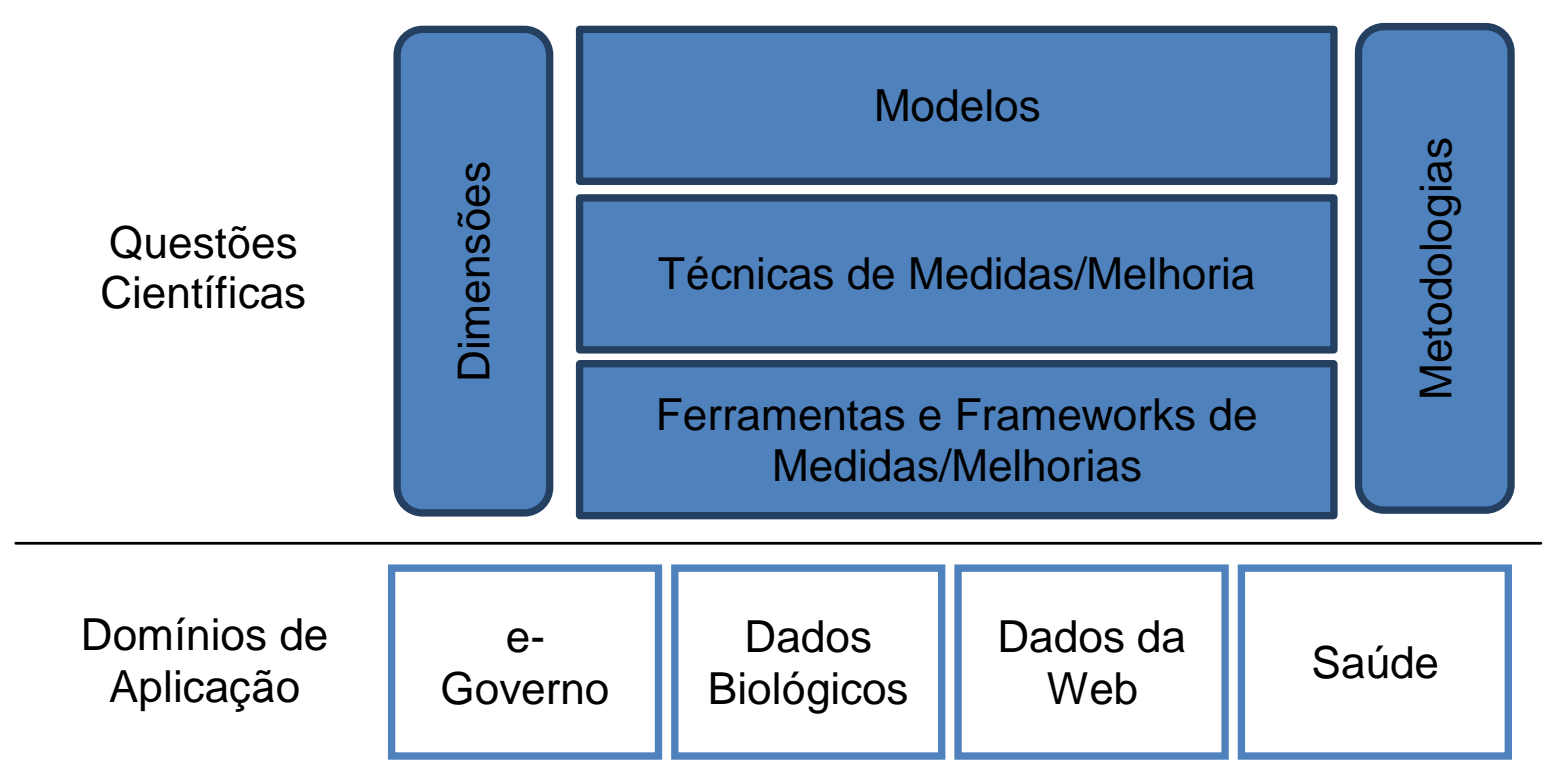

Figura 1 - Principais Questões Científicas e Domínios de Aplicação da Qualidade de Dados. Fonte: Adaptado de Batini e Scannapieca (2006).

\subsection{Controle da Qualidade de Dados}

Controlar a qualidade consiste em localizar o problema, analisar o processo, padronizar e estabelecer itens de controle de tal forma que o problema não volte a ocorrer (CAMPOS, 1999). Existem várias metodologias aplicadas para a melhoria contínua da Qualidade dos Dados, sendo a Gestão Total da Qualidade de Dados (Total Data Quality Mangement) a mais difundida (WANG, 1998). Ela é uma 
adaptação da Gestão Total da Qualidade (Total Quality Management) que consiste em assumir que a qualidade de todos os elementos da produção contribuem para a qualidade do produto final (DEMING, 1986 apud OLIVEIRA, 2008; SQUIRES et al., 2012; WANG, 1998).

A Gestão Total da Qualidade de Dados envolve as seguintes fases (WANG, 1998) (Figura 1):

- Definir (Definição das Dimensões da Qualidade de Dados e dos requisitos que elas devem representar aos usuários);

- Medir (Produção de métricas que quantifiquem a qualidade nas dimensões consideradas);

- Analisar (Análise do processo a partir dos resultados obtidos pela utilização das métricas nos dados); e

- Melhorar (Execução de ações que eliminem as causas dos problemas de qualidade identificados).

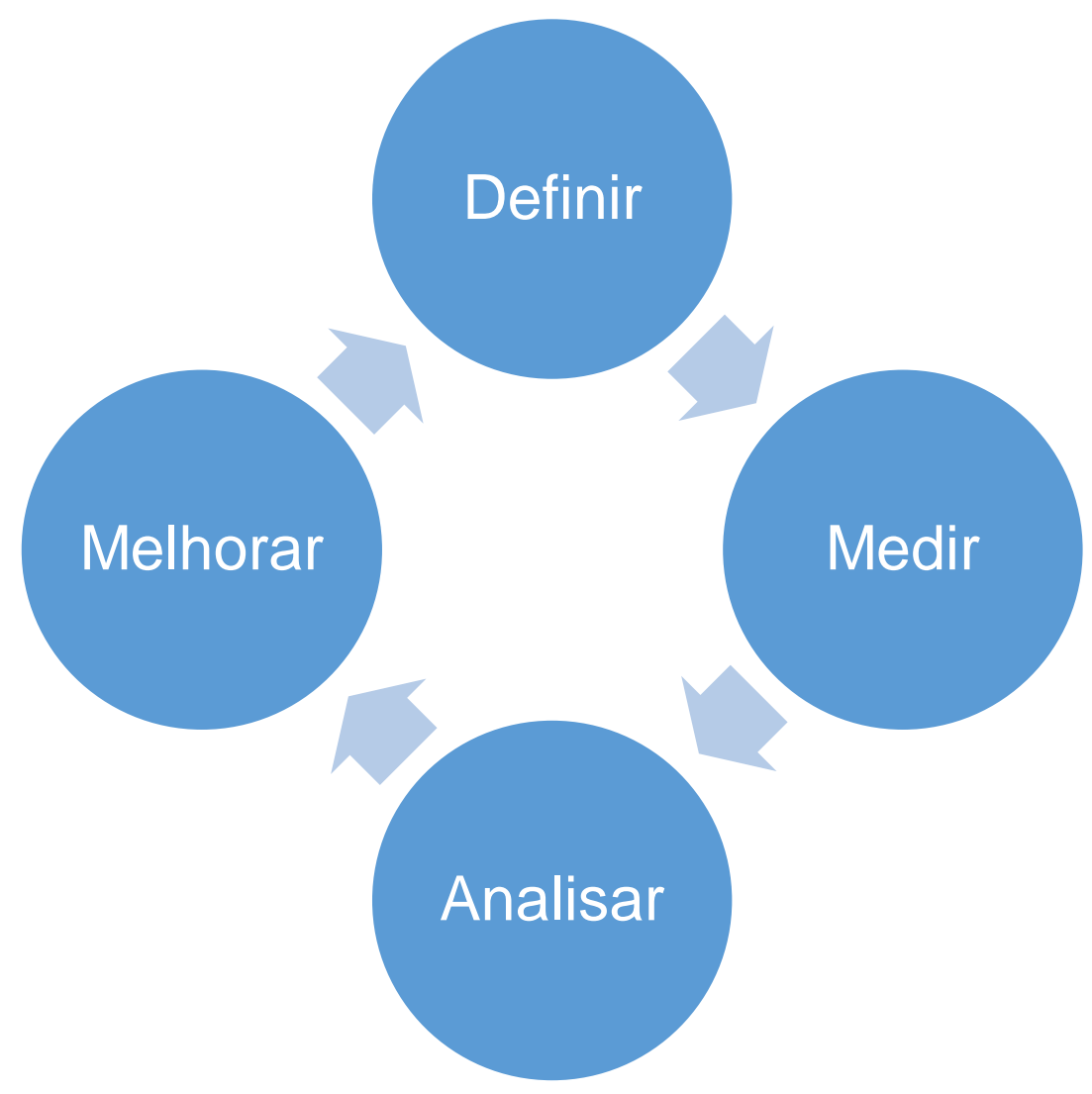

Figura 2 - Ciclo da Gestão Total da Qualidade dos Dados.

Fonte: Adaptado de Oliveira (2008) e Wang (1998). 
O início do processo de melhoria na Qualidade dos Dados se dá pela definição do conjunto de dimensões e do relacionamento entre elas, os quais serão utilizados para efetuar a avaliação da qualidade. Entretanto, não há um consenso geral para tal escolha, seja ela baseada na intuição, experiência ou literatura científica (ARAÚJO; BATISTA, 2013; BATINI; SCANNAPIECA, 2006; BOVEE; SRIVASTAVA; MAK, 2003; OLIVEIRA, 2008; SALVADOR et al., 2006; WAND; WANG, 1996;).

A medição da Qualidade dos Dados pode ser realizada de forma objetiva ou subjetiva, sendo ambas necessárias para uma avaliação completa da qualidade.

A medição subjetiva avalia a qualidade por meio da verificação da satisfação das necessidades dos usuários ao utilizar os dados ou da finalidade que os dados serão usados (SHANKARANARAYANAN, 2005 apud OLIVEIRA, 2008). Isso se dá a partir da realização de inquéritos sobre a utilização dos dados com os indivíduos que os usam.

Já a medição objetiva é aquela realizada a partir dos próprios dados, através da atribuição de valores numéricos ou categóricos a cada dimensão (GERTZ et al., 2004; PIPINO; LEE; WANG, 2002). Para isso, é necessário definir medidas padronizadas capazes de quantificar a qualidade de tal informação de modo que seja possível avaliá-la e realizar comparações. As abordagens mais utilizadas para a criação das métricas são (PIPINO; LEE; WANG, 2002):

- Razão simples, definida pela seguinte fórmula:

$$
\frac{n^{\mathrm{o}} \text { de casos com Problema de Qualidade de Dado }}{n^{\mathrm{o}} \text { total de casos }}
$$

Operação de mínimo ou máximo (usada para avaliar dimensões que envolvem múltiplos indicadores de qualidade)

- $\quad$ Média ponderada (utilizada quando se conhece a importância de cada indicador de qualidade na avaliação global de uma determinada dimensão)

Particularmente, indicadores são medidas usadas para ajudar a descrever a situação atual de um determinado fenômeno ou problema. Eles também são utilizados em termos de qualidade e quantidade para comparações, verificar mudanças ou tendências, tomada de decisões, análise crítica de resultados e avaliar a execução das ações planejadas durante um período de tempo (MASSAD et al., 2003; VIEIRA et al., 2006). Porém, é necessário que sejam construídos de forma consistente e dentro 
de um modelo lógico de acordo com a necessidade da organização e seus utilizadores, para que sejam efetivamente usados como apoio ao processo de gestão. (MASSAD et al., 2003).

Após a realização da medição da qualidade de um conjunto de dados, é possível analisar os resultados obtidos para identificar e corrigir os problemas encontrados. Esses problemas de qualidade são identificados pela presença de incongruências em uma ou mais dimensões, levando em consideração a finalidade das mesmas (WAND; WANG, 1996). A principal fonte causadora da baixa qualidade dos dados é a presença de erros, normalmente introduzidos a partir de erro humano (OLIVEIRA, 2008).

Alguns exemplos de erros dos dados que podem causar problemas de qualidade são: falta de valores referentes a atributos de preenchimento obrigatório; inconsistências entre valores de uma mesma entidade; erros ortográficos ou de codificação; representações não uniformes dos mesmos dados (uso de abreviaturas, nomenclaturas diversificadas); valores incompletos; e múltiplos registos relativos à mesma entidade (duplicidade) (OLIVEIRA, 2008).

Todavia, a correção dos dados está essencialmente ligada ao objeto real ao qual o dado está associado, de modo que em alguns casos, ao avaliar a completude de algumas variáveis, a ausência de valor representa corretamente o mundo real e não deve ser considerada como um erro.

Todos esses fatores fazem com que seja inevitável a presença de erros em um conjunto de dados e que seja necessário um programa formal de Garantia da Qualidade de Dados com processos de detecção e correção de erros (OLIVEIRA, 2008; SALVADOR et al., 2006).

Por fim, a melhoria da Qualidade de Dados pode ser obtida através da abordagem baseada nos dados ou da baseada no processo. A primeira consiste na detecção automática dos problemas de qualidade e sua correção automatizada ou manual, enquanto a segunda consiste da análise das atividades que geram os problemas de qualidade (REDMAN, 1997). A partir de problemas previamente conhecidos ou após a sua detecção, seja ela computadorizada ou não, são realizadas as atividades de correção, transformação, limpeza e enriquecimento dos dados. Contudo, a generalização dessas atividades só é possível quando há um domínio das causas específicas. 


\subsection{Qualidade de Dados na Saúde}

É sabido que os dados em saúde são especiais por serem muito complexos, pouco estruturados, altamente volumosos, gerados e utilizados por estruturas complexas, os serviços de saúde (SALVADOR et al., 2006). Além disso, esses dados são essenciais epidemiologicamente para o planejamento, monitoramento, execução e avaliação das ações de saúde, em especial nas populações com alta desigualdade socioeconômica (ROMERO; CUNHA, 2007).

A crescente utilização de sistemas de informação e/ou vigilância em saúde tem o objetivo de monitorar os problemas de saúde pública. Desse modo, a incorporação da informática nos serviços de saúde favorece a agilidade na produção das informações e a disseminação/divulgação das mesmas, principalmente por meio da Internet, subsidiando melhorias no cuidado à saúde (MATHIAS; SOBOLL, 1998; MONTEIRO, 2008).

Para que seja possível utilizar os dados armazenados nesses sistemas na melhoria dos problemas de saúde pública por meio de ações concretas, os mesmos devem conter atributos capazes de refletir as necessidades dos estabelecimentos de saúde e de seus pacientes e também possam gerar indicadores relevantes sobre a situação de saúde da população em questão (CDC, 2001; ROMERO; CUNHA, 2007).

Um estudo sobre confiabilidade dos dados de internações em hospitais privados contratados pelo município do Rio de Janeiro/RJ e registrados pelos formulários de Autorização de Internação Hospitalar (AIH) no ano de 1986 (VERAS; MARTINS, 1994) verificou que o diagnóstico principal foi o item de menor confiabilidade, enquanto os procedimentos realizados, os óbitos e as transferências mostraram serem os itens com melhor grau de confiabilidade. Outro problema grave encontrado foi a não inclusão de diagnósticos secundários, impossibilitando a classificação do paciente por níveis de gravidade. Gouvêa, Travassos e Fernandes (1997) também relataram problemas devido à qualidade de dados para a verificação da qualidade dos serviços de saúde. Eles explicam que as bases de dados projetadas para fins administrativos dentro das instituições de saúde oferecem grandes vantagens para avaliação de qualidade do serviço prestado por conterem grande volume de dados e estarem disponíveis próximos da ocorrência da internação, 
reduzindo consideravelmente o custo das avaliações. Porém, algumas desvantagens podem ser apontadas, como: insuficiência de dados para distinguir pacientes com níveis de gravidade distintos; baixa qualidade dos dados de diagnósticos e tratamentos em contrapartida com as informações pessoais e demográficas.

Tais estudos mostram que a busca pela avaliação da qualidade dos dados vêm sendo realizados há bastante tempo no Brasil. Assim, a disseminação e uso dos resultados de tais estudos para fins epidemiológicos certamente contribuem para o aperfeiçoamento das informações, desde que sejam levadas em consideração as limitações dos dados, sejam relacionadas com o viés na coleta, codificação ou então no armazenamento e divulgação desses dados (MONTEIRO, 2008). Outro fator que sempre deve ser considerado é que, na maioria das vezes, a qualidade dos dados inseridos nos sistemas de informação em saúde não é avaliada, fazendo com que a qualidade da informação gerada não seja totalmente confiável.

Outro fator capaz de auxiliar na melhoria da qualidade dos dados em saúde é a padronização das informações com o intuito de diminuir erros de escrita, o uso de termos inapropriados ou até a falta de dados. Especificamente para os dados referentes a alta do paciente, a Associação Brasileira de Normas Técnicas (ABNT) iniciou o desenvolvimento de um Sumário de Alta para ser utilizado como padrão pelas instituições de saúde brasileiras e proporcionar indicadores de gestão hospitalar e assistência em saúde mais qualificados e também uma maior comparabilidade entre os dados de diversos hospitais (DELFINI; MIYOSHI; ALVES, 2015).

A descentralização na validação e análise dos dados para os locais de coleta também permitiria uma melhor qualificação nos mesmos, gerando informações mais fidedignas e apoiando de forma mais ampla a gestão em saúde localmente. Tal ação pode ser realizada a partir da construção ou adaptação de sistemas de informação informatizados capazes de avaliar, durante ou após a coleta dos dados, se os mesmo estão sendo preenchidos e se seu preenchimento é feito a partir das características específicas de cada estabelecimento. Também é de interesse a geração de relatórios capazes de descrever a qualidade desses dados a partir da definição de métricas que avaliem essa qualidade. Mesmo assim, pouca coisa tem sido feita com relação ao dado e sua qualidade (SALVADOR et al., 2006). 


\subsection{CPDH e ORAH}

O Centro de Processamento de Dados Hospitalares (CPDH) iniciou suas atividades em 1970 auxiliando na organização dos Serviços de Arquivo Médico e Estatística (SAME) dos hospitais do município de Ribeirão Preto, no estado de São Paulo, a partir da obtenção e do processamento de dados sobre as altas hospitalares e censo das enfermarias. Essas informações, depois de codificadas, eram digitadas e processadas trimestralmente no Centro de Processamento de Dados (CPD) da Faculdade de Engenharia de São Carlos, da Universidade de São Paulo (USP). Também eram elaborados relatórios gerais e por estabelecimento, resultando em um total de 14 tabelas e listagens que caracterizavam os pacientes egressos segundo idade, sexo, procedência, categoria da internação, operações, condições do egresso, etc. além do perfil geral da morbidade e mortalidade hospitalar (MAZZER et al., 2010; SANTOS et al., 2010).

Em 1985, essa sistemática foi modificada com o início da digitação e processamento da Folha de Alta Hospitalar e Censo Hospitalar por meio de sistemas desenvolvidos no próprio CPDH. O acervo de dados sobre a assistência hospitalar no município, trabalho inédito nacionalmente até aquele momento, permitiu 0 desenvolvimento de inúmeras publicações acadêmicas de interesse clínico e epidemiológico além das aplicações administrativas e de gestão dos serviços e da assistência à saúde.

A partir de 1987, o CPDH expandiu sua área de cobertura para incluir hospitais da região de Ribeirão Preto, tanto públicos quanto privados.

Até 1995, as Folhas de Altas Hospitalares (Anexo A) e o Censo Diário eram manualmente preenchidos pelos estabelecimentos de saúde para posteriormente serem enviados ao $\mathrm{CPDH}$. A partir desta data, com o do desenvolvimento do sistema CPDH - Versão Hospitalar, instalado em 22 hospitais de Ribeirão Preto e região, os hospitais se beneficiaram com o preenchimento informatizado da Folha de Alta, com a impressão da Folha de Alta e do Censo Diário, e com a geração de um arquivo eletrônico contendo as informações a serem enviadas ao CPDH (MAZZER et al., 2010). A partir do ano 2000, uma nova versão foi desenvolvida para incluir ferramentas de checagem do preenchimento e de erros nos dados, o que permitiu a criação de um 
processo de auditoria na geração dos arquivos a serem enviados ao CPDH. (MAZZER et al., 2010).

Em casos de hospitais com sistemas de informações próprios, foi disponibilizado um layout da Folha de Alta para a geração dos dados das altas a partir dos dados presentes em seus próprios sistemas e, assim, poder enviá-los mensalmente ao $\mathrm{CPDH}$ em formato texto para que eles pudessem ser importados à base de dados do centro.

No CPDH, o recebimento do arquivo eletrônico gerou modificações na rotina dos trabalhos para incluir a conferência, correções e complementações das Folhas de Altas, além da codificação e digitação em alguns casos. Além disso, o sistema conseguiu disponibilizar recursos de extrema importância para os funcionários dos hospitais que se utilizavam do mesmo, como, por exemplo, equívocos e falta de preenchimento de campos fundamentais da Folha de Alta Hospitalar (SIMÕES; COUTINHO; ALMEIDA, 1991; MAZZER et al., 2010).

A atuação do CPDH tem sido única no contexto dos sistemas de informação hospitalares brasileiros. Com isso, em 2009, a Secretaria de Estado da Saúde de São Paulo (SES/SP), por meio do Departamento Regional de Saúde da Região de Ribeirão Preto (DRS XIII) e o Departamento de Medicina Social da Faculdade de Medicina de Ribeirão Preto (FMRP/USP), criou o Observatório Regional de Assistência Hospitalar (ORAH).

Com o objetivo de incorporar e ampliar o serviços já prestados pelo CPDH e criar instrumentos tecnológicos capazes de auxiliar na gestão da saúde na região, o ORAH passou a fornecer cenários como: o perfil nosológico informatizado de cada hospital, análise de fluxo de pacientes entre hospitais e microrregiões por meio de mapas e tabelas dinâmicas, análise informatizada de procedimentos realizados durante as internações hospitalares, identificação de internações por doenças sensíveis à Atenção Básica, geração automática de indicadores hospitalares, dentre outros recursos (CARVALHO et al., 2013b); por meio da continuidade no uso do robusto protocolo de coleta e manutenção da qualidade das informações sobre internações de hospitais públicos e privados da região de Ribeirão Preto já adotado pelo $\mathrm{CPDH}$. Também deve-se levar em consideração o grande número de informações processadas, sendo aproximadamente 170 mil altas anuais e mais de 4 milhões de altas durante toda a existência do CPDH/ORAH (MAZZER et al., 2010; CARVALHO et al., 2013b). 
Como já comentado, a principal fonte de dados que alimenta o banco de dados do CPDH/ORAH é a Folha de Alta Hospitalar (Anexo A). Essa ficha é preenchida pelos médicos dos hospitais que relatam os diagnósticos principais e secundários, os procedimentos realizados, as complicações e a condição de saída. Após ser preenchida pelos médicos, a Folha de Alta Hospitalar é enviada ao ORAH em conjunto com o arquivo eletrônico gerado, no caso dos hospitais que utilizam o sistema CPDH - Versão Hospitalar ou seus próprios sistemas de informação para digitalizá-la. Então, a mesma passa por um processamento no observatório, quando é revista qualitativa e quantitativamente e codificada, segundo os códigos da CID-10 (Classificação Internacional de Doenças e Problemas Relacionados à Saúde - Décima Revisão) e ICD-9-CM (International Classification of Diseases, Ninth Revision, Clinical Modification). Assim, é realizada a digitação da ficha no sistema ou então é feita a complementação do arquivo eletrônico com as novas informações codificadas. Finalmente, uma nova revisão é realizada, para, posteriormente, se armazenar e disponibilizar as altas em um banco de dados relacional (SIMÕES; COUTINHO; ALMEIDA, 1991; SILVA et al., 2008). Esse fluxo pode ser melhor visualizado na Figura 3.

Um dos diferenciais do observatório é o protocolo de verificação desenvolvido para a melhoria e manutenção da qualidade dos dados, impedindo a existência de informações não preenchidas ou então preenchidas de forma incorreta ao final do processamento (SIMÕES; COUTINHO; ALMEIDA, 1991). Abaixo segue, de maneira resumida, o protocolo seguido pela equipe do ORAH/CPDH para manter a qualidade de dados:

1) Conferência da folha de alta com o censo diário.

2) Complementação dos dados que estão faltando ou inconsistentes.

3) Importação do arquivo eletrônico (Sistema próprio/terceirizado).

4) Codificação e digitação complementar no sistema.

5) Controle de qualidade de todos os dados pela sua submissão a um programa de verificação de consistências e preenchimento.

6) Conferência individual de cada Folha de Alta com os dados já conferidos e inseridos no sistema. 


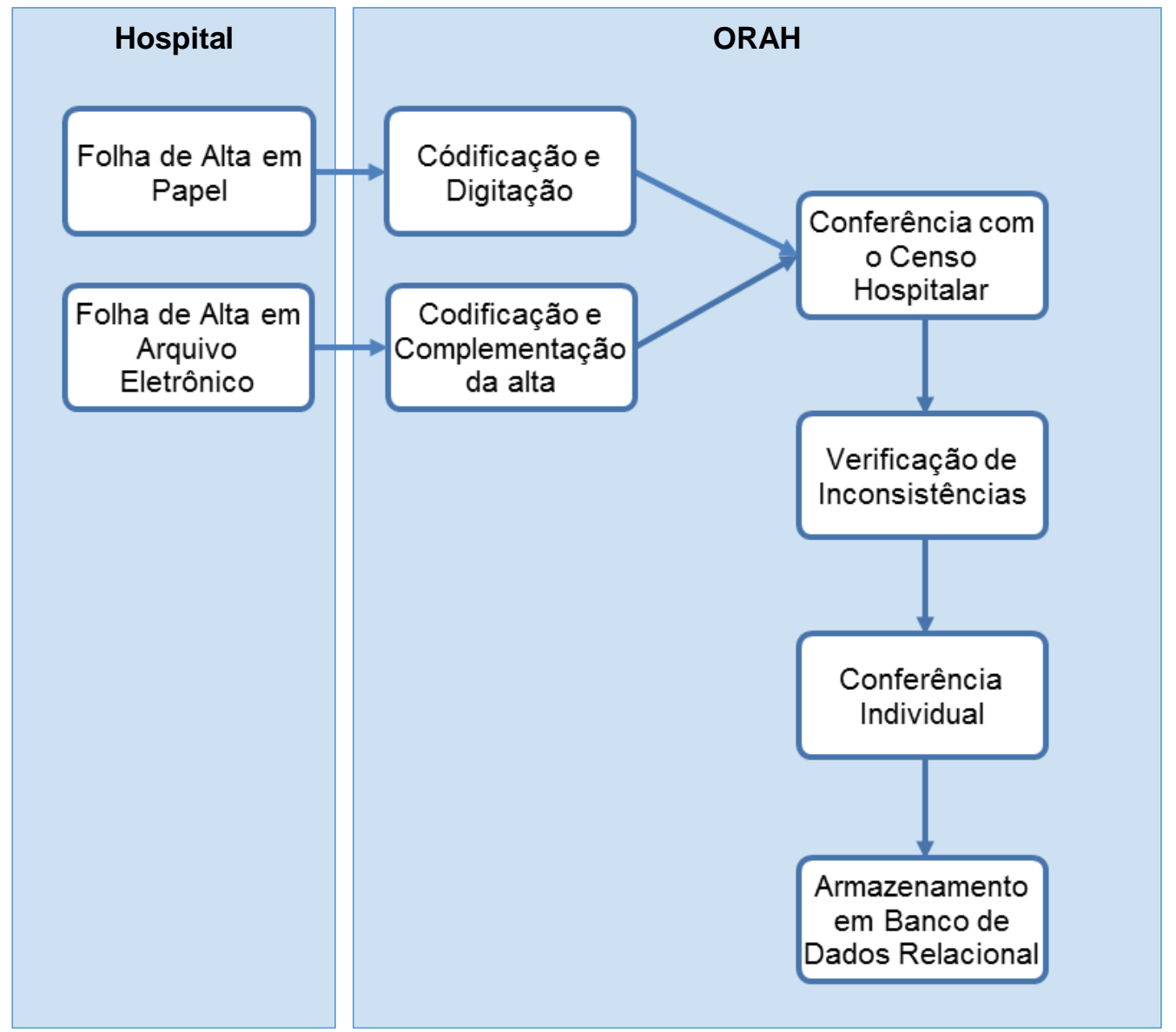

Figura 3 - Fluxograma da Obtenção e Processamento das Folhas de Altas no ORAH.

Um estudo comparativo entre os dados presentes na Folha de Alta e os Prontuários do Paciente das internações no município de Ribeirão Preto em 1972 verificou um percentual de 7,54\% de não concordância entre os mesmos (YAZLLE ROCHA, 1974 apud SIMÕES; COUTINHO; ALMEIDA, 1991). Em 1989, outra pesquisa analisou 33 tipos de inconsistências que poderiam ocorrer aos dados do CPDH e verificou a presença de uma pequena proporção de erros $(2,28 \%)$ nos dados recebidos, sendo que a rotina de verificação adotada era capaz de encontrá-los e corrigi-Ios (SIMÕES; COUTINHO; ALMEIDA, 1991). Recentemente, um estudo de uma amostra das internações por causas externas em três hospitais comparou a qualidade das informações de internações por causas externas registradas pelo $\mathrm{CPDH}$ com as presentes nos Prontuários dos Pacientes, sendo este considerado como padrão ouro, e teve como resultado uma ótima sensibilidade para os dados de identificação do paciente (de $95 \%$ a 99\%) e para a natureza da lesão $(72,8 \%)$ desses diagnósticos (MONTEIRO, 2008). 
Apesar destes estudos, não foi realizada uma análise mais completa e atualizada sobre a qualidade dos dados do sistema de informação do ORAH e como essa qualidade se comporta durante o processamento dos mesmos. Particularmente, não existe uma definição de indicadores de qualidade em qualquer parte do fluxo de processamento dos dados. Além disso, também é importante verificar o quanto as informações oriundas dos hospitais e recebidas pelo ORAH são fidedignas àquelas presentes no Prontuário dos Pacientes, uma vez que ele armazena as anotações do médico e os relatórios de enfermagem, que contém a informação essencial sobre a evolução clínica do paciente. Isso torna o Prontuário do Paciente como a principal fonte de informações referente às atividades assistenciais e o principal documento de uma organização de saúde sob aspectos administrativos, assistenciais e jurídicos (APM; CREMESP, 2009).

\subsection{Objetivo}

Diante desse cenário, o objetivo deste estudo é estabelecer o panorama da qualidade dos dados das altas hospitalares ocorridas em 2012 para cada hospital parceiro do ORAH e também analisar e identificar o ganho ou perda de qualidade nos dados durante as etapas de coleta e processamento dos mesmos pelo ORAH.

\subsubsection{Objetivos Específicos}

a) Descrição e análise da produção dos dados e do fluxo de informação nos hospitais conveniados ao ORAH.

b) Descrição e análise da qualidade dos dados produzidos pelos hospitais e processados pelo ORAH a partir da criação de indicadores de qualidade para os mesmos.

c) Avaliação da qualidade dos dados em cada etapa do protocolo interno de verificação adotado pelo ORAH a partir da criação de indicadores de qualidade para os mesmos.

d) Avaliação da correção entre os dados registrados no ORAH e o Prontuário Médico do Paciente. 


\section{Materiais e Métodos}

\subsection{Fontes de Dados}

Como já comentado inicialmente, a base de dados da pesquisa está sendo disponibilizada pelo Observatório Regional de Atenção Hospitalar (ORAH). As variáveis de interesse são todas as presentes na Folha de Alta Hospitalar (Anexo A) e serão estudadas as internações ocorridas e registradas nos hospitais do Departamento Regional de Saúde da Região de Ribeirão Preto (DRS XIII) conveniados ao ORAH, cuja data de saída tenha ocorrido no ano de 2012.

Neste período em específico, o observatório manteve convênio com 13 hospitais da cidade de Ribeirão Preto e mais 12 hospitais da região compreendida pelo DRS XIII, totalizando 25 hospitais. Desses, 4 hospitais de Ribeirão Preto não serão considerados na pesquisa por não ser feito nenhum tipo de processamento das Folhas de Altas dos mesmos pelo ORAH.

A base do ORAH apresenta 152.908 altas realizadas durante o ano de 2012. Entretanto, para este estudo, foram consideradas somente as altas de 21 hospitais, 0 que resulta num total de 108.012 altas. Outra observação é que um dos hospitais de Ribeirão Preto parou de realizar internações a partir de maio de 2012, pois tornou-se um ambulatório.

Para um melhor entendimento das informações armazenadas pela Folha de Alta, é possível verificar no Anexo A uma descrição sucinta dos 27 campos presentes na mesma e das 33 variáveis representativas destes no sistema de informação do ORAH.

Também serão utilizados dados colhidos em dois estudos realizados por meio de seguintes instrumentos de pesquisa de campo:

- O Questionário para Avaliação da Coleta de Dados Hospitalares (Anexo B), que foi criado pelo CPDH para a coleta de informações administrativas, caracterização da infraestrutura e atendimento dos hospitais conveniados. Ele apresenta variáveis para a avaliação do nível de informatização e sistemas de informação utilizados nos hospitais. Outro grupo de variáveis é responsável pela identificação do fluxo da informação dentro do hospital. 
- $\quad$ O Instrumento para Avaliação da Qualidade dos Dados Registrados no ORAH e Prontuário Médico do Paciente (Anexo D), que contém as mesmas variáveis presentes na Folha de Alta (Anexo A) objetivando a correta comparação entre os dados do prontuário e o da base de dados. Este instrumento apresenta duas colunas: Descrição, onde são reproduzidas as informações presentes no ORAH; e Codificação, onde são reproduzidas as informações presentes no Prontuário do Paciente.

A disponibilização desses dados pelo ORAH foi realizada a partir da concordância com as especificações contidas no Termo de Responsabilidade para Uso de Informações presente no Anexo $\mathrm{E}$.

O processamento dos dados referente as Folhas de Altas e do Instrumento para Avaliação da Qualidade dos Dados Registrados no ORAH e Prontuário Médico do Paciente foi realizado com ajuda de rotinas computacionais desenvolvidas em linguagem de programação Java ${ }^{\mathrm{TM}}$ (SE 7 update 71$)^{1}$ na plataforma Netbeans ${ }^{\mathrm{TM}}$ IDE 8.0.12 e do gerenciador de banco de dados MySQL ${ }^{\mathrm{TM}}$ 5.6.173. Para a digitalização dos dados do Questionário para Avaliação da Coleta de Dados Hospitalares utilizou-se também da ferramenta Epi Info ${ }^{\mathrm{TM}}$ 3.5.3. $3^{4}$. Também foram utilizados os aplicativos do pacote Microsoft ${ }^{\circledR}$ Office 2013 e o sistema operacional Windows ${ }^{\circledR} 7$

\subsection{Descrição e Análise da Produção dos Dados e do Fluxo de Informação nos Hospitais conveniados ao ORAH}

Esta análise utilizou-se das informações obtidas a partir do Questionário de Avaliação da Coleta de Dados (Anexo B), mencionado anteriormente, para 20 dos hospitais conveniados ao ORAH. Em um dos hospitais não houve a realização da entrevista, pois o mesmo tem um número relativamente pequeno de internação (menor ou igual a uma por mês) e também por ser administrado por outro hospital que já tinha sido entrevistado.

1 Java $^{\mathrm{TM}}$ Platform, Standard Edition. Disponível em: <https://www.oracle.com/java/technologies/javase.html>. Acesso em: nov. 2014.

${ }^{2}$ Netbeans $^{\mathrm{TM}}$ IDE. Disponível em: <https://netbeans.org/>. Acesso em: nov. 2014.

${ }^{3}$ MySQL ${ }^{\mathrm{TM}}$. Disponível em: <http://www.mysql.com/>. Acesso em: nov. 2014.

${ }^{4}$ Epi Info ${ }^{\mathrm{TM}}$. Disponível em: <http://wwwn.cdc.gov/epiinfo/>. Acesso em: nov. 2012. 
A aplicação do Questionário de Avaliação da Coleta de Dados (Anexo B) é um processo rotineiro realizado pela equipe do ORAH e consiste em entrevistas, por telefone ou pessoalmente, com funcionários chaves em cada hospital integrantes do observatório. Para este estudo em específico, foram utilizadas as informações resultantes da aplicação de tal instrumento realizada no início de 2012 pela funcionária Sra. Maria Goreti Cassiano.

Primeiramente, nesta fase da pesquisa, as informações obtidas por essas entrevistas foram agrupadas em tabelas, de modo a caracterizar os hospitais da região com relação as seguintes categorias: Perfil Hospitalar, Informatização Hospitalar, Fluxo da Informação, e Diagnóstico e Codificação. Os dados coletados foram analisados quantitativamente de maneira a caracterizar o grau de informatização dos hospitais e a utilização informacional de cada instituição, ou seja, o modo como a informação do paciente é tratada, desde sua admissão até a sua alta. Em particular, deu-se ênfase ao grau de conhecimento de cada instituição com relação à codificação de dados médicos e a utilização de estatísticas hospitalares na gestão do atendimento ao paciente.

\subsection{Descrição e Análise da Qualidade dos Dados produzidos pelos Hospitais e processados pelo ORAH}

Os dados foram analisados inicialmente de forma a identificar a Qualidade em cada campo presente na Folha de Alta obtendo-se, assim, a Proporção de Preenchimento de cada campo e a Proporção de Ocorrência das regras de consistência em cada um dos hospitais e para a base de dados do ORAH estudada.

Complementarmente, foi realizada a verificação da qualidade de cada Folha de Alta Hospitalar já consolidada, ou seja, após ela já ter sido integralmente processada pelo ORAH, por meio de indicadores criados especificamente para esses casos e com foco nas seguintes dimensões da Qualidade de Dados: a consistência e a completude.

Estas análises foram realizadas para as 108.012 Folhas de Alta do ano de 2012 de 21 hospitais conveniados.

A avaliação da completude da Folha de Alta analisou o preenchimento ou não dos campos presentes na mesma levando-se em consideração a obrigatoriedade ou não deste preenchimento. Já para a consistência das Folhas de Alta analisou-se o 
preenchimento de forma incorreta ou inconsistente de acordo com as regras em vigor no ORAH, sendo que elas encontram-se especificadas nos Quadros de Códigos de Consistência presentes no Anexo $\mathrm{C}$ desta dissertação.

Para a avaliação da completude, foi elaborado uma medida derivada da razão simples entre os casos de campos não preenchidos e o total de campos em cada Folha de Alta. Essa medida representa o percentual de campos preenchidos na Folha de Alta e foi chamada de Grau de Completude $\left(\mathrm{C}_{\mathrm{p}}\right)$, sendo representada pela equação 2. Vale ressaltar que o total de campos a ser considerado é variável em cada Folha de Alta devido a obrigatoriedade ou não do preenchimento dos campos, sendo que alguns deles tem o seu preenchimento condicionado ao preenchimento de outra variável.

$$
C_{p}=\frac{\text { número de campos preenchidos da Folha de Alta }(F A)}{\text { total de campos da Folha de Alta }(F A)} \times 100
$$

A partir dessa medida, é possível avaliar a completude de conjuntos de Folhas de Alta em análises espaço-temporais a serem especificadas utilizando-se a média do Grau de Completude $\left(\overline{\mathrm{C}_{\mathrm{p}}}\right)$ das altas destes conjuntos. Isto foi realizado para cada mês de cada hospital (equação 3), para o hospital no ano de 2012 (equação 4) e para o conjunto total de dados dos hospitais parceiros do ORAH avaliados neste estudo (equação 5).

$$
\frac{\sum_{i=1}^{n} C p_{i}}{n}
$$

Com $n=$ total de FA do hospital no mês $m$.

$$
\frac{\sum_{m=1}^{12} \frac{\sum_{i=1}^{n} C p_{i}}{n}}{12}
$$

Com $n=$ total de FA do hospital no mês $m$. 


$$
\frac{\sum_{h=1}^{21} \frac{\sum_{i=1}^{n} C p_{i}}{n}}{21}
$$

Com n=total de FA do hospital h em 2012.

De forma semelhante, o Grau de Consistência $\left(\mathrm{C}_{\mathrm{t}}\right)$ foi elaborado para avaliar a consistência de uma Folha de Alta a partir de uma medida baseada na razão simples entre os casos de inconsistências encontrados e o total de regras de consistência existentes. Esta medida representa o percentual de consistência da Folha de Alta e está apresentada na equação 6.

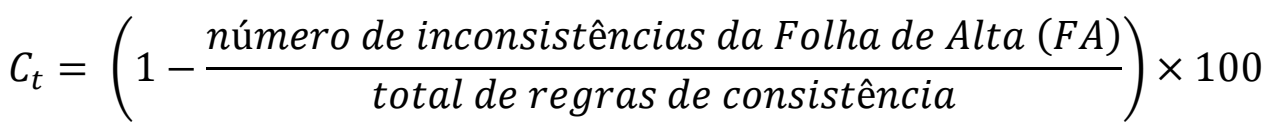

$$
\begin{aligned}
& =\left(1-\frac{n^{\circ} \text { de inconsistências da } F A}{38}\right) \times 100
\end{aligned}
$$

Com isso, também é possível avaliar a consistência de conjuntos de Folhas de Alta em análises espaço-temporais a serem especificadas utilizando-se a média do Grau de Consistência $\left(\overline{C_{\mathrm{t}}}\right)$ das altas destes conjuntos. Isto foi realizado para cada mês de cada hospital (equação 7), para o hospital no ano de 2012 (equação 8) e para o conjunto total de dados dos hospitais parceiros do ORAH avaliados neste estudo (equação 9).

$$
\frac{\sum_{i=1}^{n} C t_{i}}{n}
$$

Com $\mathrm{n}=$ total de FA do hospital no mês $\mathrm{m}$.

$$
\frac{\sum_{m=1}^{12} \frac{\sum_{i=1}^{n} C t_{i}}{n}}{12}
$$

Com $n=$ total de FA do hospital no mês $m$. 


$$
\frac{\sum_{h=1}^{21} \frac{\sum_{i=1}^{n} C t_{i}}{n}}{21}
$$

Com $\mathrm{n}=$ total de FA do hospital h em 2012.

Para uma análise mais abrangente das medidas resultantes, foi estabelecida uma classificação dos resultados em cinco categorias: Excelente, Bom, Regular, Ruim e Péssimo (CDC, 2001; ROMERO; CUNHA, 2007). Os valores referentes a cada categoria pode ser visto na Tabela 1.

Tabela 1 - Categorias para a Classificação de Medidas de Qualidade.

\begin{tabular}{ccc}
\hline Categoria & Valor & Intervalo \\
\hline Excelente & Igual ou maior que 95\% & {$[95,0 \% ; 100,0 \%]$} \\
Bom & 90 a $95 \%$ & {$[90,0 \% ; 95,0 \%)$} \\
Regular & 80 a $90 \%$ & {$[80,0 \% ; 90,0 \%)$} \\
Ruim & 50 a $80 \%$ & {$[50,0 \% ; 80,0 \%)$} \\
Péssimo & Menor que $50 \%$ & {$[0,0 \% ; 50,0 \%)$} \\
\hline
\end{tabular}

\subsection{Avaliação da Qualidade nas Etapas de Processamento das Folhas de Alta no ORAH}

Além da análise da Qualidade da Folha de Alta, também se faz necessária uma avaliação mais detalhada do ganho ou perda de Qualidade na informação obtidos pela execução dos protocolos de validação e consistência adotados pelo ORAH. Assim, serão analisadas as seguintes etapas do protocolo de verificação:

1) Recebimento dos dados Eletrônicos Oriundos dos Hospitais;

2) Digitação e Codificação dos dados;

3) Revisão e Conferência dos dados.

Devido a discrepância entre a forma de envio das Folhas de Alta por cada hospital, eles foram divididos em dois grupos: hospitais com envio da Folha de Alta em papel e sem arquivo eletrônico, e hospitais com envio da Folha de Alta em arquivo eletrônico e em papel. Por esse motivo, cada grupo terá uma quantidade diferente de etapas avaliadas.

Para o primeiro grupo, foi estimada somente a "diferença" da Qualidade entre as etapas 2 e 3, pois não há arquivo eletrônico para realizar a análise da etapa 1. Já 
para o segundo grupo, foi estimada a "diferença" da Qualidade entre as etapas 1 e 2 e entre a 2 e 3.

Outro critério utilizado para a escolha dos hospitais participantes desta análise refere-se a homogeneidade na quantidade de altas de cada mês entre as etapas analisadas. Essas variações na quantidade de altas entre os meses ocorreu para a maioria dos hospitais e pode ser explicado com base nos protocolos de consistência e validação utilizados, uma vez que todos os arquivos recebidos são conferidos com o Censo Hospitalar. Com isso, para esses meses com variação não foi possível identificar unicamente todas as Folhas de Alta entre as etapas, fazendo com que se utilizasse somente os dados de hospitais com quatro (04) ou mais meses com o mesmo número de Folhas de Alta entre as etapas, sendo descartados os meses com quantidades diferentes de altas.

As análises entre as etapas avaliaram três dimensões da Qualidade de Dados: a completude, a consistência e a volatilidade de cada. As medidas elaboradas para esta análise foram os Coeficientes de Completude $\left(\mathrm{CC}_{\mathrm{p}}\right)$, de Consistência $\left(\mathrm{CC}_{\mathrm{t}}\right)$ e de Volatilidade $(\mathrm{CV})$. As medidas de completude e consistência foram utilizadas para avaliar a magnitude com que a qualidade dos dados modificou entre as etapas, enquanto a de volatilidade representa a razão de campos com presença de alterações nos dados, sem avaliar se isso acarretou em mudança da qualidade ou não, e com uso restrito para a realização da auditoria do conjunto de processos.

As dimensões de completude e consistência foram verificadas para cada uma das etapas da mesma forma que a explicada anteriormente na seção 2.3, sendo que as medidas de Grau de Completude e Consistência serviram como base para a elaboração dos Coeficientes de Completude e Consistência expressos nas equações 10 e 11 , respectivamente.

$$
\begin{gathered}
C C p=\frac{C p_{i}-C p_{i-1}}{100} \\
C C t=\frac{C t_{i}-C t_{i-1}}{100}
\end{gathered}
$$

Com i = etapa atual e $\mathrm{i}-1=$ etapa anterior. 
Assim, foi construído o Indicador de Qualidade dos Dados entre Processos do $\mathrm{ORAH}$ (IQP) para avaliar se houve mudança na qualidade dos dados entre uma etapa e a sua predecessora. Este indicador é aplicado para uma mesma Folha de Alta nas duas etapas do processamento avaliadas a partir da combinação dos valores obtidos pelos coeficientes das dimensões de completude e consistência. A equação 13 representa o indicador elaborado especificamente para esta análise.

$$
I Q P=\frac{(C C p+C C t)}{2}
$$

É importante notar que os coeficientes criados para as dimensões incorporadas nesse indicador tem como resultado valores entre $[-1,0 ; 1,0]$, sendo que quanto maiores os coeficientes maior foi a melhora na qualidade dos dados entre as etapas. De forma mais simplista, valores negativos de CCp e CCt indicam, respectivamente, uma piora na qualidade do preenchimento e consistência dos dados entre as etapas enquanto valores positivos de CCp e CCt indicam, respectivamente, uma melhora na qualidade do preenchimento e consistência dos dados entre as etapas. Já quando o resultados das medidas forem iguais a zero $(0)$, significa que não houve alteração na qualidade entre as etapas.

Nesse sentido, ao analisar essas características conjuntamente e com um mesmo peso, o indicador de qualidade IQP proposto segue o mesmo padrão de resultados dos coeficientes e, assim, estimando o ganho ou perda da qualidade entre duas etapas e podendo ser utilizado para a verificação dessa alteração para cada hospital e também para o conjunto total de hospitais definidos neste estudo.

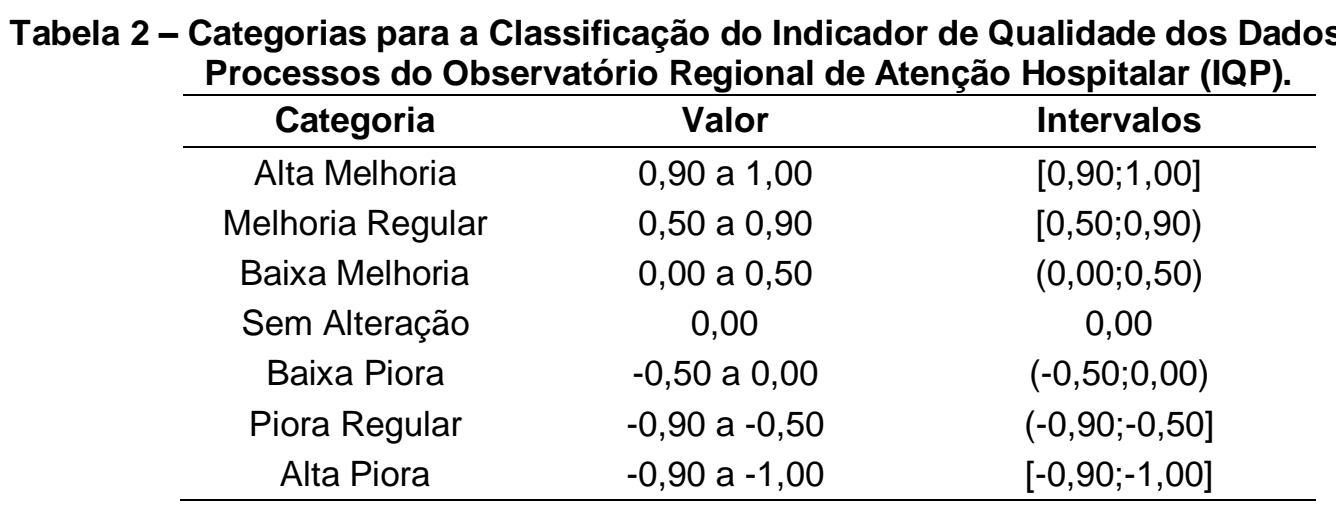


Para a avaliação deste indicador foram estabelecidas sete categorias, definidas como: Alta Melhoria, Melhoria Regular, Baixa Melhoria, Sem Alteração, Baixa Piora, Piora Regular e Alta Piora. As novas categorias e os valores referentes a elas podem ser visualizados na Tabela 2.

Já para a avaliação da volatilidade, foi elaborada uma medida de Coeficiente de Volatilidade (CV) a partir da razão simples entre os casos de campos de umas mesma Folha de Alta que foram modificados de uma etapa para a outra e o total de campos existentes na Folha de Alta. Essas modificações podem ser desde a mudança do valor armazenado no campo, o preenchimento de um campo antes vazio ou até a remoção de um valor armazenado na variável e deixando-a vazia. Esta medida está representada na equação 12.

$$
C V=\frac{\text { número de campos modificados da Folha de Alta }(F A)}{\text { total de campos da Folha de Alta (FA) }}
$$

A interpretação dos resultados desse coeficiente mostram que valores pequenos de $\mathrm{CV}$ indicam pequeno grau de volatilidade entre as etapas, ou seja, os dados entre as etapas não estão sendo alterados e, portanto, já atingiram um ótimo grau de qualidade. Já os valores altos de CV indicam que os dados precisaram ser revistos e modificados pela equipe do ORAH para a melhoria da qualidade dos mesmos. Um outro uso para os resultados obtidos por esse coeficiente pode estar associado a análise de custo/benefício na realização dos processos com relação ao ganho de qualidade das informações.

Em vista disso, foram estabelecidas quatro categorias definidas para a avaliação desse coeficiente, sendo elas: Nenhuma, Baixa, Moderada e Alta volatilidade. As novas categorias e os valores referentes a elas podem ser visualizados na Tabela 3.

Tabela 3 - Categorias para a Classificação do Coeficiente de Volatilidade (CV) entre os Processos do Observatório Regional de Atenção Hospitalar.

\begin{tabular}{ccc}
\hline Categoria & Valor & Intervalos \\
\hline Nenhuma & 0,00 & 0,00 \\
Baixa & 0,05 a 0,00 & {$[0,05 ; 0,00)$} \\
Moderada & 0,25 a 0,05 & {$[0,25 ; 0,05)$} \\
Alta & Maior que 0,25 & {$[1,00 ; 0,25)$} \\
\hline
\end{tabular}




\subsection{Avaliação da Correção entre a Folha de Alta e o Prontuário Médico}

Esta análise utilizou-se das informações coletadas a partir do Instrumento de Avaliação da Qualidade dos Dados Registrados no ORAH e Prontuário Médico do Paciente (Anexo D), mencionado anteriormente. As informações obtidas por esse instrumento avaliaram a dimensão da qualidade de correção dos dados, ou seja, da inexistência de erros entre as informações presentes no Prontuário do Paciente e na Folha de Alta Hospitalar, com a criação de métricas capazes de identificar as diferenças entre os dois.

A pesquisa envolvendo o instrumento disponível no Anexo $D$ foi realizada por funcionários do ORAH sob a coordenação da Sra. Dulce Helena de Brito. De fato, o estudo se constitui na comparação das informações presentes no banco de dados relacional do ORAH com seus pares contidos nos Prontuários do Paciente a partir da escolha aleatória de uma amostra obtida por meio do software estatístico $\mathrm{R}^{5}$, versão x64 2.15.2. Tal amostra consistia em $10 \%$ do total de internações ocorridas entre os meses de Novembro de 2011 e Janeiro de 2012 para cada hospital, sendo o tamanho amostral escolhido por conveniência.

Inicialmente, este estudo foi idealizado para a realização nos 21 hospitais conveniados ao ORAH, mas devido a não concordância de alguns hospitais e problemas durante a coleta da amostra em outros, só foi possível a sua realização em 14 hospitais. Desta forma, a Tabela 4 apresenta o número de prontuários por mês idealizados para a amostragem em cada hospital, o total de prontuários verificados e o percentual de não realização ao final do estudo.

A partir dos dados resultantes da coleta amostral foi possível realizar duas análises diferentes: a do nível de discrepância do preenchimento da Folha de Alta e do Prontuário do Paciente, e a do nível de concordância entre os valores preenchidos na Folha de Alta e no Prontuário do Paciente.

5 The $R$ Project for Statistical Computing. Disponível em: <http://www.r-project.org/>. Acesso em: nov. 2012. 
Tabela 4 - Total de internações da amostra de Prontuários e Folhas de Alta a serem avaliadas por hospital, Novembro de 2011 a Janeiro de 2012.

\begin{tabular}{cccccccc}
\hline Cód. do Hospital & Município & Nov/11 & Dez/11 & Jan/12 & Total & $\begin{array}{c}\text { Total } \\
\text { Realizado }\end{array}$ & $\begin{array}{c}\text { \% Não } \\
\text { Realizado }\end{array}$ \\
\hline 1 & Ribeirão Preto & 88 & 86 & 86 & $\mathbf{2 6 0}$ & $\mathbf{2 4 8}$ & $\mathbf{4 , 6 \%}$ \\
3 & Ribeirão Preto & 8 & 6 & 8 & $\mathbf{2 2}$ & $\mathbf{2 2}$ & $\mathbf{0} \%$ \\
6 & Ribeirão Preto & 3 & 2 & 2 & $\mathbf{7}$ & $\mathbf{7}$ & $\mathbf{0 \%}$ \\
7 & Ribeirão Preto & 62 & 55 & 65 & $\mathbf{1 8 2}$ & $\mathbf{1 7 3}$ & $\mathbf{4 , 9 \%}$ \\
10 & São Simão & 5 & 6 & 6 & $\mathbf{1 7}$ & $\mathbf{1 6}$ & $\mathbf{5 , 9 \%}$ \\
11 & Guariba & 22 & 25 & 19 & $\mathbf{6 6}$ & $\mathbf{5 9}$ & $\mathbf{1 0 , 6 \%}$ \\
12 & Serrana & 19 & 19 & 21 & $\mathbf{5 9}$ & $\mathbf{5 4}$ & $\mathbf{8 , 5 \%}$ \\
13 & Cajuru & 31 & 28 & 30 & $\mathbf{8 9}$ & $\mathbf{8 9}$ & $\mathbf{0 \%}$ \\
14 & Cravinhos & 3 & 5 & 6 & $\mathbf{1 4}$ & $\mathbf{1 4}$ & $\mathbf{0 \%}$ \\
15 & Sertãozinho & 21 & 24 & 23 & $\mathbf{6 8}$ & $\mathbf{5 2}$ & $\mathbf{2 3 , 5 \%}$ \\
16 & Pontal & 14 & 14 & 15 & $\mathbf{4 3}$ & $\mathbf{2 6}$ & $\mathbf{3 9 , 5} \%$ \\
17 & Altinópolis & 8 & 9 & 8 & $\mathbf{2 5}$ & $\mathbf{2 1}$ & $\mathbf{1 6 , 0 \%}$ \\
20 & Santa Rosa do Viterbo & 13 & 11 & 11 & $\mathbf{3 5}$ & $\mathbf{3 1}$ & $\mathbf{1 1 , 4 \%}$ \\
21 & Monte Alto & 8 & 9 & 9 & $\mathbf{2 6}$ & $\mathbf{2 6}$ & $\mathbf{0 \%}$ \\
& Amostra Total & $\mathbf{3 0 5}$ & $\mathbf{2 9 9}$ & $\mathbf{3 0 9}$ & $\mathbf{9 1 3}$ & $\mathbf{8 3 8}$ & $\mathbf{2 4 , 8 \%}$ \\
\hline
\end{tabular}

Para a análise de discrepância, foram utilizados os conceitos de especificidade e sensibilidade para averiguar o preenchimento dos campos na Folha de Alta em relação aos dados contidos no Prontuário do Paciente. Para isso, foi idealizada uma tabela de contingência 2x2 cujas colunas correspondem ao Prontuário do Paciente e as linhas correspondem à Folha de Alta (Tabela 5).

Tabela 5 - Tabela de Contingência 2x2 do Preenchimentos dos Campos da Folha de Alta e do Prontuário do Paciente.

\begin{tabular}{ccc}
\hline \multirow{2}{*}{ Folha de Alta } & \multicolumn{2}{c}{ Prontuário do Paciente } \\
\cline { 2 - 3 } & Campos Preenchidos & Campos Não Preenchidos \\
\hline Campos Preenchidos & $\mathrm{a}$ & $\mathrm{b}$ \\
Campos Não Preenchidos & $\mathrm{c}$ & $\mathrm{d}$ \\
\hline
\end{tabular}

Neste ponto, a sensibilidade (S) será definida pela probabilidade de um campo estar preenchido na Folha de Alta e a informação estar presente no Prontuário do Paciente (equação 14), tanto para os casos em que as informações são similares quanto para quando elas diferem. Já a especificidade (E) será a probabilidade de um mesmo campo não ter sido preenchido na Folha de Alta e a informação estar ausente do Prontuário do Paciente (equação 15).

$$
S=\frac{a}{a+c} \times 100
$$




$$
E=\frac{d}{b+d} \times 100
$$

Para a análise de concordância dos valores contidos nos campos, foi utilizado o conceito de Acurácia. São considerados corretos os casos em que tanto o campo da Folha de Alta e do Prontuário do Paciente estão preenchidos com um mesmo valor e os casos em que um campo não é preenchido tanto a Folha de Alta quanto o Prontuário do Paciente. A partir disso, é possível verificar a Acurácia $(A)$ dos campos a partir da aplicação da equação 16 aos dados.

$$
A=\frac{\begin{array}{c}
\text { Campos Igualmente Preenchidos }+ \\
\text { Campos Sem Preenchimento }
\end{array}}{\text { Total de Campos }} \times 100
$$

Por meio da aplicação dessa medida para cada par de Folha de Alta e Prontuário, é possível encontrar a Acurácia para cada hospital e também para a amostra total.

Além disso, também foram feitos os levantamentos dos acertos e erros para cada campo avaliado de forma semelhante ao comentado anteriormente. Assim, foi possível obter a média de Acertos $(\overline{\mathrm{A}})$ de cada variável (I) para cada hospital e também para a amostra total, e que está representada na equação 17.

$$
\bar{A}_{i}=\frac{N \text { o de Campos i Igualmente Preenchidos }+}{\text { Total de pares de Folha de Alta e Prontuário do Paciente }}
$$

\subsection{Aspectos Éticos}

No desenvolvimento deste trabalho foram cumpridas todas as exigências éticas prescritas pela resolução 196/96 do Conselho Nacional de Saúde (CNS) e suas complementares. Vale ressaltar que a metodologia proposta não envolve experimentação em seres humanos, nem tem foco em grupos especiais, e que a utilização das informações será feita de forma sigilosa e com a finalidade proposta neste trabalho. 
Para tal, o projeto deste trabalho foi submetido ao Comitê de Ética em Pesquisa (CEP) e obteve aprovação em 03 de dezembro de 2012/ Parecer № 161.531.

Visando a manutenção do sigilo das informações, nenhum paciente ou hospital conveniado será identificado no estudo. 


\section{Resultados e Discussão}

\subsection{Descrição e Análise da Produção dos Dados e do Fluxo de Informação nos Hospitais conveniados ao ORAH}

Conforme apresentado na seção 2.2, os dados dessa etapa foram coletados através entrevistas a funcionários dos hospitais a partir do questionário de Avaliação da Coleta de Dados (Anexo B). A seguir serão apresentados os resultados obtidos a partir dos dados coletados por meio de relatórios gerados em quatro categorias: Perfil Hospitalar, Informatização Hospitalar, Fluxo da Informação e Diagnóstico e Codificação.

\subsubsection{Perfil Hospitalar}

Os hospitais da região do Departamento Regional de Saúde XIII (DRS XIII) que compõem o ORAH estão distribuídos entre os municípios conforme a Tabela 6. Os nomes dos hospitais não serão apresentados de acordo com o explicitado na seção 2.6.

Tabela 6 - Distribuição dos Hospitais por Município.

\begin{tabular}{ccc}
\hline Município & Quantidade & Percentual (\%) \\
\hline Ribeirão Preto & 8 & $40,0 \%$ \\
Sertãozinho & 2 & $10,0 \%$ \\
Altinópolis & 1 & $5,0 \%$ \\
Cajuru & 1 & $5,0 \%$ \\
Cravinhos & 1 & $5,0 \%$ \\
Guariba & 1 & $5,0 \%$ \\
Jaboticabal & 1 & $5,0 \%$ \\
Monte Alto & 1 & $5,0 \%$ \\
Pontal & 1 & $5,0 \%$ \\
Santa Rosa Do Viterbo & 1 & $5,0 \%$ \\
São Simão & 1 & $5,0 \%$ \\
Serrana & 1 & $5,0 \%$ \\
Total & $\mathbf{2 0}$ & $\mathbf{1 0 0 , 0 \%}$ \\
\hline
\end{tabular}

Na Tabela 7 é possível verificar a distribuição desses hospitais de acordo com a sua categoria de internação desses hospitais. Há uma predominância de 75,0\% de hospitais mistos, que atendem tanto os pacientes do Sistema Único de Saúde (SUS) 
quanto Convênios e Pacientes Particulares, sendo que quatro (4) encontram-se localizados no município de Ribeirão Preto e os outros onze (11) distribuídos pelos municípios que compõem a Região do Departamento Regional de Saúde XIII (DRS XIII). Os hospitais de atendimento particular e convênios correspondem a 20,0\% dos entrevistados, sendo majoritariamente presentes no município de Ribeirão Preto com quatro (4) hospitais. Também é importante destacar que somente um dos hospitais da região atendem somente pacientes SUS.

Tabela 7 - Categoria de Internação atendida pelos Hospitais entrevistados.

\begin{tabular}{ccccc}
\hline $\begin{array}{c}\text { Categorias de internação atendidas } \\
\text { pelo Hospital }\end{array}$ & $\begin{array}{c}\text { Ribeirão } \\
\text { Preto }\end{array}$ & $\begin{array}{c}\text { Outros } \\
\text { Municípios }\end{array}$ & Total & Percentual (\%) \\
\hline SUS/Convênios/Particular & 4 & 11 & 15 & $75,0 \%$ \\
Convênios/Particular & 3 & 1 & 4 & $20,0 \%$ \\
SUS & 1 & 0 & 1 & $5,0 \%$ \\
Total & $\mathbf{8}$ & $\mathbf{1 2}$ & $\mathbf{2 0}$ & $\mathbf{1 0 0 \%}$ \\
\hline
\end{tabular}

Quando considera-se o tipo de especialidade atendida pelos hospitais, foi verificado uma predominância de $90,0 \%$ de hospitais gerais, sendo 6 localizados no município de Ribeirão Preto e os outros 12 distribuídos pela região. Os únicos hospitais especialistas entre os entrevistados encontram-se no município de Ribeirão Preto, sendo eles uma Maternidade e um hospital Psiquiátrico. Essas informações estão apresentadas na Tabela 8.

Tabela 8 - Características dos Hospitais entrevistados, segundo o tipo de especialidade atendida.

\begin{tabular}{ccccc}
\hline Característica do Hospital & $\begin{array}{c}\text { Ribeirão } \\
\text { Preto }\end{array}$ & $\begin{array}{c}\text { Outros } \\
\text { Municípios }\end{array}$ & Total & Percentual (\%) \\
\hline Geral & 6 & 12 & 18 & $90,0 \%$ \\
Maternidade & 1 & 0 & 1 & $5,0 \%$ \\
Psiquiátrico & 1 & 0 & 1 & $5,0 \%$ \\
Total & $\mathbf{8}$ & $\mathbf{1 2}$ & $\mathbf{2 0}$ & $\mathbf{1 0 0 \%}$ \\
\hline
\end{tabular}

Para avaliar a qualidade do Censo Diário dos leitos enviados pelos hospitais ao ORAH foi incluído no questionário uma pergunta sobre a periodicidade com que a ocupação dos leitos era feita por cada hospital, sendo constatado que a maioria dos hospitais fazem uma verificação diária de sua ocupação $(82,1 \%)$, conforme apresenta a Tabela 9. 
Tabela 9 - Periodicidade da contagem ou verificação da ocupação dos leitos nos Hospitais entrevistados.

\begin{tabular}{ccc}
\hline $\begin{array}{c}\text { Periodicidade da contagem ou verificação } \\
\text { da ocupação dos leitos }\end{array}$ & Frequência & Percentual (\%) \\
\hline Diariamente & 15 & $82,1 \%$ \\
Mensalmente & 3 & $10,7 \%$ \\
Quinzenalmente & 2 & $7,1 \%$ \\
Total & $\mathbf{2 0}$ & $\mathbf{1 0 0 \%}$ \\
\hline
\end{tabular}

\subsubsection{Informatização Hospitalar}

Em relação ao grau de informatização dos hospitais, todos têm setor de informática trabalhando em rede interna e a presença de computadores em alguns setores específicos dos hospitais pode ser vista na Tabela 10. Verifica-se que a presença de computadores nos hospitais ocorre predominantemente no setor de Faturamento (100\%), seguido pela Recepção $(80,0 \%)$, SAME $(70,0 \%)$ e Enfermaria $(60,0 \%)$.

Tabela 10 - Presença de Computadores nos Setores dos Hospitais entrevistados.

\begin{tabular}{ccccccccc}
\hline Presença de & \multicolumn{7}{c}{ Setor do Hospital } \\
\cline { 2 - 9 } Computadores & Recepção & (\%) & Enfermaria & (\%) & Faturamento & (\%) & SAME & (\%) \\
\hline Sim & 16 & $80,0 \%$ & 12 & $60,0 \%$ & 20 & $100,0 \%$ & 14 & $70,0 \%$ \\
Não & 4 & $20,0 \%$ & 7 & $35,0 \%$ & & $0,0 \%$ & 5 & $25,0 \%$ \\
Não Informado & & $0,0 \%$ & 1 & $5,0 \%$ & & $0,0 \%$ & 1 & $5,0 \%$ \\
Total & $\mathbf{2 0}$ & $\mathbf{1 0 0 \%}$ & $\mathbf{2 0}$ & $\mathbf{1 0 0 \%}$ & $\mathbf{2 0}$ & $\mathbf{1 0 0} \%$ & $\mathbf{2 0}$ & $\mathbf{1 0 0 \%}$ \\
\hline
\end{tabular}

Também verificou-se o nível de informatização do prontuário do paciente (Tabela 11), do preenchimento do diagnóstico (Tabela 12) e do censo hospitalar. Os resultados encontrados foram que menos da metade dos hospitais tem o seu prontuário informatizado $(40,0 \%)$ enquanto que somente $25,0 \%$ dos hospitais têm o preenchimento dos diagnósticos informatizado. Entretanto, o censo hospitalar é informatizado em todos os hospitais.

Tabela 11 - Nível de Informatização do Prontuário do Paciente nos Hospitais entrevistados.

\begin{tabular}{ccc}
\hline O prontuário do paciente é informatizado? & Frequência & Percentual (\%) \\
\hline Sim & 8 & $40,0 \%$ \\
Não & 12 & $60,0 \%$ \\
Total & $\mathbf{2 0}$ & $\mathbf{1 0 0 \%}$ \\
\hline
\end{tabular}


Tabela 12 - Informatização do preenchimento dos diagnósticos nos Hospitais entrevistados.

\begin{tabular}{ccc}
\hline $\begin{array}{c}\text { O preenchimento dos diagnósticos } \\
\text { é informatizado? }\end{array}$ & Frequência & Percentual (\%) \\
\hline Sim & 5 & $25,0 \%$ \\
Não & 15 & $75,0 \%$ \\
Total & $\mathbf{2 0}$ & $\mathbf{1 0 0 \%}$ \\
\hline
\end{tabular}

Outra característica examinada foi o sistema de informação utilizado pelos hospitais entrevistados para o armazenamento e geração das Folhas de Alta Hospitalar e do Censo Hospitalar enviados ao ORAH. Observou-se que a maioria faz uso de sistemas terceirizados que geram os dados da Folha de Alta obedecendo o layout disponibilizado. Vale ressaltar que um dos hospitais ainda faz o preenchimento manual da Folha de Alta. A distribuição dos hospitais de acordo com o tipo de sistema de informação utilizado pode ser visto na Tabela 13.

Tabela 13 - Sistema de Informação utilizado para armazenamento dos dados do Observatório Regional de Atenção Hospitalar (ORAH) nos Hospitais entrevistados.

\begin{tabular}{ccc}
\hline $\begin{array}{c}\text { Sistema de Informação utilizado para } \\
\text { armazenamento dos dados ORAH }\end{array}$ & Frequência & Percentual (\%) \\
\hline Terceirizado & 13 & $65,0 \%$ \\
CDPH - versão hospitalar & 6 & $30,0 \%$ \\
Manual & 1 & $5,0 \%$ \\
Total & $\mathbf{2 0}$ & $\mathbf{1 0 0 \%}$ \\
\hline
\end{tabular}

\subsubsection{Fluxo da Informação}

Para ajudar na identificação do fluxo da informação dos pacientes nos hospitais durante a sua internação até a sua alta, algumas questões foram feitas sobre esse fluxo. Foram identificados dois fluxos, sendo que a Tabela 14 apresenta a distribuição desses fluxos por hospitais. Na maioria dos hospitais $(85,0 \%)$, as informações das internações são coletadas na Enfermaria e enviadas para o Faturamento, sendo posteriormente direcionadas para o SAME do hospital e, por fim, serem armazenadas no Prontuário do Paciente.

Da mesma forma, foram averiguados quais os locais onde são feitas as coletas de algumas das informações importantes para o preenchimento da Folha de Alta. Verificou-se que em todos os hospitais a recepção é a responsável por obter os dados de identificação do paciente, tais como nome, idade, sexo, entre outros. 
Tabela 14 - Fluxo da informação do paciente durante a internação até o preenchimento da Folha de Alta nos Hospitais entrevistados.

\begin{tabular}{ccc}
\hline $\begin{array}{c}\text { Fluxo da informação do paciente até } \\
\text { chegar à Folha de Alta }\end{array}$ & Frequência & Percentual (\%) \\
\hline Enfermaria, Faturamento, SAME, Prontuário & 17 & $85,0 \%$ \\
Enfermaria, SAME, Faturamento, Prontuário & 3 & $15,0 \%$ \\
Total & $\mathbf{2 0}$ & $\mathbf{1 0 0 \%}$ \\
\hline
\end{tabular}

Também é na recepção que a maioria dos hospitais imprimem a Folha de Alta $(70,0 \%)$, sendo em segundo lugar o faturamento $(20,0 \%)$. A distribuição dos setores hospitalares em que a Folha de Alta é impressa pode ser visto na Tabela 15.

Tabela 15 - Local da impressão da Folha de Alta nos Hospitais entrevistados.

\begin{tabular}{ccc}
\hline Local da impressão da Folha de Alta & Frequência & Percentual (\%) \\
\hline Recepção & 14 & $70,0 \%$ \\
Faturamento & 4 & $20,0 \%$ \\
Enfermaria & 1 & $5,0 \%$ \\
SAME & 1 & $5,0 \%$ \\
Total & $\mathbf{2 0}$ & $\mathbf{1 0 0} \%$ \\
\hline
\end{tabular}

\subsubsection{Diagnóstico e Codificação}

Nesta categoria, as questões levantadas visavam estabelecer um panorama sobre como os diagnósticos são realizados e preenchidos na Folha de Alta. Essas informações são importantes para identificar a confiabilidade no registro e codificação dos diagnósticos e procedimentos realizados nos hospitais, uma vez que a realização desses procedimentos por profissionais qualificados resultam em dados com melhor qualidade na Folha de Alta e, respectivamente, na base de dados do ORAH. Outro ponto importante foi a identificação dos hospitais com deficiência nesses processos para que se pudesse investir na capacitação dos mesmos quanto ao registro e codificação dos diagnósticos e procedimentos.

Verificou-se que na maioria dos hospitais o médico é o responsável pelo registro do diagnóstico na Folha de Alta $(85,0 \%)$, conforme a Tabela 16. Também identificou-se que a enfermaria é o setor onde os diagnósticos são preenchidos na maioria dos hospitais (85,0\%), conforme Tabela 17. 
Tabela 16 - Profissional responsável pelo registro do diagnóstico na Folha de Alta nos Hospitais entrevistados.

\begin{tabular}{ccc}
\hline $\begin{array}{c}\text { Profissional responsável pelo registro do } \\
\text { diagnóstico na Folha de Alta }\end{array}$ & Frequência & Percentual (\%) \\
\hline Médico & 17 & $85,0 \%$ \\
SAME & 2 & $10,0 \%$ \\
Faturamento & 1 & $5,0 \%$ \\
Total & $\mathbf{2 0}$ & $\mathbf{1 0 0 \%}$ \\
\hline
\end{tabular}

Tabela 17 - Setor onde os diagnósticos são preenchidos na Folha de Alta nos Hospitais entrevistados.

\begin{tabular}{ccc}
\hline $\begin{array}{c}\text { Setor onde os diagnósticos são preenchidos } \\
\text { na Folha de Alta }\end{array}$ & Frequência & Percentual (\%) \\
\hline Enfermaria & 17 & $85,0 \%$ \\
Recepção & 1 & $5,0 \%$ \\
SAME & 1 & $5,0 \%$ \\
Faturamento & 1 & $5,0 \%$ \\
Total & $\mathbf{2 0}$ & $\mathbf{1 0 0 \%}$ \\
\hline
\end{tabular}

Averiguou-se que os médicos são os responsáveis pelo registro dos procedimentos cirúrgicos e da condição de saída na Folha de Alta na maioria dos hospitais, na proporção de $90,0 \%$ e $80,0 \%$ respectivamente. A distribuição dos profissionais responsáveis pelo registro dos procedimentos cirúrgicos pode ser vista na Tabela 18 e a do registro da condição de saída na Tabela 19.

Tabela 18 - Profissional responsável pelo registro dos procedimentos cirúrgicos na Folha de Alta nos Hospitais entrevistados.

\begin{tabular}{ccc}
\hline $\begin{array}{c}\text { Profissional responsável pelo registro dos } \\
\text { procedimentos cirúrgicos na Folha de Alta }\end{array}$ & Frequência & Percentual (\%) \\
\hline Médico & 18 & $90,0 \%$ \\
Faturamento & 1 & $5,0 \%$ \\
Não respondeu & 1 & $5,0 \%$ \\
Total & $\mathbf{2 0}$ & $\mathbf{1 0 0 \%}$ \\
\hline
\end{tabular}

Tabela 19 - Profissional responsável pelo registro da condição de saída do paciente na Folha de Alta nos Hospitais entrevistados.

\begin{tabular}{ccc}
\hline $\begin{array}{c}\text { Profissional responsável pelo registro da } \\
\text { condição de saída do paciente na Folha de } \\
\text { Alta }\end{array}$ & Frequência & Percentual (\%) \\
\hline Médico & 16 & $80,0 \%$ \\
Faturamento & 2 & $10,0 \%$ \\
SAME & 2 & $10,0 \%$ \\
Total & $\mathbf{2 0}$ & $\mathbf{1 0 0 \%}$ \\
\hline
\end{tabular}


Por fim, a Tabela 20 apresenta a presença ou não de um profissional codificador de doenças nos hospitais, sendo que há pelo menos um codificador em $95,0 \%$ deles e somente um hospital não possui nenhum $(5,0 \%)$.

Tabela 20 - Identificação da presença de um profissional codificador de doenças nos Hospitais entrevistados.

\begin{tabular}{ccc}
\hline $\begin{array}{c}\text { O hospital possui algum codificador de } \\
\text { doenças? }\end{array}$ & Frequência & Percentual (\%) \\
\hline Sim & 19 & $95,0 \%$ \\
Não & 1 & $5,0 \%$ \\
Total & $\mathbf{2 0}$ & $\mathbf{1 0 0 \%}$ \\
\hline
\end{tabular}

\subsection{Descrição e Análise da Qualidade dos Dados produzidos pelos Hospitais e processados pelo ORAH}

\subsubsection{Descrição e Análise da Qualidade dos Dados de cada campo presente na Folha de Alta}

Com o objetivo de descrever a Qualidade dos Dados presentes na base de dados do ORAH, foi realizada uma medição da proporção de preenchimento de cada campo da Folha de Alta para os hospitais conveniados no ano de 2012. Para a análise do preenchimento dos campos, foi levada em consideração a obrigatoriedade ou não dos campos e a relação de preenchimentos entre os campos em cada uma das Folhas de Alta analisadas.

Os resultados encontrados foram que 100,0\% dos campos apresentam-se com uma qualidade Excelente de preenchimento quando considera-se as categorias apresentadas na Tabela 1 da seção 2.3, ou seja, todos os campos apresentam um preenchimento superior a $95 \%$. Verificou-se também que somente um campo não apresentou preenchimento igual a $100,0 \%$, sendo ele relacionado a codificação do procedimento cirúrgico principal (Operação Principal) e cuja proporção de preenchimento foi de 99,2\%. Isso ocorreu em altas com a data de realização da cirurgia preenchida, mas sem a informação do código referente a mesma, ou então quando houve o preenchimento da cirurgia principal nos campos referentes a outros procedimentos deixando o campo correto vazio.

As proporções de preenchimento de cada campo para cada hospital avaliado podem ser visualizada nas Tabelas 21 e 22, sendo que na primeira são apresentados 
os resultados encontrados para cada hospital do município de Ribeirão Preto e a segunda os dos hospitais dos outros municípios da região de Ribeirão Preto. A partir desses resultados é possível verificar que a grande maioria dos campos foram totalmente preenchimentos em todos os hospitais e averiguar a distribuição do preenchimento dos campos não obrigatórios entre os hospitais. Também é possível identificar que os problemas de falta de preenchimento dos campos relacionados aos procedimentos ocorreram somente em dois hospitais, os hospitais 9 e 21, e também verificar que houve a falta de preenchimento do campo obrigatório Procedimento SUS para um dos hospitais (hospital 15).

Tabela 21 - Proporção de Preenchimento (\%) de cada Variável presente na Folha de Alta por Hospital do Município de Ribeirão Preto conveniados ao Observatório Regional de Atenção Hospitalar (ORAH), 2012.

\begin{tabular}{|c|c|c|c|c|c|c|c|c|c|}
\hline \multirow{2}{*}{ Variável } & \multicolumn{9}{|c|}{ Proporção de Preenchimento (\%) } \\
\hline & 1 & 2 & 3 & 4 & 5 & 6 & 7 & 8 & 9 \\
\hline Prontuário & 100,0 & 100,0 & 100,0 & 100,0 & 100,0 & 100,0 & 100,0 & 100,0 & 100,0 \\
\hline Hospital & 100,0 & 100,0 & 100,0 & 100,0 & 100,0 & 100,0 & 100,0 & 100,0 & 100,0 \\
\hline Enfermaria & 100,0 & 100,0 & 100,0 & 100,0 & 100,0 & 100,0 & 100,0 & 100,0 & 100,0 \\
\hline Especialidade & 100,0 & 100,0 & 100,0 & 100,0 & 100,0 & 100,0 & 100,0 & 100,0 & 100,0 \\
\hline Nome & 100,0 & 100,0 & 100,0 & 100,0 & * & 100,0 & 100,0 & 100,0 & 100,0 \\
\hline Iniciais do Nome & 100,0 & 100,0 & 100,0 & 100,0 & 100,0 & 100,0 & 100,0 & 100,0 & 100,0 \\
\hline Sexo & 100,0 & 100,0 & 100,0 & 100,0 & 100,0 & 100,0 & 100,0 & 100,0 & 100,0 \\
\hline Idade na internação & 100,0 & 100,0 & 100,0 & 100,0 & 100,0 & 100,0 & 100,0 & 100,0 & 100,0 \\
\hline Ocupação & 100,0 & 100,0 & 100,0 & 100,0 & 100,0 & 100,0 & 100,0 & 100,0 & 100,0 \\
\hline Categoria de internação & 100,0 & 100,0 & 100,0 & 100,0 & 100,0 & 100,0 & 100,0 & 100,0 & 100,0 \\
\hline Código IBGE do Município & 100,0 & 100,0 & 100,0 & 100,0 & 100,0 & 100,0 & 100,0 & 100,0 & 100,0 \\
\hline Sigla UF & 100,0 & 100,0 & 100,0 & 100,0 & 100,0 & 100,0 & 100,0 & 100,0 & 100,0 \\
\hline Data Internação & 100,0 & 100,0 & 100,0 & 100,0 & 100,0 & 100,0 & 100,0 & 100,0 & 100,0 \\
\hline Data Saída & 100,0 & 100,0 & 100,0 & 100,0 & 100,0 & 100,0 & 100,0 & 100,0 & 100,0 \\
\hline Afecção Principal & 100,0 & 100,0 & 100,0 & 100,0 & 100,0 & 100,0 & 100,0 & 100,0 & 100,0 \\
\hline Outras Afecções 1 & 100,0 & 100,0 & 100,0 & 100,0 & * & * & 100,0 & 100,0 & 100,0 \\
\hline Outras Afecções 2 & 100,0 & 100,0 & 100,0 & 100,0 & * & * & 100,0 & 100,0 & 100,0 \\
\hline Outras Afecções 3 & 100,0 & 100,0 & 100,0 & 100,0 & * & * & 100,0 & 100,0 & 100,0 \\
\hline Outras Afecções 4 & 100,0 & 100,0 & * & 100,0 & * & * & 100,0 & 100,0 & 100,0 \\
\hline Data Cirurgia & 100,0 & 100,0 & * & 100,0 & * & * & 100,0 & 100,0 & 100,0 \\
\hline Operação Principal & 100,0 & 100,0 & * & 100,0 & * & * & 100,0 & 71,5 & 100,0 \\
\hline Outras Operações 1 & 100,0 & 100,0 & * & 100,0 & * & * & 100,0 & 100,0 & 100,0 \\
\hline Outras Operações 2 & 100,0 & 100,0 & * & 100,0 & * & * & 100,0 & 100,0 & 100,0 \\
\hline Reoperação & 100,0 & * & * & 100,0 & * & * & 100,0 & * & * \\
\hline Causa do Acid., Viol. ou Env. & 100,0 & 100,0 & * & 100,0 & * & * & 100,0 & 100,0 & 100,0 \\
\hline Complicação Hospitalar & 100,0 & 100,0 & * & 100,0 & * & * & 100,0 & 100,0 & 100,0 \\
\hline CRM & 100,0 & 100,0 & 100,0 & 100,0 & 100,0 & 100,0 & 100,0 & 100,0 & 100,0 \\
\hline Condição Saída & 100,0 & 100,0 & 100,0 & 100,0 & 100,0 & 100,0 & 100,0 & 100,0 & 100,0 \\
\hline Procedimento SUS & 100,0 & 100,0 & 100,0 & 100,0 & 100,0 & 100,0 & 100,0 & 100,0 & 100,0 \\
\hline
\end{tabular}

Legenda: * Não houve o preenchimento deste campo em nenhuma Folha de Alta do hospital em questão. 
Tabela 22 - Proporção de Preenchimento (\%) de cada Variável presente na Folha de Alta por Hospital de Municípios da Região de Ribeirão Preto conveniados ao Observatório Regional de Atenção Hospitalar (ORAH), 2012.

\begin{tabular}{|c|c|c|c|c|c|c|c|c|c|c|c|c|}
\hline \multirow{2}{*}{ Variável } & \multicolumn{12}{|c|}{ Proporção de Preenchimento (\%) } \\
\hline & 10 & 11 & 12 & 13 & 14 & 15 & 16 & 17 & 18 & 19 & 20 & 21 \\
\hline Prontuário & 100,0 & 100,0 & 100,0 & 100,0 & 100,0 & 100,0 & 100,0 & 100,0 & 100,0 & 100,0 & 100,0 & 100,0 \\
\hline Hospital & 100,0 & 100,0 & 100,0 & 100,0 & 100,0 & 100,0 & 100,0 & 100,0 & 100,0 & 100,0 & 100,0 & 100,0 \\
\hline Enfermaria & 100,0 & 100,0 & 100,0 & 100,0 & 100,0 & 100,0 & 100,0 & 100,0 & 100,0 & 100,0 & 100,0 & 100,0 \\
\hline Especialidade & 100,0 & 100,0 & 100,0 & 100,0 & 100,0 & 100,0 & 100,0 & 100,0 & 100,0 & 100,0 & 100,0 & 100,0 \\
\hline Nome & 100,0 & * & 100,0 & 100,0 & 100,0 & 100,0 & 100,0 & 100,0 & 100,0 & 100,0 & 100,0 & 100,0 \\
\hline $\begin{array}{l}\text { Iniciais do } \\
\text { Nome }\end{array}$ & 100,0 & 100,0 & 100,0 & 100,0 & 100,0 & 100,0 & 100,0 & 100,0 & 100,0 & 100,0 & 100,0 & 100,0 \\
\hline Sexo & 100,0 & 100,0 & 100,0 & 100,0 & 100,0 & 100,0 & 100,0 & 100,0 & 100,0 & 100,0 & 100,0 & 100,0 \\
\hline $\begin{array}{l}\text { Idade na } \\
\text { internação }\end{array}$ & 100,0 & 100,0 & 100,0 & 100,0 & 100,0 & 100,0 & 100,0 & 100,0 & 100,0 & 100,0 & 100,0 & 100,0 \\
\hline Ocupação & 100,0 & 100,0 & 100,0 & 100,0 & 100,0 & 100,0 & 100,0 & 100,0 & 100,0 & 100,0 & 100,0 & 100,0 \\
\hline $\begin{array}{l}\text { Categoria de } \\
\text { internação }\end{array}$ & 100,0 & 100,0 & 100,0 & 100,0 & 100,0 & 100,0 & 100,0 & 100,0 & 100,0 & 100,0 & 100,0 & 100,0 \\
\hline $\begin{array}{l}\text { Código IBGE do } \\
\text { Município }\end{array}$ & 100,0 & 100,0 & 100,0 & 100,0 & 100,0 & 100,0 & 100,0 & 100,0 & 100,0 & 100,0 & 100,0 & 100,0 \\
\hline Sigla UF & 100,0 & 100,0 & 100,0 & 100,0 & 100,0 & 100,0 & 100,0 & 100,0 & 100,0 & 100,0 & 100,0 & 100,0 \\
\hline Data Internação & 100,0 & 100,0 & 100,0 & 100,0 & 100,0 & 100,0 & 100,0 & 100,0 & 100,0 & 100,0 & 100,0 & 100,0 \\
\hline Data Saída & 100,0 & 100,0 & 100,0 & 100,0 & 100,0 & 100,0 & 100,0 & 100,0 & 100,0 & 100,0 & 100,0 & 100,0 \\
\hline $\begin{array}{l}\text { Afecção } \\
\text { Principal }\end{array}$ & 100,0 & 100,0 & 100,0 & 100,0 & 100,0 & 100,0 & 100,0 & 100,0 & 100,0 & 100,0 & 100,0 & 100,0 \\
\hline $\begin{array}{l}\text { Outras } \\
\text { Afecções } 1\end{array}$ & 100,0 & 100,0 & 100,0 & 100,0 & 100,0 & 100,0 & 100,0 & 100,0 & 100,0 & 100,0 & 100,0 & 100,0 \\
\hline $\begin{array}{l}\text { Outras } \\
\text { Afecções } 2\end{array}$ & 100,0 & 100,0 & 100,0 & 100,0 & * & 100,0 & 100,0 & 100,0 & 100,0 & 100,0 & 100,0 & 100,0 \\
\hline $\begin{array}{l}\text { Outras } \\
\text { Afecções } 3\end{array}$ & * & 100,0 & 100,0 & 100,0 & * & 100,0 & 100,0 & 100,0 & * & 100,0 & 100,0 & 100,0 \\
\hline $\begin{array}{l}\text { Outras } \\
\text { Afecções } 4\end{array}$ & * & 100,0 & 100,0 & * & * & 100,0 & * & * & * & 100,0 & 100,0 & 100,0 \\
\hline Data Cirurgia & 100,0 & 100,0 & 100,0 & 100,0 & * & 100,0 & 100,0 & 100,0 & 100,0 & 100,0 & 100,0 & 99,8 \\
\hline $\begin{array}{l}\text { Operação } \\
\text { Principal }\end{array}$ & 100,0 & 100,0 & 100,0 & 100,0 & * & 100,0 & 100,0 & 100,0 & 100,0 & 100,0 & 100,0 & 99,8 \\
\hline $\begin{array}{l}\text { Outras } \\
\text { Operações } 1\end{array}$ & 100,0 & 100,0 & 100,0 & 100,0 & * & 100,0 & 100,0 & 100,0 & 100,0 & 100,0 & 100,0 & 100,0 \\
\hline $\begin{array}{l}\text { Outras } \\
\text { Operações } 2\end{array}$ & * & 100,0 & 100,0 & * & * & 100,0 & 100,0 & * & * & 100,0 & * & 100,0 \\
\hline Reoperação & * & * & * & * & * & * & * & * & * & 100,0 & * & 100,0 \\
\hline $\begin{array}{l}\text { Causa do Acid., } \\
\text { Viol. ou Env. }\end{array}$ & 100,0 & 100,0 & 100,0 & 100,0 & * & 100,0 & 100,0 & 100,0 & 100,0 & 100,0 & 100,0 & 100,0 \\
\hline $\begin{array}{l}\text { Complicação } \\
\text { Hospitalar }\end{array}$ & * & * & 100,0 & * & * & 100,0 & * & * & * & 100,0 & * & * \\
\hline CRM & 100,0 & 100,0 & 100,0 & 100,0 & 100,0 & 100,0 & 100,0 & 100,0 & 100,0 & 100,0 & 100,0 & 100,0 \\
\hline Condição Saída & 100,0 & 100,0 & 100,0 & 100,0 & 100,0 & 100,0 & 100,0 & 100,0 & 100,0 & 100,0 & 100,0 & 100,0 \\
\hline $\begin{array}{l}\text { Procedimento } \\
\text { SUS }\end{array}$ & 100,0 & 100,0 & 100,0 & 100,0 & 100,0 & * & 100,0 & 100,0 & 100,0 & 100,0 & 100,0 & 100,0 \\
\hline
\end{tabular}

Legenda: * Não houve o preenchimento deste campo em nenhuma Folha de Alta do hospital em questão. 
Outra análise importante para descrever a Qualidade dos Dados analisados foi o cálculo do percentual de ocorrência de cada uma das regras de consistência utilizadas pelo ORAH e especificadas no Anexo C. Para esse caso específico, quanto menor a proporção encontrada, melhor é a qualidade dos dados. Verificou-se que a regra com maior ocorrência $(9,5 \%)$ foi a referente a codificação incorreta do parto (diagnóstico com letra O) como afecção principal em internações com mais de um diagnóstico, seguida pela regra que verifica a ausência de informação no campo iniciais do nome paciente $(4,1 \%)$ e pela regra da codificação incorreta da afecção principal com diagnósticos de sintomas (R00 - R99) (2,3\%). As regras restantes tiveram uma ocorrência muito baixa, menor que $1,0 \%$ ou nula, o que mostra que os dados apresentam uma ótima qualidade no geral. Na Tabela 23 é possível verificar as regras de consistência que tiveram um percentual de ocorrência não nulo, considerando-se o conjunto completo dos dados.

As proporções de ocorrência das regras de consistência para cada hospital podem ser vistas nas Tabelas 24 e 25, sendo que na primeira são apresentados os resultados encontrados para cada hospital do município de Ribeirão Preto e a segunda os dos hospitais dos outros municípios da região de Ribeirão Preto. É possível verificar que somente três hospitais não apresentaram ocorrência de inconsistência em suas Folhas de Alta (hospitais 3, 5 e 6). Já para o restante, conseguiu-se verificar quais os principais problemas de inconsistências de cada um, o que pode ajudar no treinamento e capacitação dos mesmos para o melhor preenchimento das Folhas de Alta.

Tabela 23 - Percentual de Ocorrência (\%) Não Nulos para as Regra de Consistência utilizada pelo Observatório Regional de Atenção Hospitalar (ORAH), 2012.

\begin{tabular}{cc}
\hline $\begin{array}{c}\text { Regra de } \\
\text { Consistência }\end{array}$ & $\begin{array}{c}\text { Percentual de } \\
\text { Ocorrência (\%) }\end{array}$ \\
\hline 5 & $9,5 \%$ \\
G & $4,1 \%$ \\
0 & $2,3 \%$ \\
E & $0,9 \%$ \\
H & $0,9 \%$ \\
S & $0,4 \%$ \\
7 & $0,2 \%$ \\
\hline
\end{tabular}


Tabela 24 - Percentual de Ocorrência (\%) para cada Regra de Consistência por Hospital do Município de Ribeirão Preto conveniados ao Observatório Regional de Atenção Hospitalar (ORAH), 2012.

\begin{tabular}{|c|c|c|c|c|c|c|c|c|c|}
\hline \multirow{2}{*}{$\begin{array}{l}\text { Regra de } \\
\text { Consistência }\end{array}$} & \multicolumn{9}{|c|}{ Percentual de Ocorrência (\%) } \\
\hline & 1 & 2 & 3 & 4 & 5 & 6 & 7 & 8 & 9 \\
\hline 0 & 2,0 & 0,6 & 0,0 & 2,6 & 0,0 & 0,0 & 2,5 & 1,8 & 2,8 \\
\hline 1 & 0,0 & 0,0 & 0,0 & 0,0 & 0,0 & 0,0 & 0,0 & 0,1 & 0,0 \\
\hline 2 & 0,0 & 0,0 & 0,0 & 0,0 & 0,0 & 0,0 & 0,0 & 0,0 & 0,0 \\
\hline 3 & 0,0 & 0,0 & 0,0 & 0,0 & 0,0 & 0,0 & 0,0 & 0,0 & 0,0 \\
\hline 4 & 0,0 & 0,0 & 0,0 & 0,0 & 0,0 & 0,0 & 0,0 & 0,0 & 0,0 \\
\hline 5 & 0,0 & 16,9 & 0,0 & 0,1 & 0,0 & 0,0 & 1,4 & 1,8 & 9,8 \\
\hline 6 & 0,0 & 0,0 & 0,0 & 0,0 & 0,0 & 0,0 & 0,0 & 0,0 & 0,0 \\
\hline 7 & 0,0 & 0,0 & 0,0 & 0,0 & 0,0 & 0,0 & 0,0 & 3,7 & 0,0 \\
\hline 8 & 0,0 & 0,0 & 0,0 & 0,0 & 0,0 & 0,0 & 0,0 & 0,0 & 0,0 \\
\hline 9 & 0,0 & 0,0 & 0,0 & 0,0 & 0,0 & 0,0 & 0,0 & 0,0 & 0,0 \\
\hline -- & 0,0 & 0,0 & 0,0 & 0,0 & 0,0 & 0,0 & 0,0 & 0,0 & 0,0 \\
\hline * & 0,0 & 0,0 & 0,0 & 0,0 & 0,0 & 0,0 & 0,0 & 0,0 & 0,0 \\
\hline A & 0,0 & 0,0 & 0,0 & 0,0 & 0,0 & 0,0 & 0,0 & 0,0 & 0,0 \\
\hline B & 0,0 & 0,0 & 0,0 & 0,0 & 0,0 & 0,0 & 0,0 & 0,0 & 0,0 \\
\hline C & 0,0 & 0,0 & 0,0 & 0,0 & 0,0 & 0,0 & 0,0 & 0,0 & 0,0 \\
\hline D & 0,0 & 0,0 & 0,0 & 0,0 & 0,0 & 0,0 & 0,0 & 0,4 & 0,0 \\
\hline$E$ & 0,0 & 0,0 & 0,0 & 0,0 & 0,0 & 0,0 & 0,0 & 18,0 & 0,0 \\
\hline $\mathrm{F}$ & 0,0 & 0,0 & 0,0 & 0,0 & 0,0 & 0,0 & 0,0 & 0,0 & 0,0 \\
\hline G & 0,0 & 14,4 & 0,0 & 0,0 & 0,0 & 0,0 & 1,1 & 0,0 & 4,1 \\
\hline $\mathrm{H}$ & 0,0 & 0,0 & 0,0 & 0,0 & 0,0 & 0,0 & 0,0 & 18,0 & 0,0 \\
\hline I & 0,0 & 0,0 & 0,0 & 0,0 & 0,0 & 0,0 & 0,0 & 0,0 & 0,0 \\
\hline $\mathrm{J}$ & 0,0 & 0,0 & 0,0 & 0,0 & 0,0 & 0,0 & 0,0 & 0,0 & 0,0 \\
\hline K & 0,0 & 0,0 & 0,0 & 0,0 & 0,0 & 0,0 & 0,0 & 0,0 & 0,0 \\
\hline L & 0,0 & 0,0 & 0,0 & 0,0 & 0,0 & 0,0 & 0,0 & 0,0 & 0,0 \\
\hline M & 0,0 & 0,0 & 0,0 & 0,0 & 0,0 & 0,0 & 0,0 & 0,4 & 0,0 \\
\hline $\mathrm{N}$ & 0,0 & 0,0 & 0,0 & 0,0 & 0,0 & 0,0 & 0,0 & 0,0 & 0,0 \\
\hline 0 & 0,0 & 0,0 & 0,0 & 0,0 & 0,0 & 0,0 & 0,0 & 0,0 & 0,0 \\
\hline$P$ & 0,0 & 0,0 & 0,0 & 0,0 & 0,0 & 0,0 & 0,0 & 0,0 & 0,0 \\
\hline$Q$ & 0,0 & 0,0 & 0,0 & 0,0 & 0,0 & 0,0 & 0,0 & 0,0 & 0,0 \\
\hline$R$ & 0,0 & 0,0 & 0,0 & 0,0 & 0,0 & 0,0 & 0,0 & 0,0 & 0,0 \\
\hline $\mathrm{s}$ & 0,0 & 0,0 & 0,0 & 0,0 & 0,0 & 0,0 & 0,0 & 7,5 & 0,0 \\
\hline $\mathrm{T}$ & 0,0 & 0,0 & 0,0 & 0,0 & 0,0 & 0,0 & 0,0 & 0,0 & 0,0 \\
\hline U & 0,0 & 0,0 & 0,0 & 0,0 & 0,0 & 0,0 & 0,0 & 0,0 & 0,0 \\
\hline V & 0,0 & 0,0 & 0,0 & 0,0 & 0,0 & 0,0 & 0,0 & 0,0 & 0,0 \\
\hline W & 0,0 & 0,0 & 0,0 & 0,0 & 0,0 & 0,0 & 0,0 & 0,0 & 0,0 \\
\hline$x$ & 0,0 & 0,0 & 0,0 & 0,0 & 0,0 & 0,0 & 0,0 & 0,0 & 0,0 \\
\hline$Y$ & 0,0 & 0,0 & 0,0 & 0,0 & 0,0 & 0,0 & 0,0 & 0,0 & 0,0 \\
\hline Z & 0,0 & 0,0 & 0,0 & 0,0 & 0,0 & 0,0 & 0,0 & 0,0 & 0,0 \\
\hline
\end{tabular}


Tabela 25 - Percentual de Ocorrência (\%) para cada Regra de Consistência por Hospital de Municípios da Região de Ribeirão Preto conveniados ao Observatório Regional de Atenção Hospitalar (ORAH), 2012.

\begin{tabular}{|c|c|c|c|c|c|c|c|c|c|c|c|c|}
\hline \multirow{2}{*}{$\begin{array}{l}\text { Regra de } \\
\text { Consistência }\end{array}$} & \multicolumn{12}{|c|}{ Percentual de Ocorrência (\%) } \\
\hline & 10 & 11 & 12 & 13 & 14 & 15 & 16 & 17 & 18 & 19 & 20 & 21 \\
\hline 0 & 0,4 & 2,5 & 1,2 & 4,20 & 4,73 & 4,98 & 2,09 & 2,44 & 3,06 & 2,25 & 1,81 & 7,83 \\
\hline 1 & 0,0 & 0,0 & 0,0 & 0,0 & 0,0 & 0,2 & 0,0 & 0,0 & 0,0 & 0,0 & 0,0 & 0,0 \\
\hline 2 & 0,0 & 0,0 & 0,03 & 0,0 & 0,0 & 0,0 & 0,0 & 0,0 & 0,0 & 0,0 & 0,0 & 0,0 \\
\hline 3 & 0,0 & 0,0 & 0,0 & 0,0 & 0,0 & 0,0 & 0,0 & 0,0 & 0,0 & 0,0 & 0,0 & 0,0 \\
\hline 4 & 0,0 & 0,0 & 0,0 & 0,0 & 0,0 & 0,0 & 0,0 & 0,0 & 0,0 & 0,0 & 0,0 & 0,0 \\
\hline 5 & 6,7 & 25,4 & 20,8 & 13,9 & 0,6 & 6,4 & 17,6 & 15,1 & 15,6 & 14,3 & 7,9 & 5,2 \\
\hline 6 & 0,0 & 0,0 & 0,0 & 0,0 & 0,0 & 0,0 & 0,0 & 0,0 & 0,0 & 0,0 & 0,0 & 0,0 \\
\hline 7 & 0,0 & 0,0 & 0,0 & 0,0 & 0,0 & 0,0 & 0,0 & 0,0 & 0,0 & 0,0 & 0,0 & 0,0 \\
\hline 8 & 0,0 & 0,0 & 0,0 & 0,0 & 0,0 & 0,0 & 0,0 & 0,0 & 0,0 & 0,0 & 0,0 & 0,0 \\
\hline 9 & 0,0 & 0,0 & 0,0 & 0,0 & 0,0 & 0,0 & 0,0 & 0,0 & 0,0 & 0,0 & 0,0 & 0,0 \\
\hline-- & 0,0 & 0,0 & 0,0 & 0,0 & 0,0 & 0,0 & 0,0 & 0,0 & 0,0 & 0,0 & 0,0 & 0,0 \\
\hline * & 0,0 & 0,0 & 0,0 & 0,0 & 0,0 & 0,0 & 0,0 & 0,0 & 0,0 & 0,0 & 0,0 & 0,0 \\
\hline A & 0,0 & 0,0 & 0,0 & 0,0 & 0,0 & 0,0 & 0,0 & 0,0 & 0,0 & 0,0 & 0,0 & 0,0 \\
\hline B & 0,0 & 0,0 & 0,0 & 0,0 & 0,0 & 0,0 & 0,0 & 0,0 & 0,0 & 0,0 & 0,0 & 0,0 \\
\hline C & 0,0 & 0,0 & 0,0 & 0,0 & 0,0 & 0,0 & 0,0 & 0,0 & 0,0 & 0,0 & 0,0 & 0,0 \\
\hline D & 0,0 & 0,0 & 0,0 & 0,0 & 0,0 & 0,0 & 0,0 & 0,0 & 0,0 & 0,0 & 0,0 & 0,0 \\
\hline E & 0,0 & 0,0 & 0,0 & 0,0 & 0,0 & 0,0 & 0,0 & 0,0 & 0,0 & 0,0 & 0,0 & 0,0 \\
\hline $\mathrm{F}$ & 0,0 & 0,0 & 0,0 & 0,0 & 0,0 & 0,0 & 0,0 & 0,0 & 0,0 & 0,0 & 0,0 & 0,0 \\
\hline G & 0,0 & 3,6 & 4,5 & 0,0 & 0,0 & 2,5 & 7,5 & 0,0 & 0,0 & 7,4 & 0,0 & 0,3 \\
\hline $\mathrm{H}$ & 0,0 & 0,0 & 0,0 & 0,0 & 0,0 & 0,0 & 0,0 & 0,0 & 0,0 & 0,0 & 0,0 & 0,0 \\
\hline 1 & 0,0 & 0,0 & 0,0 & 0,0 & 0,0 & 0,0 & 0,0 & 0,0 & 0,0 & 0,0 & 0,0 & 0,0 \\
\hline $\mathrm{J}$ & 0,0 & 0,0 & 0,0 & 0,0 & 0,0 & 0,0 & 0,0 & 0,0 & 0,0 & 0,0 & 0,0 & 0,0 \\
\hline K & 0,0 & 0,0 & 0,0 & 0,0 & 0,0 & 0,0 & 0,0 & 0,0 & 0,0 & 0,0 & 0,0 & 0,0 \\
\hline L & 0,0 & 0,0 & 0,0 & 0,0 & 0,0 & 0,0 & 0,0 & 0,0 & 0,0 & 0,0 & 0,0 & 0,0 \\
\hline M & 0,0 & 0,0 & 0,0 & 0,0 & 0,0 & 0,0 & 0,0 & 0,0 & 0,0 & 0,0 & 0,0 & 0,0 \\
\hline $\mathrm{N}$ & 0,0 & 0,0 & 0,0 & 0,0 & 0,0 & 0,0 & 0,0 & 0,0 & 0,0 & 0,0 & 0,0 & 0,0 \\
\hline 0 & 0,0 & 0,0 & 0,0 & 0,0 & 0,0 & 0,0 & 0,0 & 0,0 & 0,0 & 0,0 & 0,0 & 0,0 \\
\hline$P$ & 0,0 & 0,0 & 0,0 & 0,0 & 0,0 & 0,0 & 0,0 & 0,0 & 0,0 & 0,0 & 0,0 & 0,0 \\
\hline$Q$ & 0,0 & 0,0 & 0,0 & 0,0 & 0,0 & 0,0 & 0,0 & 0,0 & 0,0 & 0,0 & 0,0 & 0,0 \\
\hline $\mathrm{R}$ & 0,0 & 0,0 & 0,0 & 0,0 & 0,0 & 0,0 & 0,0 & 0,0 & 0,0 & 0,0 & 0,0 & 0,1 \\
\hline$S$ & 0,0 & 0,0 & 0,0 & 0,0 & 0,0 & 0,0 & 0,0 & 0,0 & 0,0 & 0,0 & 0,0 & 0,0 \\
\hline $\mathrm{T}$ & 0,0 & 0,0 & 0,0 & 0,0 & 0,0 & 0,0 & 0,0 & 0,0 & 0,0 & 0,0 & 0,0 & 0,0 \\
\hline $\mathrm{U}$ & 0,0 & 0,0 & 0,0 & 0,0 & 0,0 & 0,0 & 0,0 & 0,0 & 0,0 & 0,0 & 0,0 & 0,1 \\
\hline V & 0,0 & 0,0 & 0,0 & 0,0 & 0,0 & 0,0 & 0,0 & 0,0 & 0,0 & 0,0 & 0,0 & 0,0 \\
\hline W & 0,0 & 0,0 & 0,0 & 0,0 & 0,0 & 0,0 & 0,0 & 0,0 & 0,0 & 0,0 & 0,0 & 0,0 \\
\hline $\mathrm{x}$ & 0,0 & 0,0 & 0,0 & 0,0 & 0,0 & 0,0 & 0,0 & 0,0 & 0,0 & 0,0 & 0,0 & 0,0 \\
\hline$Y$ & 0,0 & 0,0 & 0,0 & 0,0 & 0,0 & 0,0 & 0,0 & 0,0 & 0,0 & 0,0 & 0,0 & 0,0 \\
\hline Z & 0,0 & 0,0 & 0,0 & 0,0 & 0,0 & 0,0 & 0,0 & 0,0 & 0,0 & 0,0 & 0,0 & 0,0 \\
\hline
\end{tabular}




\subsubsection{Análise da Completude da Folha de Alta}

Além da análise da Qualidade dos Dados em cada campo da Folha de Alta, foi realizada a verificação da Qualidade da Folha de Alta por completo, conforme especificado na seção 2.3. Nesta seção está apresentada a avaliação da Completude da Folha de Alta através do Grau de Completude $\left(C_{p}\right)$.

Ao avaliar o total de Folhas de Alta no ano de 2012, verificou-se que o percentual médio do Grau de Completude das mesmas foi de 100,0\%. Desta forma, averiguou-se que a Completude das mesmas pode ser considerada excelente conforme a Tabela 1. Considerando cada hospital isoladamente, obteve-se um Grau de Completude de 100,0\% para a maioria dos hospitais, sendo que somente um ficou abaixo desse grau (99,2\%). A análise por meses do ano de 2012 para cada hospital também resultou em Graus de Completude próximos a 100,0\%. A partir desses resultados, foi possível verificar que a Completude da Folha de Alta foi excelente para todos os hospitais, e o Grau de Completude $\left(C_{p}\right)$ no ano de 2012 para eles está representado na Tabela 26.

Tabela 26 - Percentual Médio do Grau de Completude $\left(C_{p}\right)$ por Hospital Conveniado ao Observatório Regional de Atenção Hospitalar (ORAH), 2012.

\begin{tabular}{ccc}
\hline Cód. do Hospital & Município & $\mathbf{C}_{\boldsymbol{p}}(\%)$ \\
\hline 1 & Ribeirão Preto & 100,0 \\
2 & Ribeirão Preto & 100,0 \\
3 & Ribeirão Preto & 100,0 \\
4 & Ribeirão Preto & 100,0 \\
5 & Ribeirão Preto & 100,0 \\
6 & Ribeirão Preto & 100,0 \\
7 & Ribeirão Preto & 100,0 \\
8 & Ribeirão Preto & 99,2 \\
9 & Ribeirão Preto & 100,0 \\
10 & São Simão & 100,0 \\
11 & Guariba & 100,0 \\
12 & Serrana & 100,0 \\
13 & Cajuru & 100,0 \\
14 & Cravinhos & 100,0 \\
15 & Sertãozinho & 100,0 \\
16 & Pontal & 100,0 \\
17 & Altinópolis & 100,0 \\
18 & Jaboticabal & 100,0 \\
19 & Sertãozinho & 100,0 \\
20 & Santa Rosa do Viterbo & 100,0 \\
21 & Monte Alto & 100,0 \\
& $\mathbf{C}_{\mathbf{p}(\%)}$ médio & 100,0 \\
\hline
\end{tabular}




\subsubsection{Análise da Consistência da Folha de Alta}

Outra análise realizada para a verificação da Qualidade da Folha de Alta por completo foi a da Consistências dos valores presentes nos seus campos através do Grau de Consistência $\left(C_{t}\right)$, conforme especificado na seção 2.3

Os resultados obtidos para a aplicação do Grau de Consistência $\left(C_{t}\right)$ para os dados de cada hospital conveniado para o ano de 2012 podem ser vistos na Tabela 27 e apresentam percentuais médios próximo a 100,0\% para cada hospital individualmente e de $99,5 \%$ para o conjunto total de dados. Esses resultados demonstram que a Consistência da Folha de Alta após o processamento dos dados pelo ORAH pode ser considerada excelente, de acordo com as categorias apresentadas na Tabela 1. Já a Tabela 28 apresenta a distribuição do Grau de Consistência entre os meses do ano de 2012, sendo que somente um hospital teve consistência boa, ou seja, menor que $95,0 \%$, durante dois meses do ano enquanto o restante manteve-se entre 98,0 e $100,0 \%$. Particularmente, somente três hospitais apresentaram 100,0\% durante todos os meses que tiveram internação.

Tabela 27 - Percentual Médio do Grau de Consistência $\left(C_{t}\right)$ por Hospital conveniado ao Observatório Regional de Atenção Hospitalar (ORAH), 2012.

\begin{tabular}{|c|c|c|}
\hline Cód. do Hospital & Município & $C_{t}(\%)$ \\
\hline 1 & Ribeirão Preto & 99,9 \\
\hline 2 & Ribeirão Preto & 99,2 \\
\hline 3 & Ribeirão Preto & 100,0 \\
\hline 4 & Ribeirão Preto & 99,9 \\
\hline 5 & Ribeirão Preto & 100,0 \\
\hline 6 & Ribeirão Preto & 100,0 \\
\hline 7 & Ribeirão Preto & 99,9 \\
\hline 8 & Ribeirão Preto & 98,6 \\
\hline 9 & Ribeirão Preto & 99,6 \\
\hline 10 & São Simão & 99,8 \\
\hline 11 & Guariba & 99,2 \\
\hline 12 & Serrana & 99,3 \\
\hline 13 & Cajuru & 99,5 \\
\hline 14 & Cravinhos & 99,9 \\
\hline 15 & Sertãozinho & 99,6 \\
\hline 16 & Pontal & 99,3 \\
\hline 17 & Altinópolis & 99,5 \\
\hline 18 & Jaboticabal & 99,5 \\
\hline 19 & Sertãozinho & 99,4 \\
\hline 20 & Santa Rosa do Viterbo & 99,7 \\
\hline 21 & Monte Alto & 99,6 \\
\hline \multicolumn{2}{|c|}{ Ct (\%) médio } & 99,5 \\
\hline
\end{tabular}


Tabela 28 - Percentual Médio do Grau de Consistência $\left(C_{t}\right)$ para cada Hospital conveniado ao Observatório Regional de Atenção Hospitalar (ORAH), Jan-Dez/ 2012

\begin{tabular}{|c|c|c|c|c|c|c|c|c|c|c|c|c|c|}
\hline \multirow{2}{*}{ Cód. do Hospital } & \multirow{2}{*}{ Município } & \multicolumn{11}{|c|}{$\mathrm{C}_{\mathrm{t}}(\%)$} & \multirow[b]{2}{*}{ Dez } \\
\hline & & Jan & Fev & Mar & Abr & Mai & Jun & Jul & Ago & Set & Out & Nov & \\
\hline 1 & Ribeirão Preto & 99,9 & 99,9 & 99,9 & 99,9 & 99,9 & 99,9 & 99,9 & 100,0 & 100,0 & 99,9 & 100,0 & 99,9 \\
\hline 2 & Ribeirão Preto & 99,5 & 99,6 & 99,5 & 99,5 & 99,5 & 98,8 & 98,8 & 98,8 & 99,5 & 98,7 & 98,8 & 98,7 \\
\hline 3 & Ribeirão Preto & 100,0 & 100,0 & 100,0 & 100,0 & 100,0 & 100,0 & 100,0 & 100,0 & 100,0 & 100,0 & 100,0 & 100,0 \\
\hline 4 & Ribeirão Preto & 99,9 & 99,9 & 100,0 & 99,9 & 99,9 & 99,9 & 99,9 & 99,9 & 99,9 & 99,9 & 99,9 & 99,9 \\
\hline 5 & Ribeirão Preto & 100,0 & * & * & * & 100,0 & * & * & * & 100,0 & * & 100,0 & 100,0 \\
\hline 6 & Ribeirão Preto & 100,0 & 100,0 & 100,0 & 100,0 & $* *$ & $* *$ & ** & $\star *$ & $\star *$ & $* *$ & $\star *$ & $* *$ \\
\hline 7 & Ribeirão Preto & 99,9 & 99,9 & 99,9 & 99,8 & 99,9 & 99,9 & 99,9 & 99,8 & 99,9 & 99,9 & 99,8 & 99,9 \\
\hline 8 & Ribeirão Preto & 99,9 & 99,9 & 99,9 & 99,9 & 99,8 & 93,0 & 93,0 & 99,9 & 99,9 & 99,9 & 99,8 & 99,9 \\
\hline 9 & Ribeirão Preto & 99,7 & 99,4 & 99,6 & 99,6 & 99,5 & 99,4 & 99,7 & 99,5 & 99,7 & 99,7 & 99,5 & 99,4 \\
\hline 10 & São Simão & 99,9 & 99,6 & 99,7 & 99,7 & 99,7 & 99,8 & 99,9 & 100,0 & 99,9 & 99,9 & 99,7 & 99,9 \\
\hline 11 & Guariba & 99,3 & 99,3 & 99,2 & 99,3 & 99,3 & 99,3 & 98,9 & 99,3 & 98,7 & 99,3 & 98,9 & 99,2 \\
\hline 12 & Serrana & 99,1 & 99,4 & 99,2 & 99,4 & 99,5 & 99,6 & 99,3 & 99,2 & 99,0 & 99,2 & 99,3 & 99,3 \\
\hline 13 & Cajuru & 99,5 & 99,4 & 99,5 & 99,5 & 99,5 & 99,5 & 99,5 & 99,6 & 99,6 & 99,5 & 99,4 & 99,6 \\
\hline 14 & Cravinhos & 99,5 & 99,7 & 100,0 & 99,8 & 99,8 & 99,9 & 100,0 & 100,0 & 99,9 & 100,0 & 99,7 & 99,8 \\
\hline 15 & Sertãozinho & 99,7 & 99,4 & 99,7 & 99,7 & 99,7 & 99,5 & 99,6 & 99,4 & 99,6 & 99,7 & 99,7 & 99,7 \\
\hline 16 & Pontal & 99,5 & 98,9 & 99,6 & 99,5 & 99,5 & 99,5 & 99,6 & 98,9 & 99,0 & 99,7 & 98,9 & 98,8 \\
\hline 17 & Altinópolis & 99,6 & 99,5 & 99,6 & 99,5 & 99,5 & 99,5 & 99,6 & 99,7 & 99,5 & 99,5 & 99,5 & 99,5 \\
\hline 18 & Jaboticabal & 99,5 & 99,5 & 99,5 & 99,4 & 99,6 & 99,5 & 99,5 & 99,6 & 99,5 & 99,5 & 99,5 & 99,5 \\
\hline 19 & Sertãozinho & 99,6 & 99,6 & 99,6 & 99,1 & 99,2 & 99,2 & 99,2 & 99,2 & 99,6 & 99,2 & 99,5 & 99,5 \\
\hline 20 & Santa Rosa do Viterbo & 99,9 & 99,8 & 99,9 & 99,8 & 99,5 & 99,7 & 99,8 & 99,7 & 99,8 & 99,7 & 99,6 & 99,7 \\
\hline 21 & Monte Alto & 99,7 & 99,6 & 99,4 & 99,8 & 99,7 & 99,6 & 99,7 & 99,6 & 99,7 & 99,6 & 99,5 & 99,7 \\
\hline
\end{tabular}

Legenda: * Não houve internações no período.

** Hospital virou ambulatório e deixou de realizar internações. 


\subsection{Avaliação da Qualidade nas Etapas de Processamento das Folhas de Alta no ORAH}

Para esta etapa do projeto, foram analisadas as quantidades de Folha de Alta de cada um dos três processos a serem verificados de modo a identificar hospitais e meses que correspondessem aos critérios citados anteriormente (sessão 2.4).

A seguir serão apresentados o universo dos dados e os resultados obtidos para a análise da qualidade entre as etapas dos hospitais que não enviaram arquivo eletrônico (sessão 3.3.1) e a dos hospitais que enviaram arquivo eletrônico (sessão 3.3.2).

\subsubsection{Avaliação da Qualidade nas Etapas de Processamento das Folhas de Alta dos Hospitais que Não Enviaram Arquivo Eletrônico}

Entre os hospitais conveniados ao ORAH, seis deles tiveram suas Folhas de Alta digitadas integralmente em seis ou mais meses de 2012. Dentre estes, somente três deles tiveram quatro ou mais meses com a mesma quantidade de Folha de Alta entre a etapa de Digitação e Codificação e a de Revisão e Conferência dos dados.

Com isso, os hospitais analisados foram: o com código 11 do município de Guariba, com seis (06) meses avaliados e um total de 1577 Folhas de Alta; o com código 16 do município de Pontal, com nove (09) meses avaliados e um total de 1726 Folhas de Alta; e o com código 17 do município de Altinópolis, com seis (06) meses avaliados e um total de 561 Folhas de Alta.

O indicador de Qualidade dos Dados entre Processos (IQP) resultante para os hospitais em questão verificaram que não houveram alterações na qualidade do preenchimento e consistência entre as etapas de Digitação e Codificação e a de Revisão, pois o IQP em cada um dos hospitais foi de 0,00. Com isso, a qualidade dos dados dos processos entre esse conjunto de hospitais também não apresentou alteração $(I Q P=0,00)$.

Já os Coeficientes de Volatilidade (CV) desses hospitais foram considerados baixos, pois se igualaram a 0,01 , ou seja, somente $1 \%$ dos campos sofreram modificações entre as etapas em cada hospital. Com isso, o conjunto total de Folhas 
de Altas desse grupo de hospitais também apresentou a mesma situação de volatilidade $(\mathrm{CV}=0,01)$.

A explicação para a não ocorrência de modificações na qualidade para esses hospitais é explicada pelo processo de digitação e codificação em si, uma vez que ao realizar essa etapa, a equipe do ORAH também realiza os processos de verificação de consistência, correção e rastreio das informações faltantes nas Folhas de Alta antes da inserção das mesmas no sistema, resultando em Folhas de Alta extremamente qualificadas. Esse fato é reforçado pelos valores extremamente pequenos registrados pelo coeficiente de volatilidade de cada hospital.

\subsubsection{Avaliação da Qualidade nas Etapas de Processamento das Folhas de Alta dos Hospitais que Enviaram Arquivo Eletrônico}

Entre os hospitais conveniados ao ORAH, dezessete deles enviaram o arquivo eletrônico referente as Folhas de Alta em quatro ou mais meses de 2012, sendo que três desses hospitais tiveram meses sem o envio do arquivo eletrônico, o que ocasionou a digitação das Folhas de Alta pela equipe do observatório. Dentre o total de hospitais, somente seis deles tiveram quatro ou mais meses com a mesma quantidade de Folha de Alta entre a etapa de Recebimento dos dados Eletrônicos Oriundos dos Hospitais, a de Digitação e Codificação e a de Revisão e Conferência dos dados.

Com isso, os hospitais analisados foram: o com código 3 do município de Ribeirão Preto, com doze (12) meses avaliados e um total de 856 Folhas de Alta; o com código 6 do município de Ribeirão Preto, com quatro (04) meses avaliados e um total de 71 Folhas de Alta; o com código 8 do município de Ribeirão Preto, com sete (07) meses avaliados e um total de 3483 Folhas de Alta; o com código 10 do município de São Simão, com doze (12) meses avaliados e um total de 667 Folhas de Alta; o com código 14 do município de Cravinhos, com sete (07) meses avaliados e um total de 309 Folhas de Alta; o com código 21 do município de Monte Alto, com quatro (04) meses avaliados e um total de 403 Folhas de Alta.

Em relação a análise da modificação na Qualidade dos Dados por meio do indicador de Qualidade dos Dados entre Processos (IQP), verificou-se que não houve 
alteração da qualidade entre as três etapas de processamento da Folha de Alta pelo ORAH para o conjunto total de Folhas de Alta dos hospitais selecionados e em cada hospital em específico. Isso foi constatado pela obtenção de coeficientes de preenchimento (CCp) e consistências (CCt) e do indicador de qualidade (IQP) iguais a zero $(0,00)$ entre a etapa de recebimento dos dados eletrônicos dos hospitais e de digitação e codificação pela equipe do ORAH, e entre a de digitação e codificação e a de revisão e conferência dos dados para cada um dos hospitais.

Tais resultados foram confirmados com a avaliação entre os dados eletrônicos oriundos dos hospitais e os obtidos após a revisão e conferência pela equipe do ORAH, os quais explicitaram a ausência de alteração na Qualidade dos Dados em cada um dos hospitais analisados e para o conjunto total de Folhas de Alta em questão.

Entretanto, essa manutenção na qualidade não significa que as informações contidas nas Folhas de Alta não tiveram alterações. Ao observar os Coeficiente de Volatilidade (CV) entre as etapas, é possível verificar que houve baixa volatilidade para o conjunto geral de Folhas de Altas $(\mathrm{CV}=0,05)$ entre a etapa de recebimento dos arquivos eletrônicos e a digitação e codificação dos dados nas Folhas de Alta, enquanto não houve nenhuma mudança na volatilidade entre a etapa de digitação e codificação e a de revisão e conferência para o conjunto total avaliado $(C V=0,00)$.

Analisando cada hospital em particular, verificou-se também que os coeficientes de volatilidade foram maiores entre a etapa de recebimento dos arquivos eletrônicos e a de digitação e codificação dos dados nas Folhas de Alta do que entre a etapa de digitação e codificação e a de revisão e conferência. A maioria dos hospitais registraram uma volatilidade moderada dos campos entre a etapa de recebimento dos arquivos eletrônicos e a de digitação e codificação, sendo que somente dois hospitais registraram uma volatilidade baixa na análise dessas etapas. Já para a verificação entre a etapa de digitação e codificação e a de revisão e conferência dos dados, três hospitais registraram uma baixa volatilidade enquanto os outros três não apresentaram mudanças nos campos.

Os Coeficientes de Volatilidade obtidos para cada hospital entre a etapa de recebimento dos arquivos eletrônicos e a de digitação e codificação dos dados pode ser visualizada na Tabela 29. Já os coeficientes obtidos para cada hospital entre a etapa de digitação e codificação e a de revisão e conferência dos dados pode ser visualizada na Tabela 30 . 
Tabela 29 - Coeficiente de Volatilidade (CV) entre a Etapa de Recebimento dos dados Eletrônicos Oriundos dos Hospitais e a Etapa de Digitação e Codificação dos dados do Observatório Regional de Atenção Hospitalar (ORAH).

\begin{tabular}{ccc}
\hline $\begin{array}{c}\text { Cód. do } \\
\text { Hospital }\end{array}$ & Município & CV \\
\hline $\mathbf{3}$ & Ribeirão Preto & 0,07 \\
$\mathbf{6}$ & Ribeirão Preto & 0,03 \\
$\mathbf{8}$ & Ribeirão Preto & 0,07 \\
$\mathbf{1 0}$ & São Simão & 0,10 \\
$\mathbf{1 4}$ & Cravinhos & 0,06 \\
$\mathbf{2 1}$ & Monte Alto & 0,04 \\
& Média & 0,05 \\
\hline
\end{tabular}

Tabela 30 - Coeficiente de Volatilidade (CV) entre a Etapa de Digitação e Codificação e a Etapa de Revisão e Conferência dos dados do Observatório Regional de Atenção Hospitalar (ORAH).

\begin{tabular}{ccc}
\hline $\begin{array}{c}\text { Cód. do } \\
\text { Hospital }\end{array}$ & Município & CV \\
\hline $\mathbf{3}$ & Ribeirão Preto & 0,02 \\
$\mathbf{6}$ & Ribeirão Preto & 0,00 \\
$\mathbf{8}$ & Ribeirão Preto & 0,01 \\
$\mathbf{1 0}$ & São Simão & 0,01 \\
$\mathbf{1 4}$ & Cravinhos & 0,00 \\
$\mathbf{2 1}$ & Monte Alto & 0,00 \\
& Média & 0,00 \\
\hline
\end{tabular}

Uma análise complementar da volatilidade apresentada na Tabela $31 \mathrm{e}$ realizada nos hospitais selecionados entre os dados eletrônicos oriundos dos hospitais e os obtidos após a revisão e conferência pela equipe do ORAH, identificou que os valores do coeficiente de volatilidade de cada hospital se mantiveram similares aqueles obtidos entre os resultantes da análise entre a etapa de recebimento dos arquivos eletrônicos e a digitação e codificação dos dados pelo ORAH, visualizados na Tabela 29.

Tabela 31 - Coeficiente de Volatilidade (CV) entre a Etapa de Recebimento dos dados Eletrônicos Oriundos dos Hospitais e a Etapa de Revisão e Conferência dos dados do Observatório Regional de Atenção Hospitalar (ORAH).

\begin{tabular}{ccc}
\hline $\begin{array}{c}\text { Cód. do } \\
\text { Hospital }\end{array}$ & Município & CV \\
\hline $\mathbf{3}$ & Ribeirão Preto & 0,08 \\
$\mathbf{6}$ & Ribeirão Preto & 0,03 \\
$\mathbf{8}$ & Ribeirão Preto & 0,07 \\
$\mathbf{1 0}$ & São Simão & 0,10 \\
$\mathbf{1 4}$ & Cravinhos & 0,06 \\
$\mathbf{2 1}$ & Monte Alto & 0,04 \\
& Média & 0,05 \\
\hline
\end{tabular}


Tal cenário pode ser explicado pelas restrições feitas na realização dessa análise e não pela ineficiência desses processos na melhoria da qualidade dos dados. Os protocolos de consistência e validação utilizados são de extrema importância para a manutenção da qualidade e fidedignidade das informações, uma vez que todos os arquivos recebidos são conferidos a partir da Folha de Alta em papel, do Censo Hospitalar e também diretamente do Prontuário do Paciente em alguns casos. Assim, uma avaliação mais específica a posteriori sobre as etapas de processamento dos dados se faz necessária para que se obtenha o real custo/benefício da realização desses processos na melhoria da qualidade dos dados.

\subsection{Avaliação da Correção entre a Folha de Alta e o Prontuário Médico}

Conforme apresentado na seção 2.5, foram feitas análises nas informações coletadas pelo instrumento de Avaliação da Qualidade dos Dados Registrados no ORAH e Prontuário Médico do Paciente (Anexo D) a partir da amostra definida para averiguar a inexistência de erros entre as informações presentes no Prontuário do Paciente e na Folha de Alta.

Primeiramente, foi verificada a probabilidade de um campo estar preenchido na Folha de Alta e a informação estar presente no Prontuário do Paciente através da Sensibilidade (S). Averiguou-se que a sensibilidade média da amostra foi de 99,0\% (IC95\% 98,8\% - 99,2\%) e manteve-se próxima a esse valor em cada um dos hospitais da amostra, conforme apresentado na Tabela 32. Considerando-se as categorias de classificação apresentadas na Tabela 1 da seção 2.3, tanto a sensibilidade média do conjunto de dados da amostra como a sensibilidade de cada hospital podem ser classificadas como excelente.

Também foi verificada a probabilidade de um mesmo campo não ter sido preenchido na Folha de Alta e a informação estar ausente do Prontuário do Paciente através da Especificidade (E). Averiguou-se que a especificidade média da amostra foi de 97,9\% (IC95\% 97,5\% - 98,2\%) sendo considerada excelente, conforme a classificação apresentada na Tabela 1 da seção 2.3. A maioria dos hospitais (92,9\%) também apresentou especificidade média excelente, sendo que somente um hospital teve a especificidade considerada boa, ou seja, abaixo de $95 \%$. A Tabela 33 apresenta 
as especificidades médias para cada hospital e também para o conjunto total de Folhas de Alta da amostra.

Tabela 32 - Sensibilidade (S) no preenchimento da Folha de Alta em relação ao Prontuário do Paciente para os dados da amostra.

\begin{tabular}{cccc}
\hline Cód. do Hospital & Município & Sensibilidade (S) & IC(95\%) \\
\hline 1 & Ribeirão Preto & $98,5 \%$ & $(98,0 \% ; 98,9 \%)$ \\
3 & Ribeirão Preto & $100,0 \%$ & $(100,0 \% ; 100,0 \%)$ \\
6 & Ribeirão Preto & $99,5 \%$ & $(99,1 \% ; 99,9 \%)$ \\
7 & Ribeirão Preto & $100,0 \%$ & $(100,0 \% ; 100,0 \%)$ \\
10 & São Simão & $99,8 \%$ & $(99,3 \% ; 100,3 \%)$ \\
11 & Guariba & $98,7 \%$ & $(98,2 \% ; 99,3 \%)$ \\
12 & Serrana & $99,6 \%$ & $(98,7 \% ; 100,5 \%)$ \\
13 & Cajuru & $97,3 \%$ & $(95,8 \% ; 98,9 \%)$ \\
14 & Cravinhos & $99,4 \%$ & $(98,5 \% ; 100,3 \%)$ \\
15 & Sertãozinho & $99,5 \%$ & $(98,7 \% ; 100,2 \%)$ \\
16 & Pontal & $99,5 \%$ & $(98,7 \% ; 100,3 \%$ \\
17 & Altinópolis & $99,4 \%$ & $(98,8 \% ; 100,1 \%)$ \\
20 & Santa Rosa do Viterbo & $95,9 \%$ & $(92,0 \% ; 99,9 \%)$ \\
21 & Monte Alto & $99,5 \%$ & $(99,2 \% ; 99,8 \%)$ \\
\multicolumn{2}{c}{ Sensibilidade Média } & $99,0 \%$ & $(\mathbf{9 8 , 8} \% ; 99,2 \%)$ \\
\hline
\end{tabular}

Tabela 33 - Especificidade (E) no preenchimento da Folha de Alta em relação ao Prontuário do Paciente para os dados da amostra.

\begin{tabular}{cccc}
\hline Cód. do Hospital & Município & Especificidade (E) & IC(95\%) \\
\hline 1 & Ribeirão Preto & $96,4 \%$ & $(95,6 \% ; 97,2 \%)$ \\
3 & Ribeirão Preto & $96,8 \%$ & $(94,1 \% ; 99,4 \%)$ \\
6 & Ribeirão Preto & $96,4 \%$ & $(95,0 \% ; 97,8 \%)$ \\
7 & Ribeirão Preto & $98,5 \%$ & $97,5 \% ; 99,5 \%)$ \\
10 & São Simão & $100,0 \%$ & $(100,0 \% ; 100,0 \%)$ \\
11 & Guariba & $99,4 \%$ & $(98,9 \% ; 99,9 \%)$ \\
12 & Serrana & $100,0 \%$ & $(100,0 \% ; 100,0 \%)$ \\
13 & Cajuru & $99,4 \%$ & $(98,7 \% ; 100,1 \%)$ \\
14 & Cravinhos & $95,8 \%$ & $(93,5 \% ; 98,1 \%)$ \\
15 & Sertãozinho & $99,1 \%$ & $(97,9 \% ; 100,4 \%)$ \\
16 & Pontal & $97,0 \%$ & $(94,8 \% ; 99,3 \%)$ \\
17 & Altinópolis & $97,2 \%$ & $(95,3 \% ; 99,1 \%)$ \\
20 & Santa Rosa do Viterbo & $94,8 \%$ & $(90,2 \% ; 99,3 \%)$ \\
21 & Monte Alto & $99,2 \%$ & $(98,6 \% ; 99,7 \%)$ \\
\multicolumn{2}{c}{ Especificidade Média } & $97,9 \%$ & $(97,5 \% ; 98,2 \%)$ \\
\hline
\end{tabular}

Outra análise realizada foi a de concordância dos valores contidos nos campos por meio da Acurácia (A). Averiguou-se que a acurácia média da amostra foi de 96,3\% (IC95\% 96,0\% - 96,6\%) e manteve-se próxima a esse valor em cada um dos hospitais da amostra, conforme apresentado na Tabela 34. Considerando-se as categorias de 
classificação apresentadas na Tabela 1 da seção 2.3, a acurácia média do conjunto de dados da amostra pode ser classificada como excelente assim como a da maioria dos hospitais (78,6\%). Entretanto, três hospitais de municípios da região de Ribeirão Preto, ou $21,4 \%$ dos hospitais, tiveram uma acurácia considerada boa, ou seja, abaixo de $95,0 \%$.

\begin{tabular}{cccc} 
Tabela 34 - Acurácia (A) dos valores contidos nos campos para os dados da amostra. \\
\hline Cód. do Hospital & Município & Acurácia (A) & IC(95\%) \\
\hline 1 & Ribeirão Preto & $95,5 \%$ & $(94,9 \% ; 96,1 \%)$ \\
3 & Ribeirão Preto & $95,8 \%$ & $(93,2 \% ; 98,3 \%)$ \\
6 & Ribeirão Preto & $95,1 \%$ & $(94,0 \% ; 96,2 \%)$ \\
7 & Ribeirão Preto & $98,6 \%$ & $(97,9 \% ; 99,3 \%)$ \\
10 & São Simão & $98,7 \%$ & $(97,9 \% ; 99,5 \%)$ \\
11 & Guariba & $97,5 \%$ & $(96,8 \% ; 98,2 \%)$ \\
12 & Serrana & $98,5 \%$ & $(97,4 \% ; 99,5 \%)$ \\
13 & Cajuru & $93,1 \%$ & $(91,3 \% ; 94,8 \%)$ \\
14 & Cravinhos & $94,8 \%$ & $(93,0 \% ; 96,6 \%)$ \\
15 & Sertãozinho & $97,6 \%$ & $(96,2 \% ; 99,0 \%)$ \\
16 & Pontal & $97,0 \%$ & $(95,7 \% ; 98,3 \%)$ \\
17 & Altinópolis & $96,8 \%$ & $(95,5 \% ; 98,2 \%)$ \\
20 & Santa Rosa do Viterbo & $92,3 \%$ & $(87,9 \% ; 96,8 \%)$ \\
21 & Monte Alto & $96,9 \%$ & $(96,5 \% ; 97,4 \%)$ \\
& Acurácia Média & $\mathbf{9 6 , 3 \%}$ & $(96,0 \% ; 96,6 \%)$ \\
\hline
\end{tabular}

Por fim, foi realizado o levantamento do percentual médio de acertos $(\bar{A} \%)$ dos valores contidos em cada campo da Folha de Alta. Na Tabela 35 são apresentados as proporções de acertos de todos os campos obtidas para a amostra. Dentre os quatro campos com acerto igual a 100,0\%, encontram-se dois campos obrigatórios (Hospital e Enfermaria) e dois campos não obrigatórios (Reoperação e Complicação Hospitalar). Já para os campos com menor percentual de Acerto, nota-se a presença de campos referentes aos procedimentos realizados (Procedimento SUS, Operação Principal e Data Cirurgia), diagnóstico (Afecção Principal, Outras Afecções 1 e Outras Afecções 2) e a identificação do médico (CRM).

Considerando-se as categorias de classificação apresentadas na Tabela 1 da seção 2.3, a distribuição dos campos da Folha de Alta de acordo com o percentual médio de acertos obtido para o conjunto de dados da amostra pode ser vista no Gráfico 1. A maioria dos campos (82,1\%) obteve uma média de acertos excelente. Entretanto, um campo tive uma média de acerto boa (Operação Principal), três tiveram 
uma média de acertos regular (Outras Afecções 1, Afecção Principal e Procedimento SUS) e um dos campos apresentou média de acertos ruim (CRM).

A Tabela 36 apresenta a distribuição dos percentuais de acerto de cada campo para cada hospital da amostra, apresentando o perfil de cada hospital quanto ao grau de acerto entre o Prontuário do Paciente e os dados presentes no banco de dados do ORAH.

Tabela 35 - Percentual Médio de Acerto $(\bar{A} \%)$ dos valores por campo da Folha de Alta para a amostra.

\begin{tabular}{|c|c|}
\hline Variável & Percentual Médio de Acerto ( $\overline{\mathrm{A}} \%)$ \\
\hline Hospital & 100,0 \\
\hline Enfermaria & 100,0 \\
\hline Reoperação & 100,0 \\
\hline Complicação Hospitalar & 100,0 \\
\hline Prontuário & 99,9 \\
\hline Sexo & 99,9 \\
\hline Sigla UF & 99,8 \\
\hline Especialidade & 99,4 \\
\hline Outras Operações 2 & 99,4 \\
\hline Data Internação & 99,3 \\
\hline Condição Saída & 99,3 \\
\hline Nome ou Iniciais & 99,3 \\
\hline Outras Afecções 4 & 99,2 \\
\hline Data Saída & 99,0 \\
\hline Código IBGE do Município & 98,9 \\
\hline Idade na internação & 98,4 \\
\hline Outras Afecções 3 & 98,1 \\
\hline Causa do Acid., Viol. ou Env. & 97,8 \\
\hline Ocupação & 97,5 \\
\hline Outras Operações 1 & 97,4 \\
\hline Categoria de internação & 97,0 \\
\hline Data Cirurgia & 96,5 \\
\hline Outras Afecções 2 & 95,5 \\
\hline Operação Principal & 93,0 \\
\hline Outras Afecções 1 & 89,7 \\
\hline Afecção Principal & 83,3 \\
\hline Procedimento SUS & 82,9 \\
\hline CRM & 75,1 \\
\hline
\end{tabular}




\section{Distribuição por Categorias do Percentual Médio de Acerto} $(\vec{A} \%)$ dos valores por campo da Folha de Alta

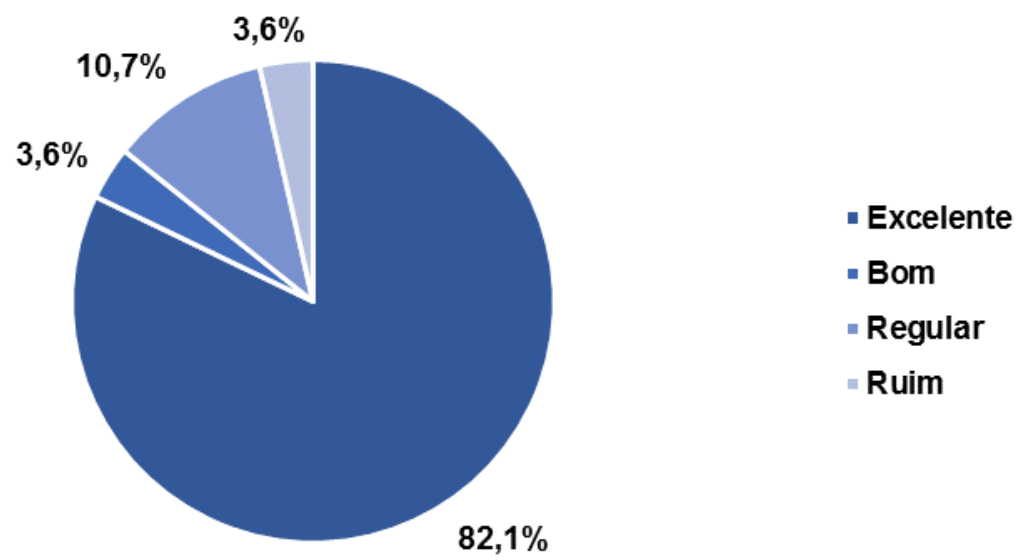

\section{Gráfico 1 - Distribuição do Percentual Médio de Acerto $(\bar{A} \%)$ dos valores por campo da Folha de Alta para a amostra.}

Algumas observações sobre esses resultados devem ser feitas para as avaliações de Acurácia e Acerto. Tais análises verificaram somente os casos onde houve um preenchimento idêntico do campo tanto na Folha de Alta quanto no Prontuário do Paciente, o que pode ter gerado alguns casos de falso negativo em campos de diagnóstico e procedimentos uma vez que a codificação dos mesmos pode sofrer um viés dependendo do observador que realizou a verificação do prontuário e o codificador da Folha de Alta. Outra observação importante refere-se ao nível de qualidade do campo de identificação do médico (CRM). Verificou-se que muitas vezes o CRM contido na Folha de Alta não correspondia ao do Prontuário devido ao envio pelos hospitais do CRM do médico que realizou o primeiro atendimento ou supervisionou o caso ao invés do que realizou a alta. Tal erro poderia ser minimizado a partir do levantamento do modo como este campo é preenchido para cada hospital e a capacitação por parte do ORAH para o preenchimento correto do mesmo pelos hospitais. 
Tabela 36 - Percentual Médio de Acerto $(\bar{A} \%)$ dos valores por campo da Folha de Alta para cada hospital da amostra.

\begin{tabular}{|c|c|c|c|c|c|c|c|c|c|c|c|c|c|c|}
\hline \multirow{2}{*}{ Variável } & \multicolumn{14}{|c|}{ Percentual Médio de Acerto ( $\overline{\mathrm{A}} \%)$} \\
\hline & 1 & 3 & 6 & 7 & 10 & 11 & 12 & 13 & 14 & 15 & 16 & 17 & 20 & 21 \\
\hline Prontuário & 100,0 & 93,7 & 100,0 & 100,0 & 100,0 & 100,0 & 100,0 & 100,0 & 100,0 & 100,0 & 100,0 & 100,0 & 100,0 & 100,0 \\
\hline Hospital & 100,0 & 100,0 & 100,0 & 100,0 & 100,0 & 100,0 & 100,0 & 100,0 & 100,0 & 100,0 & 100,0 & 100,0 & 100,0 & 100,0 \\
\hline Enfermaria & 100,0 & 100,0 & 100,0 & 100,0 & 100,0 & 100,0 & 100,0 & 100,0 & 100,0 & 100,0 & 100,0 & 100,0 & 100,0 & 100,0 \\
\hline Especialidade & 99,2 & 100,0 & 98,3 & 100,0 & 100,0 & 100,0 & 100,0 & 98,1 & 100,0 & 100,0 & 100,0 & 96,1 & 100,0 & 100,0 \\
\hline Nome ou Iniciais & 100,0 & 100,0 & 89,8 & 100,0 & 100,0 & 100,0 & 100,0 & 100,0 & 100,0 & 100,0 & 100,0 & 100,0 & 100,0 & 100,0 \\
\hline Sexo & 100,0 & 100,0 & 100,0 & 100,0 & 100,0 & 100,0 & 100,0 & 100,0 & 100,0 & 95,2 & 100,0 & 100,0 & 100,0 & 100,0 \\
\hline Idade na internação & 98,8 & 100,0 & 96,6 & 100,0 & 90,9 & 94,4 & 100,0 & 100,0 & 96,1 & 100,0 & 100,0 & 100,0 & 100,0 & 100,0 \\
\hline Ocupação & 98,8 & 100,0 & 96,6 & 100,0 & 86,4 & 100,0 & 100,0 & 98,1 & 96,1 & 95,2 & 100,0 & 100,0 & 100,0 & 94,2 \\
\hline Categoria de internação & 99,6 & 100,0 & 96,6 & 100,0 & 100,0 & 100,0 & 100,0 & 78,8 & 65,4 & 100,0 & 93,5 & 100,0 & 100,0 & 100,0 \\
\hline Código IBGE do Município & 100,0 & 100,0 & 89,8 & 100,0 & 100,0 & 98,9 & 100,0 & 96,1 & 100,0 & 100,0 & 100,0 & 100,0 & 100,0 & 100,0 \\
\hline Sigla UF & 100,0 & 100,0 & 100,0 & 100,0 & 100,0 & 100,0 & 100,0 & 96,1 & 100,0 & 100,0 & 100,0 & 100,0 & 100,0 & 100,0 \\
\hline Data Internação & 100,0 & 93,7 & 100,0 & 100,0 & 100,0 & 98,9 & 100,0 & 100,0 & 100,0 & 100,0 & 87,1 & 100,0 & 100,0 & 100,0 \\
\hline Data Saída & 98,8 & 100,0 & 100,0 & 100,0 & 100,0 & 96,6 & 100,0 & 98,1 & 100,0 & 100,0 & 96,8 & 100,0 & 100,0 & 100,0 \\
\hline Afecção Principal & 83,1 & 75,0 & 74,6 & 94,4 & 95,4 & 78,6 & 64,3 & 76,9 & 76,9 & 80,9 & 90,3 & 80,8 & 71,4 & 89,0 \\
\hline Outras Afecções 1 & 89,1 & 100,0 & 91,5 & 96,3 & 100,0 & 79,8 & 92,9 & 80,8 & 96,1 & 95,2 & 90,3 & 84,6 & 42,9 & 94,2 \\
\hline Outras Afecções 2 & 94,3 & 100,0 & 94,9 & 98,1 & 95,4 & 98,9 & 100,0 & 88,5 & 100,0 & 100,0 & 87,1 & 96,1 & 85,7 & 96,5 \\
\hline Outras Afecções 3 & 96,0 & 100,0 & 100,0 & 100,0 & 100,0 & 100,0 & 100,0 & 96,1 & 100,0 & 100,0 & 93,5 & 100,0 & 100,0 & 98,8 \\
\hline Outras Afecções 4 & 97,6 & 100,0 & 100,0 & 100,0 & 100,0 & 100,0 & 100,0 & 100,0 & 100,0 & 100,0 & 100,0 & 100,0 & 100,0 & 99,4 \\
\hline Data Cirurgia & 91,5 & 100,0 & 100,0 & 100,0 & 100,0 & 100,0 & 100,0 & 94,2 & 96,1 & 100,0 & 100,0 & 100,0 & 100,0 & 97,7 \\
\hline Operação Principal & 89,1 & 100,0 & 89,8 & 98,1 & 100,0 & 100,0 & 100,0 & 84,6 & 92,3 & 100,0 & 100,0 & 88,5 & 100,0 & 93,1 \\
\hline Outras Operações 1 & 96,8 & 100,0 & 98,3 & 100,0 & 100,0 & 100,0 & 100,0 & 96,1 & 100,0 & 100,0 & 100,0 & 100,0 & 100,0 & 93,6 \\
\hline Outras Operações 2 & 99,2 & 100,0 & 100,0 & 100,0 & 100,0 & 100,0 & 100,0 & 96,1 & 100,0 & 100,0 & 100,0 & 96,1 & 100,0 & 100,0 \\
\hline Reoperação & 100,0 & 100,0 & 100,0 & 100,0 & 100,0 & 100,0 & 100,0 & 100,0 & 100,0 & 100,0 & 100,0 & 100,0 & 100,0 & 100,0 \\
\hline Causa do Acid., Viol. ou Env. & 93,1 & 100,0 & 100,0 & 100,0 & 100,0 & 98,9 & 100,0 & 100,0 & 100,0 & 100,0 & 100,0 & 100,0 & 100,0 & 100,0 \\
\hline Complicação Hospitalar & 100,0 & 100,0 & 100,0 & 100,0 & 100,0 & 100,0 & 100,0 & 100,0 & 100,0 & 100,0 & 100,0 & 100,0 & 100,0 & 100,0 \\
\hline CRM & 73,0 & 50,0 & 86,4 & 94,4 & 100,0 & 100,0 & 100,0 & 30,8 & 80,8 & 76,2 & 100,0 & 100,0 & 42,9 & 57,8 \\
\hline Condição Saída & 98,8 & 100,0 & 100,0 & 98,1 & 95,4 & 100,0 & 100,0 & 98,1 & 100,0 & 100,0 & 100,0 & 100,0 & 100,0 & 100,0 \\
\hline Procedimento SUS & 77,4 & 68,7 & 59,3 & 81,5 & 100,0 & 84,3 & 100,0 & 98,1 & 53,8 & 90,5 & 77,4 & 69,2 & 42,9 & 100,0 \\
\hline
\end{tabular}




\subsection{Outros Resultados}

Os resultados aqui apresentados são oriundos de atividades não previstas inicialmente no projeto, mas que se fizeram importantes para a melhoria do trabalho e dos resultados a serem obtidos.

Uma apresentação deste trabalho foi feita em forma Pôster Eletrônico sob o título "Proposta para Análise e Avaliação do Controle de Qualidade de Dados Hospitalares na Região de Ribeirão Preto" no X Congresso Brasileiro de Saúde Coletiva em novembro de 2012, na cidade de Porto Alegre/RS e teve seu resumo publicado nos anais do evento ( $\mathrm{VINCl}$ et al., 2012a). Neste mesmo congresso também houve a apresentação de outros trabalhos na forma de Pôster Eletrônico (CARVALHO et al., 2012; $\mathrm{VINCl}$ et al., 2012c).

Também foram feitas participações em outros eventos nacionais e internacionais na área de Saúde Coletiva e de Informática em Saúde durante a duração deste estudo, sendo os mais importantes: Simpósio sobre Informação Clínica (SIC 2012) em agosto de 2012 na cidade de Ribeirão Preto/SP; apresentação oral no XIII Congresso Brasileiro de Informática em Saúde (CBIS) em novembro de 2012 na cidade de Curitiba/PR ( $\mathrm{VINCl}$ et al. 2012b); palestrante no Curso Sistemas de Informação em Saúde do XLIX Congresso Brasileiro de Medicina Tropical em agosto de 2013 na cidade de Campo Grande/MS; apresentação oral e publicação de resumo em revista científica (Gazeta Sanitaria ${ }^{6}$ ) no Congresso Ibero-Americano de Epidemiología y Salud Pública em Setembro de 2013 na cidade de Granada na Espanha (CARVALHO et al., 2013a; CHIARI et al., 2013; MIYOSHI et al., 2013; MONTEIRO et al., 2013; VINCl et al., 2013a, 2013b); participação na XII Mostra Nacional de Experiências Bem-Sucedidas em Epidemiologia, Prevenção e Controle de Doenças (EXPOEPI) em Outubro de 2013 na cidade de Brasília/DF; e organização do evento I Workshop Ibero-Americano de Sistemas Interoperáveis em Saúde (IASIS2014) em Fevereiro de 2014 na cidade de Ribeirão Preto/SP.

${ }^{6}$ Gaceta Sanitaria. Disponível em: <http://www.gacetasanitaria.org/es/vol-27-numsc2/suplemento/congresos/X0213911113X65133/>. Acesso em: 10 jan. 2014. 


\section{Conclusões}

O estudo aqui apresentado teve o intuito de caracterizar a Qualidade dos Dados sobre internações hospitalares na região de Ribeirão Preto a partir dos dados registrados pelo Observatório Regional de Atenção Hospitalar (ORAH) da Faculdade de Medicina de Ribeirão Preto da Universidade de São Paulo (FMRP/USP).

A partir da Folha de Alta Hospitalar, seus campos e dos valores armazenados pelo sistema de informação do ORAH no ano de 2012, foi possível a realização de análises da Qualidade dos Dados das internações hospitalares na região de Ribeirão Preto e constatação da ótima qualidade destes dados, quando levadas em consideração a completude e consistência dessas informações. Também foi avaliado o processamento dos dados pelo CPDH pela execução dos protocolos de validação e consistência adotados a partir da verificação do comportamento da completude e da consistência dos dados e também com a averiguação das modificações ocorridas nos campos da Folha de Alta entre cada etapa. Assim, foi possível constatar que mesmo com a ocorrências de alterações nos campos a qualidade dos dados manteve-se inalterada entre as etapas.

Para a obtenção de um panorama mais abrangente da qualidade, foram utilizados informações a respeito da produção das informações pelos hospitais e também a comparação dos dados armazenados no sistema de informação do ORAH com os do Prontuário do Paciente, considerado como padrão ouro. Tais análises mostraram como é o fluxo das informações hospitalares previamente a chegada dos dados no observatório através da caracterização da sua produção pelos hospitais e que, após o processamento destas pelo ORAH, as informações apresentam alta fidelidade com o Prontuário do Paciente.

A partir de todas essas análises, foi possível comprovar a excelência da qualidade das informações disponibilizadas pelo ORAH, estabelecer uma metodologia abrangente para a análise dessa qualidade e definir possíveis problemas a serem enfrentados para a constante melhoria da qualidade das informações presentes na Folha de Alta Hospitalar e, consequentemente, das informações presentes no banco de dados do Observatório Regional de Atenção Hospitalar (ORAH). 


\section{Considerações Finais}

Atualmente, com a criação do Observatório Regional de Assistência Hospitalar (ORAH) tendo o Centro de Processamento de Dados Hospitalare (CPDH) como piloto no seu desenvolvimento e implantação, a região de Ribeirão Preto iniciou uma nova fase em relação à geração, auditoria e divulgação de informações em saúde, sobretudo com o ganho em qualidade das informações sobre assistência hospitalar com desdobramentos para a gestão e pesquisa em saúde, utilizando-se de bases de dados hospitalares SUS e não-SUS integrados, além de dados caracterizadores da população (ORAH, 2013).

O ORAH visa criar instrumentos tecnológicos necessários à construção de sistemas de assistência hospitalar regionalizados de capacidade pró-ativa incorporando serviços já desenvolvidos e utilizados no $\mathrm{CPDH}$, bem como dar assessoria aos hospitais parceiros pertencentes à região.

O trabalho aqui exposto é um desses instrumentos devido a sua ênfase na avaliação de informações em âmbito regional entre hospitais de diversas categorias (SUS, Mistos, Não-SUS). Um dos aspectos importantes dele é melhorar ainda mais o serviço prestado pelo ORAH a partir da quantificação da qualidade da informação hospitalar gerada. Além disso, foi possível analisar cada etapa do processo em si, oferecendo uma visão mais detalhada do ganho de qualidade na informação obtido pela execução dos protocolos de validação e consistência adotados e servindo como auxiliar nos processos de melhorias das atividades do observatório. Especificamente, os indicadores criados poderão ser implementados para o uso durante cada etapa dos processos realizados pelo ORAH podendo, assim, comparar o ganho da qualidade ao decorrer do processo.

O uso dos resultados apresentados nessa dissertação também possibilitará a caracterização do panorama dos hospitais da região na tentativa de identificar possíveis problemas internos dos estabelecimentos hospitalares assessorando e capacitando essas instituições para o adequado registro, conservação e uso de informações da assistência hospitalar. Com efeito, também será possível criar uma classificação entre os hospitais quanto à qualidade na produção dos dados. 


\section{Referências Bibliográficas ${ }^{7}$}

APM - ASSOCIAÇÃO PAULISTA DE MEDICINA, CREMESP - CONSELHO REGIONAL DE MEDICINA DO ESTADO DE SÃO PAULO. Compromisso com a Qualidade Hospitalar - CQH: 3 Caderno de Indicadores CQH-2009. São Paulo: Van Moorsel, 2009.

Disponível

em:

<http://www.cqh.org.br/files/3\%20caderno\%20de\%20ind\%20baixa-res.pdf>. Acesso em: 01 nov. 2011.

ARAÚJO, E. M. T.; BATISTA, M. DE L. S. Uma visão sobre a Qualidade dos Dados. DevMedia.com, $2013 . \quad$ Disponível em: <http://www.devmedia.com.br/articles/viewcomp.asp?comp=6973>. Acesso em: 17 jul. 2013.

BATINI, C.; SCANNAPIECA, M. Data Quality: concepts, methodologies and techniques. [s.I.] Springer, 2006. p. 262

BOVEE, M.; SRIVASTAVA, R. P.; MAK, B. A Conceptual Framework and BeliefFunction Approach to Assessing Overall Information Quality. International Journal of Intelligent Systems, v. 18, p. 51-74, 2013.

CAMPOS, V. F. TQC - Controle da Qualidade Total. Belo Horizonte/MG, Brasil: Editora de Desenvolvimento Gerencial, 1999.

CARVALHO, I. et al. Caracterização do fluxo de pacientes na rede hospitalar envolvendo causas externas. Gaceta Sanitaria, v. 27, n. SC2, p. 349, 2013a.

\footnotetext{
${ }^{7}$ De acordo com a Associação Brasileira de Normas Técnicas. NBR 6023.
} 
CARVALHO, I. et al. Estudo da Gravidade dos Casos pelo Índice de Comorbidade de Charlson Corrigido para Idade (ICC-I) nos Hospitais da Região de Ribeirão Preto nos Anos de 2007 e 2008. In: CONGRESSO BRASILEIRO DE SAÚDE COLETIVA, 10., 2012, Porto Alegre. Anais... Porto Alegre/RS, Brasil, 2012.

CARVALHO, I. et al. Ferramentas Computacionais para Análise de Dados no Auxílio à Gestão Hospitalar na Região de Ribeirão Preto. In: WORKSHOP DE INFORMÁTICA MÉDICA (CSBC WIM 2013), 13., 2013, Maceió. Anais... Maceió/AL, Brasil, 2013b. p. 1164-1173.

<https://docs.google.com/file/d/0ByMLHgMMHCODM2hOUFRPa0tiZEE/edit?usp=shs hari>. Acesso em: 10 ago. 2013.

CDC - CENTERS FOR DISEASE CONTROL AND PREVENTION. Updated guidelines for evaluating public health surveillance systems. Washington, DC, EUA: Centers for Disease Control and Prevention (CDC), 2001. Disponível em: <http://www.ncbi.nlm.nih.gov/pubmed/18634202>. Acesso em: 10 nov. 2011.

CHIARI, N. S. et al. Perfil das internações por condições sensíveis à atenção básica na região de Ribeirão Preto. Gaceta Sanitaria, v. 27, n. SC2, p. 313, 2013.

DELFINI, M. G.; MIYOSHI, N. S. B; ALVES, D. Minimum Data Consensus: Essential Tool in Trasitions of Patientes. In: IEEE INTERNATIONAL SYMPOSIUM ON COMPUTER-BASED MEDICAL SYSTEMS, 28., 2015, São Carlos e Ribeirão Preto. Anais... São Carlos e Ribeirão Preto/SP, Brasil, 2015. Submetido.

DEMING, W. Out of Crisis. MIT Center for Advanced Enginnering Study, 1986.

GERTZ, M. et al. Report on the Dagstuhl Seminar " Data Quality on the Web " Results from Working Groups Metadata and Modeling. SIGMOD Record, v. 33, n. 1, p. 127132, 2004. 
GOMES, P.; FARINHA, J.; TRIGUEIROS, M. J. A Data Quality Metamodel Extension to CWM. In: ASIA-PACIFIC CONFERENCE ON COMCEPTUAL MODELLING, 9., 2007, Ballarat. Anais... Ballarat, Australia: Australian Computer Society, Inc., 2007, v. 67.

GOUVÊA, C. S. D. DE; TRAVASSOS, C.; FERNANDES, C. Produção de serviços e qualidade da assistência hospitalar no Estado do Rio de Janeiro, Brasil - 1992 a 1995. Revista de Saúde Pública, v. 31, n. 6, p. 601-617, 1997.

KAHN, B. K.; STRONG, D. M.; WANG, R. Y. Information quality benchmarks: product and service performance. Communications of the ACM, v. 45, n. 4ve, p. 184192, 2002.

LEE, M. L.; LING, T. W.; LOW, W. L. IntelliClean: a knowledge-based intelligent data cleaner. In: ACM SIGKDD INTERNATIONAL CONFERENCE ON KNOWLEDGE DISCOVERY AND DATA MINING (KDD '00), 6. 2000, New York. Anais... New York, NY, USA: ACM $2000 . \quad$ Disponível em: <http://portal.acm.org/citation.cfm?doid=347090.347154>. Acesso em: 10 jan. 2014.

MADNICK, S. E. et al. Overview and Framework for Data and Information Quality Research. Journal of Data and Information Quality, v. 1, n. 1, p. 1-22, 2009.

MASSAD, E.; MARIN, H. F.; AZEVEDO NETO, R. S. (EDs). O prontuário eletrônico do paciente na assistência, informação e conhecimento médico. São Paulo: $H$. de F. Marin; 2003. Disponível em: <http://www.sbis.org.br/site/arquivos/prontuario.pdf>. Acesso em: 09 jan. 2014.

MATHIAS, T. A. F.; SOBOLL, M. L. M. S. Confiabilidade de diagnósticos nos formulários de autorização de internação hospitalar. Revista de Saúde Pública, v. 32, n. 6, p. 526-532, 1998. 
MAZZER, G. et al. Sistema Informatizado para o Gerenciamento das Informações de Morbidade e Mortalidade Hospitalar. In: CONGRESSO BRASILEIRO DE INFORMÁTICA EM SAÚDE (CBIS 2010), 12., 2010, Porto de Galinhas. Anais... Porto de Galinhas/PB, Brasil, 2010.

MIYOSHI, N. S. B. et al. Perfil nosológico de internações ocorridas na região de Ribeirão Preto. Gaceta Sanitaria, v. 27, n. SC2, p. 425, 2013.

MONTEIRO, R. A. Hospitalizações por Causas Externas, Na Região de Ribeirão Preto, SP, em 2005: Análise Epidemiológica Descritiva e Avaliação da Qualidade dos Registros Em Hospitais Selecionados. 2008. 135p. Dissertação (Mestrado). Faculdade de Medicina de Ribeirão Preto, Universidade de São Paulo, Ribeirão Preto, 2008.

MONTEIRO, R. A. et al. Notificações de Violências Domésticas, Sexual e/ou Outras: Qualidade dos Dados, Brasil, 2011. Gaceta Sanitaria, v. 27, n. SC2, p. 16, 2013.

OBSERVATÓRIO REGIONAL DE ATENÇÃO HOSPITALAR (ORAH). Disponível em: $<$ http://orah.dyndns.org/>. Acesso em: 15 de dez. 2013.

OLIVEIRA, P. J. M. Detecção e Correcção de Problemas de Qualidade dos Dados: Modelo, Sintaxe e Semântica. 2008. 383p. Tese (Doutorado). Escola de Engenharia, Universidade do Minho, 2008.

PIPINO, L. L.; LEE, Y. W.; WANG, R. Y. Data Quality Assessment. Communications of the ACM, v. 45, n.4, p. 211-218, 2002.

REDMAN, T. C. Data Quality for the Information Age. [s.I.] Artech House, Inc., 1997. 
REDMAN, T. C. Data: An Unfolding Quality Disaster. Information Management Magazine Article, p. 1-6, 2004.

ROMERO, D. E.; CUNHA, C. B. Avaliação da qualidade das variáveis epidemiológicas e demográficas do Sistema de Informações sobre Nascidos Vivos, 2002. Cad. Saúde Pública, vol.23, n.3, p. 701-714, 2007.

SADIQ, S.; YEGANEH, N. K.; INDULSKA, M. 20 Years of Data Quality Research : Themes, Trends and Synergies. In: AUSTRALASIAN DATABASE CONFERENCE, 22., 2011, Perth. Anais... Perth, Australia: Australian Computer Society, 2011, v. 115.

SALVADOR, V. F. M. et al. Qualidade de Dados para Gestão de Conhecimento na Área de Saúde. In: CONGRESSO BRASILEIRO DE INFORMÁTICA EM SAÚDE (CBIS 2006), 10., 2006, Florianópolis. Anais... Florianópolis/SC, Brasil, 2006. Disponível em: <http://www.sbis.org.br/cbis/arquivos/758.pdf>. Acesso em: 26 set. 2013.

SANTOS, J. L. F. et al. Doenças e Agravos Não-Transmissíveis - Ribeirão Preto, SP e Região. $1^{\text {a }}$. ed. Ribeirão Preto/SP: Faculdade de Medicina de Ribeirão Preto (FMRP/USP), 2010. p. 261.

SHANKARANARAYANAN, G. Towards Implementing Total Data Quality Management in a Data Warehouse. Journal of Information Technology Management, v. 16, n.1, p. 21-30, 2005.

SILVA, L. M. F. R. et al. Desenvolvimento de um sistema para monitoramento e análise das séries temporais de dados hospitalares. In: CONGRESSO BRASILEIRO DE INFORMÁTICA EM SAÚDE (CBIS 2008), 11., 2008, Campos do Jorão. Anais... Campos do Jordao/SP, Brasil, 2008. Disponível em: <http://www.sbis.org.br/cbis11/arquivos/847.pdf>. Acesso em: 7 nov. 2011. 
SIMÕES, B. J.; COUTINHO, R.; ALMEIDA, M. G. V. L. Controle de Qualidade de dados hospitalares, Ribeirão Preto, SP. Medicina, Ribeirão Preto, v. 24, n. 1, p. 26$31,1991$.

SQUIRES, J. E. et al. A Data Quality Control Program for Computer-Assisted Personal Interviews. Nursing Research and Practice, v. 2012, 2012.

STRONG, D. M.; LEE, Y. W.; WANG, R. Y. Data quality in context. Communications of the ACM, v. 40, n. 5, p. 103-110, 1 maio 1997.

VERAS, C. M. T.; MARTINS, M. S. A Confiabilidade dos Dados nos Formulários de Autorização de Internação Hospitalar ( AlH ), Rio de Janeiro/RJ , Brasil. Cadernos de Saúde Pública [online], v. 10, n. 3, p. 339-355, 1994.

VIEIRA, D. K.; DETONI, D. J.; BRAUM, L. M. S. Indicadores de Qualidade em uma Unidade Hospitalar. In: SIMPÓSIO DE EXCELÊNCIA EM GESTÃO E TECNOLOGIA, 3., 2006, Resende. Anais... Resende/RJ, Brasil, 2006. Disponível em: <http://www.aedb.br/seget/artigos06/680_Indicadores\%20de\%20qualidade\%20em\% 20uma\%20Unidade\%20Hospitalar.pdf>. Acesso em 02 de Nov. 2011.

VINCI, A. L. T. et al. Análise da Qualidade dos Dados do Inquérito sobre Violências e Acidentes, Brasil, 2011. Gaceta Sanitaria, v. 27, n. SC2, p. 374, 2013a.

VINCI, A. L. T. et al. Análise Descritiva dos Partos Realizados na Região de Ribeirão Preto entre 2002 e 2008. Gaceta Sanitaria, v. 27, n. SC2, p. 253, 2013b.

VINCI, A. L. T. et al. Proposta para Análise e Avaliação do Controle de Qualidade de Dados Hospitalares na Região de Ribeirão Preto. In: CONGRESSO BRASILEIRO DE SAÚDE COLETIVA, 10., 2012, Porto Alegre. Anais... Porto Alegre/RS, Brasil, 2012a. 
VINCI, A. L. T. et al. Sistema de Validação VIVA 2011. In: CONGRESSO BRASILEIRO DE INFORMÁTICA EM SAÚDE, 13., 2012, Curitiba. Anais... Curitiba/PR, Brasil, 2012b. Disponível em: < http://www.sbis.org.br/cbis2012/arquivos/824.pdf>. Acesso em: 05 jan. 2014.

VINCI, A. L. T. et al. Sistema para Análise de Qualidade e Validação do Inquérito VIVA 2011. In: CONGRESSO BRASILEIRO DE SAÚDE COLETIVA, 10., 2012, Porto Alegre. Anais... Porto Alegre/RS, Brasil, 2012c.

WAND, Y.; WANG, R. Y. Anchoring data quality dimensions in ontological foundations. Communications of the ACM, v. 39, n. 11, p. 86-95, 1996.

WANG, R. Y. A Product Perspective on Total Data Quality Management. Communications of the ACM, v. 41, n. 2, p. 58-65, 1998.

WANG, R. Y.; STRONG, D. M. Beyond accuracy: what data quality means to data consumers. J. Manage. Inf. Syst., v. 12, n. 4, p. 5-33, 1996.

XAVIER, M. P. T.; GOMES, S. B. A Informação como Vantagem da Empresa Competitiva. Developer's Magazine, Rio de Janeiro/RJ, Brasil: 1999, p. 26-29.

YAZLLE ROCHA, J. S. Estudo da utilização de leitos hospitalares gerais no município de Ribeirão Preto (SP) pela população do município no ano de 1972. 1974. Tese (Doutorado). Faculdade de Medicina de Ribeirão Preto, Ribeirão Preto, 1974. 


\section{Anexo A - Folha de Alta Hospitalar}

Instrumento básico de coleta de dados do $\mathrm{CPDH} / \mathrm{ORAH}$, a Folha de Alta contendo 27 atributos.
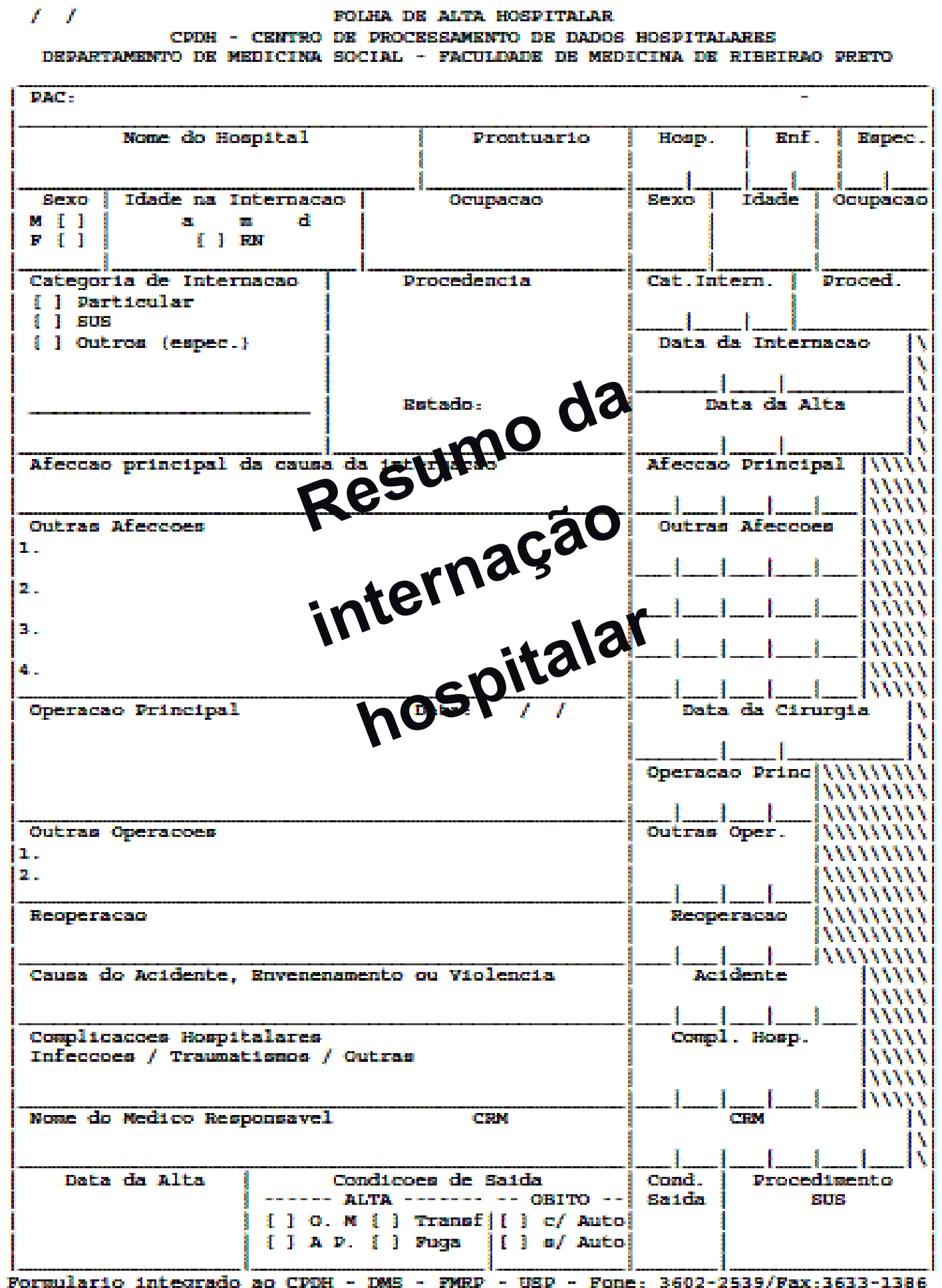

Figura 4 - Folha de Alta Hospitalar usada pelos hospitais conveniados aos CPDH/ORAH. 


\begin{tabular}{|c|c|c|}
\hline Campo & Variável & Descrição \\
\hline Prontuário & reg_pac & código do prontuário do paciente no hospital \\
\hline Hospital & hospital & nome do hospital de internação \\
\hline Enfermaria & enfermaria & local de internação dentro do hospital \\
\hline Especialidade & especialid & especialidade médica atendida na internação \\
\hline \multirow{2}{*}{ Nome } & nome & nome do paciente internado \\
\hline & iniciais & iniciais do nome do paciente internado \\
\hline Sexo & sexo & sexo do paciente internado \\
\hline Idade na internação & idade_int & $\begin{array}{l}\text { idade no momento da internação em anos, meses ou } \\
\text { dias }\end{array}$ \\
\hline Ocupação & ocupacao & $\begin{array}{l}\text { "profissão" exercida pelo paciente na época da } \\
\text { internação }\end{array}$ \\
\hline Categoria de internação & cat_int & $\begin{array}{l}\text { categoria da internação do paciente (convênios, } \\
\text { particular, pública) }\end{array}$ \\
\hline \multirow{2}{*}{ Procedência } & cod_mnibge & $\begin{array}{l}\text { código do IBGE que identifica a cidade de origem do } \\
\text { paciente internado }\end{array}$ \\
\hline & sigla_uf & sigla estado de origem do paciente internado \\
\hline Data Internação & data_inter & data de início da internação \\
\hline Data Saída & data_saida & data de saída da internação \\
\hline Afecção Principal & afeccao_1 & diagnóstico principal codificado pela CID-10 \\
\hline Outras Afecções 1 & afeccao_2 & comorbidade codificada pela CID-10 \\
\hline Outras Afecções 2 & afeccao_3 & comorbidade codificada pela CID-10 \\
\hline Outras Afecções 3 & afeccao_4 & comorbidade codificada pela CID-10 \\
\hline Outras Afecções 4 & afeccao_5 & comorbidade codificada pela CID-10 \\
\hline Data Cirurgia & data_opera & data da cirurgia realizada durante a internação; \\
\hline \multirow[t]{2}{*}{ Operação Principal } & operacao_1 & $\begin{array}{l}\text { procedimento principal realizado codificado pela ICD-9- } \\
\text { CM }\end{array}$ \\
\hline & seq_oper1 & código sequencial do procedimento realizado \\
\hline \multirow{2}{*}{ Outras Operações 1} & operacao_2 & outro procedimento realizado codificado pela ICD-9-CM \\
\hline & seq_oper2 & código sequencial do procedimento realizado \\
\hline \multirow{2}{*}{ Outras Operações 2} & operacao_3 & outro procedimento realizado codificado pela ICD-9-CM \\
\hline & seq_oper3 & código sequencial do procedimento realizado \\
\hline \multirow[t]{2}{*}{ Reoperação } & reoperacao & $\begin{array}{l}\text { procedimento de reoperação realizado codificado pela } \\
\text { ICD-9-CM }\end{array}$ \\
\hline & seq_reop & código sequencial do procedimento realizado \\
\hline $\begin{array}{l}\text { Causa do Acidente, } \\
\text { Violência ou } \\
\text { Envenenamento }\end{array}$ & ac_env_viol & causa externa codificada pela CID-10 \\
\hline Complicação Hospitalar & compl_hosp & complicação hospitalar codificada pela CID-10 \\
\hline CREMESP & CRM & código de registro do médico responsável pela alta \\
\hline Condição Saída & cond_saida & $\begin{array}{l}\text { condição de saída do paciente no momento da alta } \\
\text { (óbito, alta, transferência) }\end{array}$ \\
\hline Procedimento SUS & procsus & $\begin{array}{l}\text { procedimento cirúrgico realizado codificado pela tabela } \\
\text { de procedimento do SUS }\end{array}$ \\
\hline
\end{tabular}

Quadro 1 - Descrição dos Campos da Folha de Alta Hospitalar e as Variáveis representativas do mesmo no Banco de Dados do ORAH. 


\section{Anexo B - Questionário para Avaliação da Coleta de Dados Hospitalares}

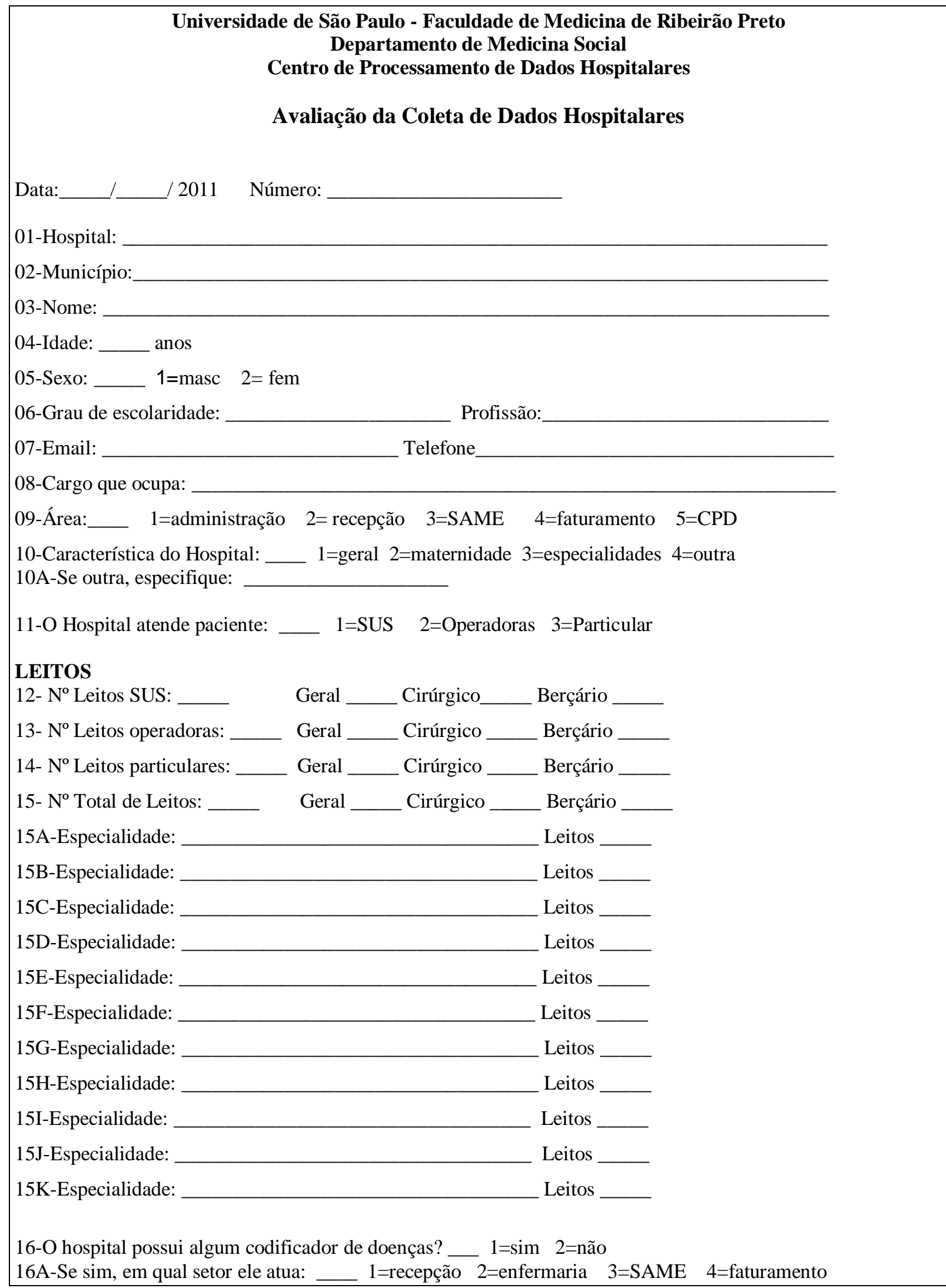




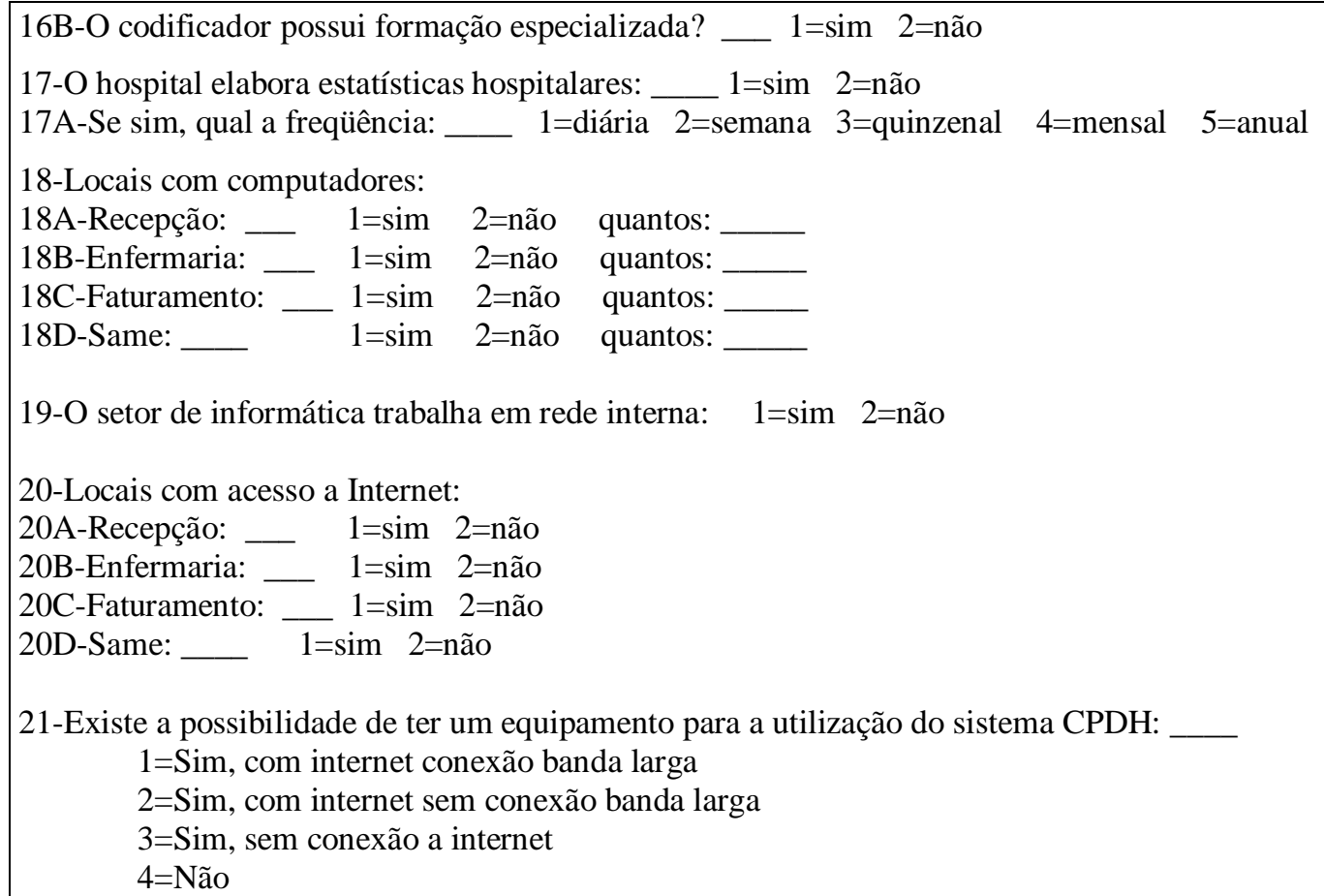

22-Qual Sistema de Informação é utilizado para armazenamento dos dados CPDH: 1=CPDH 2=Manual 3=Terceirizado 4=CPD do próprio hospital

22A-Se respondeu Terceirizado na questão 22:

Qual o nome do Sistema:

Empresa desenvolvedora:

Nome e telefone do responsável pelo sistema:

22B-Se respondeu Terceirizado ou CPD na questão 22:

O sistema utilizado tem o recurso de exportar dados de acordo com o layout das folhas de altas fornecida pelo

$\mathrm{CPDH}$ : $1=\operatorname{sim} 2=$ não $3=$ não sabe $4=$ não se aplica.

23-Nome e telefone de uma pessoa da área de informática do hospital:

24- Nome, telefone e setor de trabalho da pessoa que trabalha diretamente com as folhas de altas:

25-A impressão da folha de alta hospitalar acontece na(o):

$1=$ recepção $2=$ enfermaria $3=$ same $4=$ faturamento $5=$ gráfica (para casos manuais)

$6=$ não é impressa

26-Depois que a folha de alta é impressa ela segue para:

$1=$ recepção 2 =enfermaria $3=$ same $4=$ faturamento $5=$ não se aplica

27-Qual o fluxo da informação do paciente até chegar à folha de alta?

$1=$ enfermaria $\Rightarrow$ same $=>$ faturamento $=>$ prontuário

$2=$ enfermaria $=>$ faturamento $=>$ same $=>$ prontuário

$3=$ outro

27A- Se outros, especifique:

27B- Quais partes deste fluxo são informatizadas?

Identificação do paciente

28- A identificação do paciente (nome, idade, sexo, ocupação, procedência, data internação) é coletada:

$1=$ recepção $\quad 2=$ =nfermaria 3 =same $\quad 4$ =faturamento $5=$ outro 
29- A informação cor do paciente é registrada no prontuário médico paciente: $1=\operatorname{sim} 2=$ não

\section{Tipo de financiamento}

30-Onde é registrado o tipo de Convênio?:

$$
1=\text { recepção } 2=\text { =nfermaria } 3=\text { same } 4=\text { faturamento } 5=\text { =utro }
$$

30A- Quais são os Convênios mais utilizados?

31 - Atende paciente particular? _ $1=$ sim 2=não

31A- Alem do SUS ou CONVENIO ou PARTICULAR existe outra forma de pagamente, por exemplo: pacote,

$\%$ convenio com $\%$ particular?

32 - A identificação dos tipos de convênios é por meio da tabela da ANS? $1=\operatorname{sim} 2=$ não

\section{Diagnósticos}

33-O preenchimento dos diagnósticos na folha de alta hospitalar é feito pelo: $1=$ medico $\quad 2$ =faturamento 3 =same

34-Onde é feito o preenchimento dos diagnósticos: $1=$ recepção $2=$ =nfermaria $3=$ same $\overline{4=\text { faturamento }}$

35-O preenchimento dos diagnósticos é informatizado? __ 1=sim 2=não

35A- Se sim, o preenchimento é com: ___ 1=descrição 2=código da CID

36- Como é selecionado o diagnóstico principal?

Descrever:

37- Os diagnósticos secundários são registrados nos prontuários? $1=\operatorname{sim} 2=$ não

\section{Procedimentos Cirúrgicos}

38-Os procedimentos cirúrgicos quando ocorrem são referidos na folha de alta hospitalar pelo: $1=$ medico $\quad 2$ =faturamento 3 =same

\section{Complicações Hospitalares}

39-As complicações hospitalares quando ocorrem são referidos na folha de alta hospitalar pelo: $1=$ medico $\quad 2$ =faturamento $3=$ same

\section{Condição de saída do paciente}

40- A condição de saída do paciente é registrada na folha de alta hospitalar pelo: $1=$ medico $\quad 2$ =faturamento $3=$ same

\section{Causas externas}

41-As internações com menção de lesões e envenenamentos registram o tipo de acidente ou violência que as provocaram? _ 1=sim 2=não

41A-Se sim, onde é registrado?

41B-Se não, por que?

42-Hospital gera informações da AIH por qual Sistema de Informação? 1=CPDH 2=Ministério da Saúde 3=Terceirizado 4=próprio CPD

43-Hospital gera informações CIH por qual Sistema de Informação? 1=CPDH 2=Ministério da Saúde $3=$ Terceirizado $4=$ próprio CPD

44-As altas hospitalares que retornam do CPDH onde são armazenadas? 1=Prontuário paciente $2=$ desprezadas logo que chegam $3=$ arquivadas (arquivo inativo) 4=não se aplica

44A-Se armazena no prontuário, por quanto tempo é mantido? 


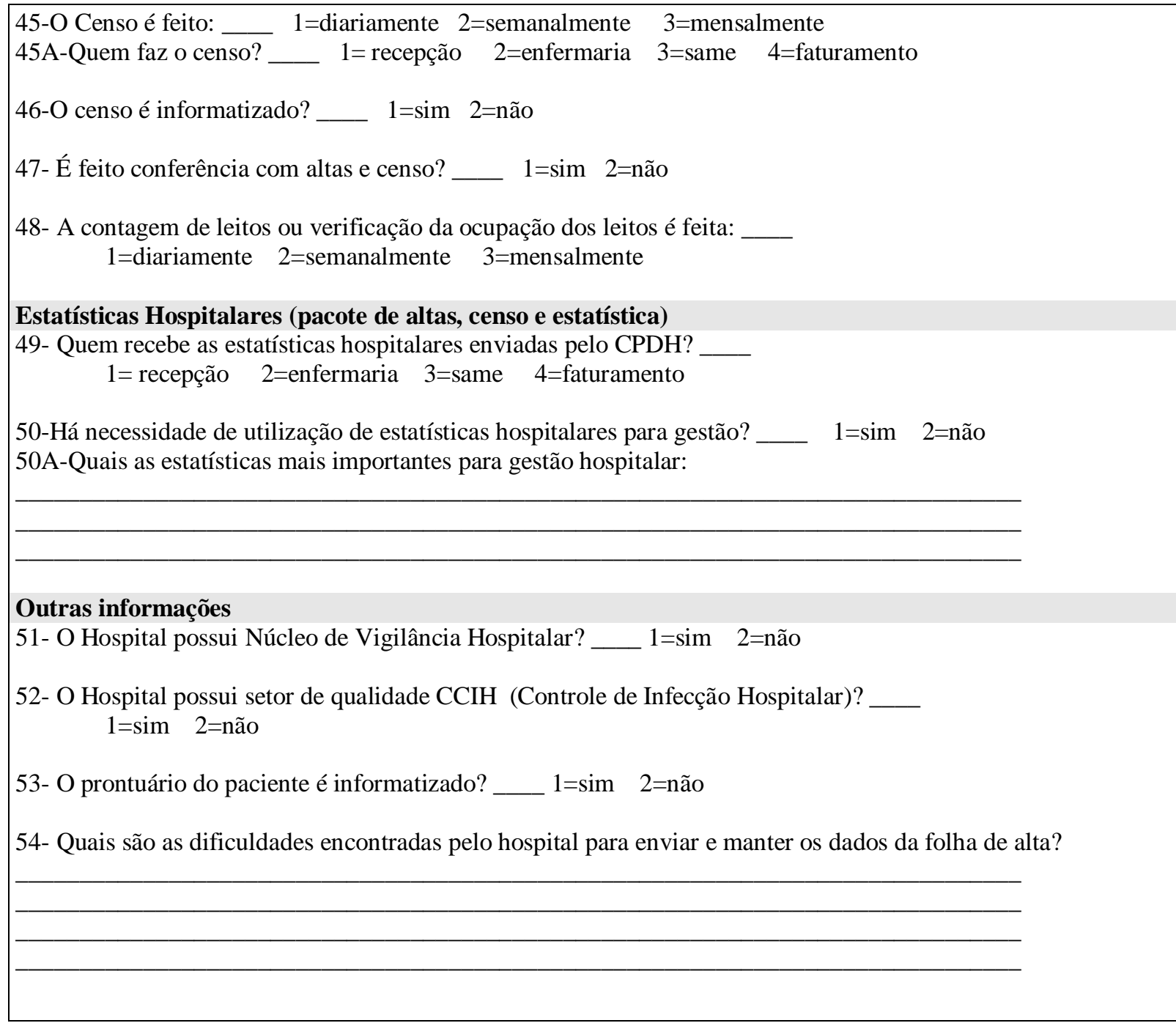




\section{Anexo C - Quadros de Códigos de Consistência}

\begin{tabular}{|c|c|}
\hline Código & Descrição \\
\hline 0 & Sintomas como Afecção Principal (R00 - R99) \\
\hline 1 & Afecções codificadas com P00 - P96 em pacientes maiores de 1 mês (01m) \\
\hline 2 & Afecções codificadas com diagnósticos do sexo masculino em pacientes mulheres - ver Quadro 3 \\
\hline 3 & Afecções codificadas com diagnósticos do sexo feminino em pacientes homens - ver tabela 25 \\
\hline 4 & Somente 1 código do Grupo XV (O80 - O84) nas Afecções por internação \\
\hline 5 & Parto com mais de 1 Afecção, diagnóstico com letra O não é Afecção Principal \\
\hline 6 & $\begin{array}{l}\text { Afecções codificadas com diagnósticos do Grupo XV (O80 - O84) em pacientes com Idade na } \\
\text { internação maior que } 50 \text { ou idade menor que } 12\end{array}$ \\
\hline 7 & $\begin{array}{l}\text { Pacientes com Idade na internação menor que } 6 \text { anos (06a) e Ocupação diferente de Menor (00901) } \\
\text { ou Estudante (00601) }\end{array}$ \\
\hline 8 & Data Internação maior que a Data Cirurgia \\
\hline 9 & Data Internação maior que a Data Saída \\
\hline- & Data Operação maior que a Data Saída \\
\hline * & Data de Saída em branco ou após 31/12/2012 \\
\hline A & Campo Hospital não preenchido ou com código não previsto \\
\hline $\mathrm{B}$ & Campo Enfermaria não preenchido ou com código não previsto \\
\hline $\mathrm{C}$ & Campo Registro do Paciente não preenchido ou maior que 6 dígitos \\
\hline D & $\begin{array}{l}\text { Campo Sexo não preenchido ou com código não previsto (códigos previstos: 1-masculino, 2-feminino, } \\
\text { 9-prejudicado) }\end{array}$ \\
\hline $\mathrm{E}$ & Campo Especialidade não preenchido ou com código não previsto \\
\hline $\mathrm{F}$ & $\begin{array}{l}\text { Campo Idade na Internação não preenchido ou com código não previsto [códigos previstos: recém- } \\
\text { nascido (00d); } 01 \text { a } 30 \text { dias (00d-30d); } 01 \text { a } 11 \text { meses }(01 \mathrm{~m}-11 \mathrm{~m}) ; 01 \text { a } 99 \text { anos (01a-99a); acima de } \\
99 \text { anos (99); prejudicado (000)] }\end{array}$ \\
\hline G & Campo Iniciais do paciente não preenchido \\
\hline $\mathrm{H}$ & Campo Ocupação não preenchido ou com código não previsto \\
\hline I & Campo Categoria de Internação não preenchido ou com código não previsto \\
\hline $\mathrm{J}$ & Campo Código Município não preenchido ou não previsto \\
\hline $\mathrm{K}$ & Campo Sigla UF não preenchido ou com campo não previsto \\
\hline $\mathrm{L}$ & Campo Data Internação não preenchido ou preenchido errado \\
\hline M & Campo Afecção Principal não preenchido ou com código não previsto \\
\hline $\mathrm{N}$ & Campo Outras Afecções 1 com código não previsto ou preenchido mas sem Afecção Principal \\
\hline O & $\begin{array}{l}\text { Campo Outras Afecções } 2 \text { com código não previsto ou preenchido mas sem Afecção Principal e/ou } \\
\text { Outras Afecções } 1\end{array}$ \\
\hline $\mathrm{P}$ & $\begin{array}{l}\text { Campo Outras Afecções } 3 \text { com código não previsto ou preenchido mas sem Afecção Principal, Outras } \\
\text { Afecções } 1 \text { e/ou Outras Afecções } 2\end{array}$ \\
\hline Q & $\begin{array}{l}\text { Campo Outras Afecções } 4 \text { com código não previsto ou preenchido mas sem Afecção Principal, Outras } \\
\text { Afecções 1, Outras Afecções } 2 \text { e/ou Outras Afecções } 3\end{array}$ \\
\hline $\mathrm{R}$ & $\begin{array}{l}\text { Campo Data Cirurgia não preenchido mas com os campos Operação Principal e/ou Outras Operações } \\
\text { preenchidos }\end{array}$ \\
\hline S & Campo Operação Principal preenchido mas com campo Data Cirurgia não preenchido \\
\hline $\mathrm{T}$ & $\begin{array}{l}\text { Campo Outras Operações preenchidos mas sem os campos Operação Principal e/ou Data Cirurgia } \\
\text { preenchidos ou preenchido com código não previsto }\end{array}$ \\
\hline U & $\begin{array}{l}\text { Campo Reoperação preenchido mas sem os campos Operação Principal e/ou Data Cirurgia } \\
\text { preenchidos ou preenchido com código não previsto }\end{array}$ \\
\hline V & $\begin{array}{l}\text { Campo Causa do Acidente, Envenenamento e Violência com código não previsto (previsto somente } \\
\text { os diagnóstico do Caps. V, W, X, Y) }\end{array}$ \\
\hline $\mathrm{X}$ & Campo Complicação Hospitalar com código não previsto \\
\hline Z & $\begin{array}{l}\text { Campo Condição Saída não preenchido ou com código não previsto (códigos previstos: 1-ordem } \\
\text { médica, 2-a pedido, 3-tranferência, 4-fuga, 7-óbito com autópsia, 8-óbito sem autópsia, 9-prejudicado) }\end{array}$ \\
\hline W & Diagnósticos V30-V39 como Outras Afecções \\
\hline Y & $\begin{array}{l}\text { Afecção Principal codificada com o diagnóstico Z38 e Condição Saída preenchido como Óbito } \\
\text { (códigos: 7-óbito com autópsia, 8-óbito sem autópsia) }\end{array}$ \\
\hline
\end{tabular}

\section{Quadro 2 - Códigos de Inconsistências.}




\begin{tabular}{|c|c|}
\hline Feminino & Masculino \\
\hline A34 & B26.0 \\
\hline B37.4 & $\mathrm{C} 60-\mathrm{C} 63$ \\
\hline C51 - C56 & D07.4 - D07.6 \\
\hline C79.6 & D17.6 \\
\hline D06.- & D29.- \\
\hline D07.0 - D07.3 & D40.- \\
\hline D25 - D28 & E29.- \\
\hline D39 & E89.5 \\
\hline E28 & F52.4 \\
\hline E89.4 & 186.1 \\
\hline F52.5 & L29.1 \\
\hline F53.- & N40 - N51 \\
\hline 186.3 & Q53 - Q55 \\
\hline L29.2 & R86 \\
\hline L70.5 & S31.2 - S31.3 \\
\hline M80.0 - M80.1 & Z12.5 \\
\hline \multicolumn{2}{|l|}{ M81.0 - M81.1 } \\
\hline \multicolumn{2}{|l|}{ M83.0 } \\
\hline \multicolumn{2}{|l|}{ N70 - N98 } \\
\hline \multicolumn{2}{|l|}{ N99.2 - N99.3 } \\
\hline \multicolumn{2}{|l|}{$000-099$} \\
\hline \multicolumn{2}{|l|}{ P54.6 } \\
\hline \multicolumn{2}{|l|}{ Q50 - Q52 } \\
\hline \multicolumn{2}{|l|}{$\mathrm{R} 87$} \\
\hline \multicolumn{2}{|l|}{ S31.4 } \\
\hline \multicolumn{2}{|l|}{ S37.4 - S37.6 } \\
\hline \multicolumn{2}{|l|}{ T19.2 - T19.3 } \\
\hline \multicolumn{2}{|l|}{ T83.3 } \\
\hline \multicolumn{2}{|l|}{ Y76.- } \\
\hline \multicolumn{2}{|l|}{ Z01.4 } \\
\hline \multicolumn{2}{|l|}{$\mathrm{Z} 12.4$} \\
\hline \multicolumn{2}{|l|}{ Z30.1 } \\
\hline \multicolumn{2}{|l|}{$Z 30.3$} \\
\hline \multicolumn{2}{|l|}{$Z 30.5$} \\
\hline \multicolumn{2}{|l|}{$Z 31.1$} \\
\hline \multicolumn{2}{|l|}{ Z31.2 } \\
\hline \multicolumn{2}{|l|}{ Z32 - Z36 } \\
\hline Z39 & \\
\hline
\end{tabular}

Quadro 3 - Diagnósticos específicos para cada sexo. 


\section{Anexo E - Termo de Responsabilidade}

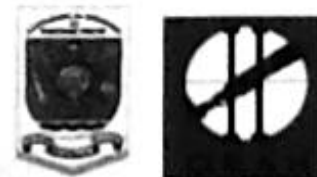

Universidade de sao Paulo

Foculdade de Medicina de Ribeirao Preto

Departamento de Madicina Social

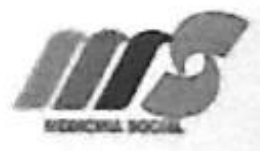

\section{OBSERVATÓRIO REGIONAL DE ATENÇÃO HOSPITALAR (ORAH) \\ Centro de Processamento de Dados Hospitalares - (CPDH)

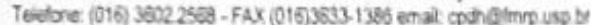

Ribeirdo Preto, 23 juho 2012

Termo de Responsabilidade

Este termo de responsabilidade refere-se ds condiçbes inerentes à uflizaça dos dados de internaples hospitalares dos hospitas RP e Regialo, periodo de 2011 e 2012, que me fol fomecido pelo Observatióno Regional de Atença Hospitalar do Centro de Processamento de Dados Hospitalares do Departamento de Medicina Social da Facuidade de Medicina de Ribeiráo Preto da Universidade de São Paulo.

Eu, abaiko-assinado, Bceito o seguinte:

(1) Finalidade: utíizar os dados apenas para os fins de pesquisa centfica na elaboraçăo do estudo de mestrado da Saúde na Comunidade.

(2) Confidencialidade: preservar a confidencialidade dos individuos e institulçes, sendo proibida a utilizaça dos dados, por si ou cruzados com outros, para apuramento de informaçào relacionada com determinado indriduo ou instituiça

(3) Copyright e acesso a terceiros nab comercializar os dados fornecidos, nem por qualquer forma, cedé-los a lerceiros

(4) Relerenciar a fonte Observalório Regional de Atenç̧o Hospitalar/Centro de Processamento de Dados Hospitalares do Departamento de Medicina SocialFMRP/USP, em qualquer publicaçáo impressa, eletrónica ou sob a forma de comunicacáo, baseada total ou parcialmente em dados fornecidos pelo ORAH/CPOH.

(5) Envio: enviar uma cópia de qualquer trabaho publicado ou relatório baseado na inforriaçlo disponiblizada pelo CPDH ou enviar o link de disponiblidade da publicação eletrơnica.

(6) Métodos, técnicas e deteçlo de erros: informar a ORAHICPDH de qualsquer problemas de naturva técnica, metodológica, do registro de dados ou de erros detectados nas bases de dados uflilzadas.

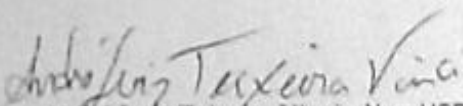

Anore Luiz Teixeira Vinci- Num USP. 510854

Departamento de Mecícina Social, Faculdade de Medicina de Ribeirào Preto, Universidade de Sđ̃o Paulo, Ribeirlo Preto, Brasil

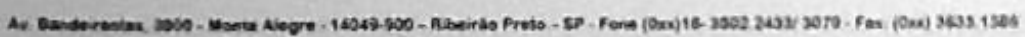

Figura 6 - Termo de Responsabilidade. 